Pacific Northwest

National Laboratory

Operated by Battelle for the

U.S. Department of Energy

Under Contract DE-AC-05-76RLO-1830
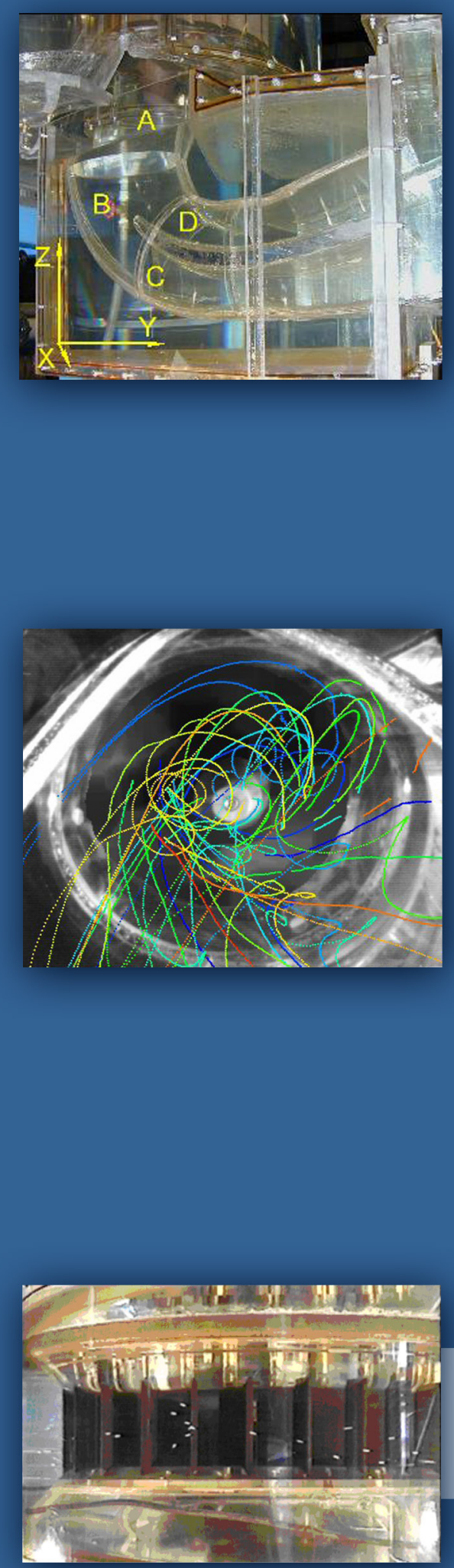

\section{Characterization of Bead Trajectories through the Draft Tube of a Turbine Physical Model}

Final Report February 2005

\author{
MA Weiland \\ RP Mueller \\ TJ Carlson \\ ZD Deng \\ CA McKinstry
}




\title{
DISCLAIMER
}

This report was prepared as an account of work sponsored by an agency of the United States Government. Neither the United States Government nor any agency thereof, nor Battelle Memorial Institute, nor any of their employees, makes any warranty, express or implied, or assumes any legal liability or responsibility for the accuracy, completeness, or usefulness of any information, apparatus, product, or process disclosed, or represents that its use would not infringe privately owned rights. Reference herein to any specific commercial product, process, or service by trade name, trademark, manufacturer, or otherwise does not necessarily constitute or imply its endorsement, recommendation, or favoring by the United States Government or any agency thereof, or Battelle Memorial Institute. The views and opinions of authors expressed herein do not necessarily state or reflect those of the United States Government or any agency thereof.

\author{
PACIFIC NORTHWEST NATIONAL LABORATORY \\ operated by \\ BATTELLE \\ for the \\ UNITED STATES DEPARTMENT OF ENERGY \\ under Contract DE-AC05-76RL01830
}

Printed in the United States of America
Available to DOE and DOE contractors from the
Office of Scientific and Technical Information,
P.O. Box 62, Oak Ridge, TN 37831-0062;
ph: (865) 576-8401
fax: (865) 576-5728
email: reports@adonis.osti.gov

Available to the public from the National Technical Information Service,

U.S. Department of Commerce, 5285 Port Royal Rd., Springfield, VA 22161

ph: (800) $553-6847$

fax: (703) 605-6900

email: orders@ntis.fedworld.gov

online ordering: http://www.ntis.gov/ordering.htm

This document was printed on recycled paper. 


\title{
Characterization of Bead Trajectories through the Draft Tube of a Turbine Physical Model
}

\author{
M.A. Weiland \\ R.P. Mueller \\ T.J. Carlson \\ Z. Deng \\ C. McKinstry
}

FINAL REPORT

February 2005

Prepared for the U.S. Department of Energy

Under Contract DE-AC05-76RL01830

Pacific Northwest National Laboratory

P.O. Box 999

Richland, Washington 99352 



\section{Executive Summary}

The U.S. Army Corps of Engineers (USACE) makes extensive use of 1:25 scale Plexiglass models of hydroelectric turbines along the Columbia River to study turbine hydraulic performance and to identify potential hazards for fish passing through the turbines. Plastic beads are sent through the models and imaging has been done with laser Doppler velocimetry and high-speed videography to measure flow field variables and to study the probable paths of fish through the turbine units. But our understanding has been limited by the lack of data showing actual bead trajectories in three dimensions (3-D) and the lack of quantified velocity, acceleration, and other kinematics describing the trajectories of beads as they pass through the physical models.

This report describes a study conducted by Pacific Northwest National Laboratory (PNNL) to determine the feasibility of using video imaging to track the trajectories of beads through the draft tubes of physical turbine models and, from those trajectories, to calculate the kinematics of the bead trajectories and the beads' responses to turbulence in the model. This project is part of a research program supported by the U.S. Department of Energy Advanced Hydropower Turbine System Program (AHTS), one goal of which is to increase the electrical generation at hydroelectric dams while reducing the risk of injury and death to salmon and other fish passing through the dam's turbines. Video data for the study were collected at the U.S. Army Corps of Engineers (USACE) Environmental Research and Development Center (ERDC) in Vicksburg, Mississippi, on May 6-9, 2003.

We used high-speed video imaging to study the kinematics of nearly neutrally buoyant beads as they passed below the turbine runner and through the draft tube region of a 1:25 scale model of a single Bonneville Dam Powerhouse 1 turbine unit. A single camera was used to produce 2-dimensional trajectories and paired cameras with overlapping fields of view were used to produce 3-dimensional trajectories of the beads as they passed through the draft tube region of the turbine model. Image data were collected at two turbine operating levels (lower 1\% efficiency and maximum rated output) for beads released mid-depth into the turbine intake from each of the three gatewell slots.

From our research we found it is possible to produce accurate bead trajectories and to quantify the movement of the beads in 3-D through the scale turbine model. It was also possible to describe differences in the response of beads, similar in size at physical model scales to juvenile salmonids, to flow field features such as turbulence, between load levels and release locations that may provide insight into injuries and mortalities observed under field conditions at full scale (prototype scale) Kaplan turbines. We found that flows through the draft tube were less turbulent at the maximum rated operation level than at the lower $1 \%$ efficiency, possibly providing safer flow conditions for fish passage. Due to the low image resolution of the cameras (320 x 280 pixels, at 500 frames/s) velocity and acceleration estimates were smoothed. The smoothed data provided good estimates of bead response to flow dynamics within the draft tube region. Tests conducted using cameras of higher resolution ( $1280 \times 512$ pixels, at 500 frames/s) show that it is possible to calculate bead velocity and acceleration estimates with little or no smoothing. 
Characterization of Bead Trajectories through the Draft Tube of a Turbine Physical Model 


\section{Acknowledgments}

The authors are grateful for the contributions of many people on this project. We thank Robert Davidson, Danea Polk, Marshall Thomas, and Jason Jackson from the U.S. Army Corps of Engineers' Environmental Research and Development Center for their assistance with model operation and testing. We thank Nathan Phillips of Pacific Northwest National Laboratory for his patience and diligence in viewing bead image data and tracking the images through the model. It was a laborious task that he performed well. Our thanks go to Theresa Gilbride who was the technical editor for this document and to Tao Fu for help with geometry and figures. Our thanks also go to Carl Shilt of BAE for editing comments. Finally, we wish to thank Peggy Brookshier, program manager of the U.S. Department of Energy's Advanced Hydropower Turbine System Program when these studies were initiated, for her support of our work. 
Characterization of Bead Trajectories through the Draft Tube of a Turbine Physical Model 


\section{Acronyms and Abbreviations}

$\begin{array}{ll}\text { 2-D } & \text { two dimensional } \\ \text { 3-D } & \text { three dimensional } \\ \text { BON1 } & \text { Bonneville Dam's first powerhouse } \\ \text { CFD } & \text { computational fluid dynamics } \\ \text { CMOS } & \text { complementary metal oxide semiconductor } \\ \text { ERDC } & \text { Environmental Research and Development Center } \\ \text { LDV } & \text { laser Doppler velocimetry } \\ \text { MGR } & \text { minimum gap runner } \\ \text { PC } & \text { personal computer } \\ \text { PNNL } & \text { Pacific Northwest National Laboratory } \\ \text { PVC } & \text { polyvinyl chloride } \\ \text { SAI } & \text { Sensors Applications Inc. } \\ \text { USACE } & \text { U.S. Army Corps of Engineers }\end{array}$

\section{Units}

$\mu \mathrm{s}$

micro second

$\mathrm{ft} / \mathrm{s}^{2}$

feet per second squared

fps

feet per second

frames/s

frames per second

$\mathrm{ft}$

foot

gal

gallon

$\mathrm{m} / \mathrm{s}$

meters per second

mg

milligram

$\mathrm{mm}$

millimeter

MW

mega Watt

S

second 
Characterization of Bead Trajectories through the Draft Tube of a Turbine Physical Model 


\section{Contents}

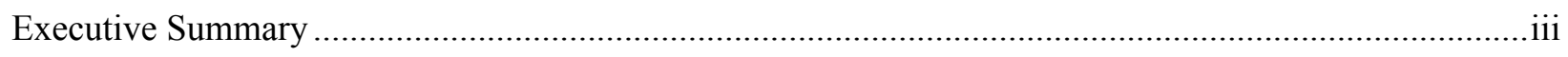

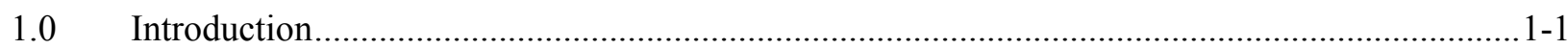

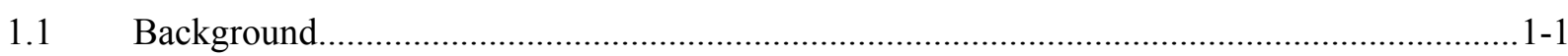

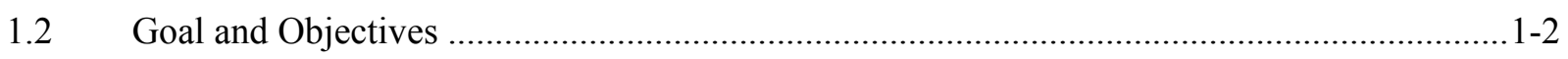

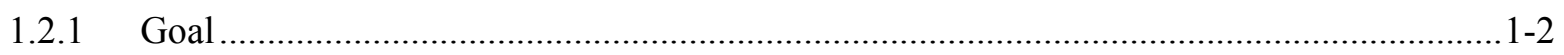

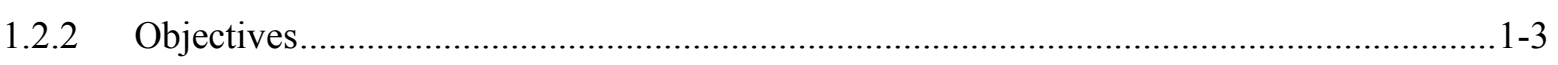

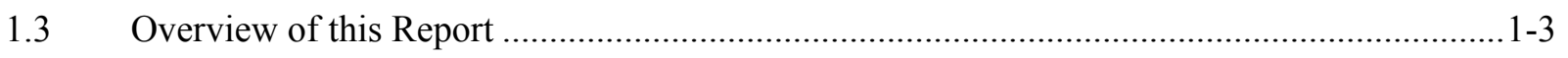

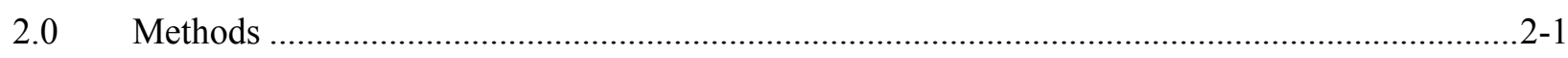

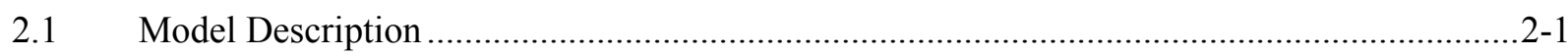

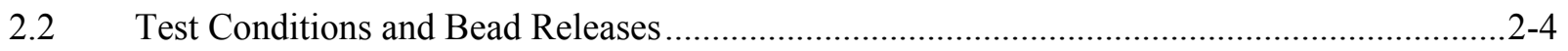

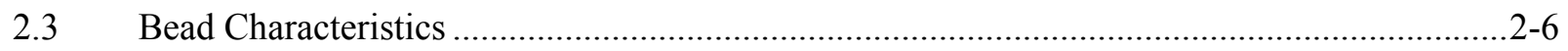

2.4 Video System, Calibration of Cameras and Image Processing .............................................2-7

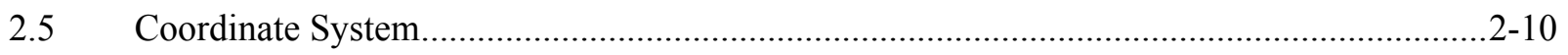

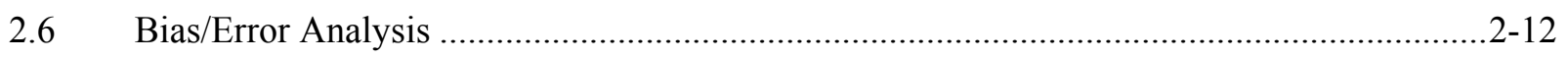

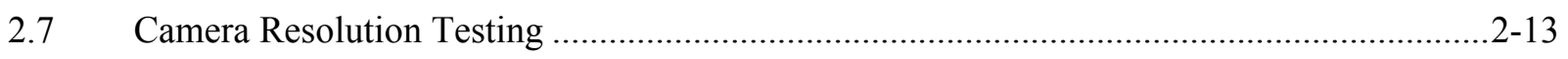

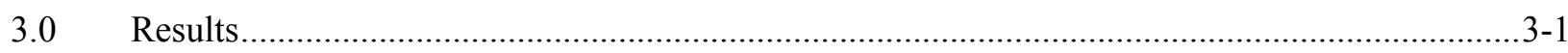

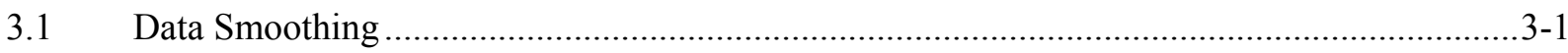

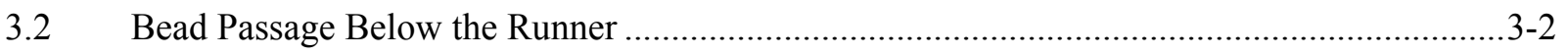

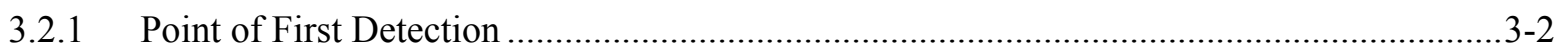

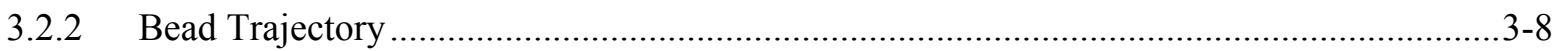

3.3 Passage through the Elbow Region .......................................................................... $3-12$

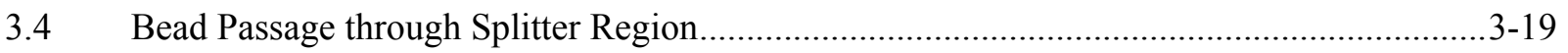

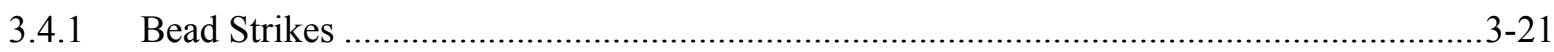

3.4.2 Estimated Bias in Position Estimates of Beads ................................................................ 3-21

3.5 Camera Resolution Comparison of Bead Tracking with Photron 1280 Camera

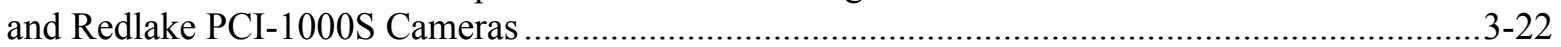

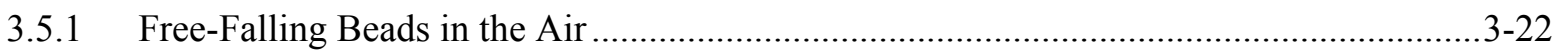

3.5.2 In-Water Bead Measurement ….............................................................................. $3-25$

3.6 Error Analysis of Bead-Tracking in 1:25 Scale Turbine Physical Model ..............................3-25

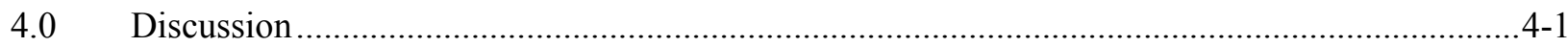

4.1 Bead Passage and Distribution below the Runner Region .................................................... $4-1$

4.1.1 Bead Passage through the Elbow Region........................................................................4-2

4.1.2 Bead Passage through the Splitter Region ..................................................................... $4-2$

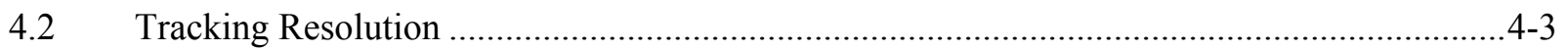

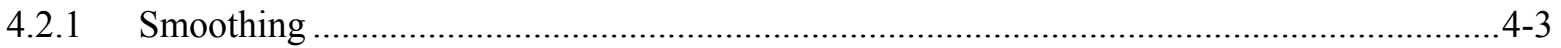


Characterization of Bead Trajectories through the Draft Tube of a Turbine Physical Model

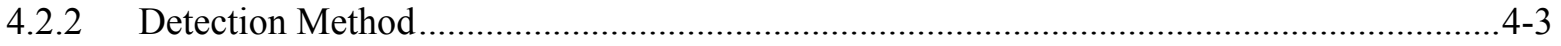

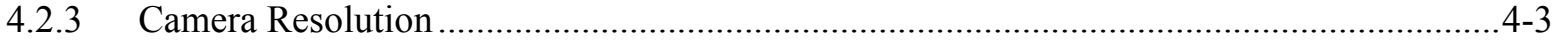

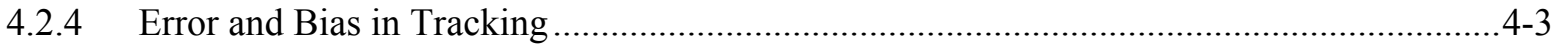

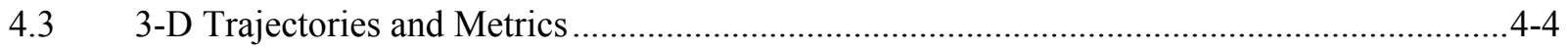

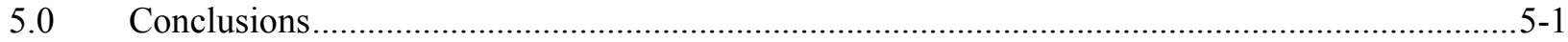

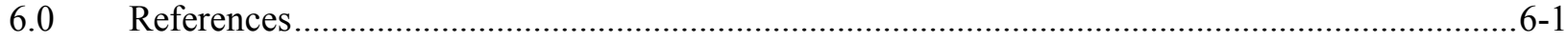




\section{Figures}

Figure 2.1. Forebay perspective showing the three intake bays A, B, and C......................................2-2

Figure 2.2. The stay vane and wicket gate cascade with the turbine runner...........................................2-3

Figure 2.3. Side view of BON1 1:25-scale model showing the general regions the cameras' field of view

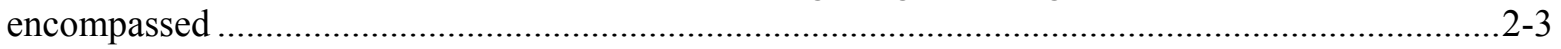

Figure 2.4. 1\% Operating efficiency range for MGR turbines at Bonneville Dam Powerhouse 1 ..........2-4

Figure 2.5. A) Bead release canister with beads visible at lower portion of funnel ...............................2-6

Figure 2.6. Beads used for bead tracking in the physical model.......................................................2-7

Figure 2.7. Camera positioning in relation to the elbow and splitter region of the model......................2-8

Figure 2.8. Calibration jig used to obtain 3-D measurements within the model.....................................2-9

Figure 2.9. Calibration jig positioned upstream of the splitter in the BON1 1:25-scale physical model. 2-9

Figure 2.10. Translation of coordinates to the plane of the physical model. ........................................2-11

Figure 2.11. Rotation of coordinates to the plane of the physical model by rotating the data on

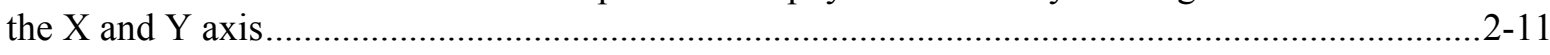

Figure 2.12. Calibration jig (middle bottom) and second jig (upper right) used to estimate

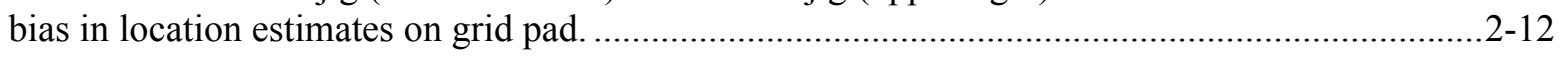

Figure 2.13. Test setup for camera comparison test at PNNL .......................................................2-14

Figure 2.14. Calibration plate with fiducial marks used for camera comparison test at PNNL.............2-14

Figure 3.1. Magnitude velocity of a bead tracked through the draft tube region of the model at maximum operation condition prior to smoothing and after smoothing by averaging the frame of interest and the frame 5 frames ahead ................................................................. $3-1$

Figure 3.2. Acceleration magnitude of a bead tracked through the draft tube region of the model at maximum operation condition prior to smoothing and after smoothing by averaging the frame of interest and the frame five frames ahead....

Figure 3.3. Position of first detection of beads below the MGR runner at the lower $1 \%$ operating efficiency for beads released mid-depth in intakes $\mathrm{A}, \mathrm{B}$, and $\mathrm{C}$.

Figure 3.4. Position of first detection of beads below the MGR runner at maximum operating condition for beads released mid-depth in intakes A, B, and C

Figure 3.5. Percent distribution of beads by quadrant of first detection below the runner for beads released in the A, B, and C intakes at lower 1\% operating efficiency

Figure 3.6. Percent distribution of beads by quadrant of first detection below the runner for beads released in the $\mathrm{A}, \mathrm{B}$, and $\mathrm{C}$ intakes at maximum operation level

Figure 3.7. Radial distribution of beads first detected, relative to the hub, below the runner for beads released in the $\mathrm{A}, \mathrm{B}$, and $\mathrm{C}$ intakes at the lower $1 \%$ operating efficiency.

Figure 3.8. Radial distribution of beads first detected, relative to the hub, below the runner for beads release in the $\mathrm{A}, \mathrm{B}$, and $\mathrm{C}$ intakes at maximum operation level

Figure 3.9. Trajectory of beads from point of first detection below the runner into the elbow of the draft tube for beads released into the A intake at lower 1\% operating efficiency and maximum operating condition 
Figure 3.10. Trajectory of beads from point of first detection below the runner into the elbow of the draft tube for beads released into the B intake at lower $1 \%$ operating efficiency and maximum operating condition

Figure 3.11. Trajectory of beads from point of first detection below the runner into the elbow of the draft tube for beads released into the $\mathrm{C}$ intake at lower $1 \%$ operating efficiency and maximum operating condition

Figure 3.12. Bead passage efficiency from beneath the turbine runner into the elbow region of the draft tube.....

Figure 3.13. Box plots of log tortuosity $(\tau)$ for 2-D tracking by release intake and flow condition........3-11

Figure 3.14. Velocity and acceleration estimates for individual beads as they passed $1.5 \mathrm{ft}$ or greater to the left of the vertical splitter above and below the horizontal splitter at the lower $1 \%$ efficiency for beads released into all three intakes

Figure 3.15. Velocity and acceleration estimates for individual beads as they passed within $1.5 \mathrm{ft}$ to the left or right of the vertical splitter above and below the horizontal splitter at the lower $1 \%$ efficiency for beads released into all three intakes

Figure 3.16. Velocity and acceleration estimates for individual beads as they passed $1.5 \mathrm{ft}$ or greater to the right of the vertical splitter above and below the horizontal splitter at the lower $1 \%$ efficiency for beads released into all three intakes

Figure 3.17. Velocity and acceleration estimates for individual beads as they passed $1.5 \mathrm{ft}$ or greater to the left of the vertical splitter above and below the horizontal splitter at maximum operation for beads released into all three intakes

Figure 3.18. Velocity and acceleration estimates for individual beads as they passed within $1.5 \mathrm{ft}$ to the left or right of the vertical splitter above and below the horizontal splitter at maximum operation for beads released into all three intakes

Figure 3.19. Velocity and acceleration estimates for individual beads as they passed $1.5 \mathrm{ft}$ or greater to the right of the vertical splitter above and below the horizontal splitter at maximum operation for beads released into all three intakes

Figure 3.20. Average velocity and acceleration contour plots for beads as they passed through a plane of the model $6.25 \mathrm{ft}$ to the left of the vertical splitter above and below the horizontal splitter at lower $1 \%$ efficiency for beads released into all three intakes

Figure 3.21. Average velocity and acceleration contour plots for beads as they passed through a plane in line with the vertical splitter above and below the horizontal splitter at the lower $1 \%$ efficiency for beads released into all three intakes

Figure 3.22. Average velocity and acceleration contour plots for beads as they passed through a plane $6.25 \mathrm{ft}$ to the right of the vertical splitter above and below the horizontal splitter at the lower $1 \%$ efficiency for beads released into all three intakes

Figure 3.23. Average velocity and acceleration contour plots for beads as they passed through a plane $6.25 \mathrm{ft}$ to the left of the vertical splitter above and below the horizontal splitter at maximum operation level for beads released into all three intakes

Figure 3.24. Average velocity and acceleration contour plots for beads as they passed through a plane in line with the vertical splitter above and below the horizontal splitter at maximum operation level for beads released into all three intakes

Figure 3.25. Average velocity and acceleration contour plots for beads as they passed through a plane $6.25 \mathrm{ft}$ to the right of the vertical splitter above and below the horizontal splitter at maximum operation level for beads released into all three intakes

Figure 3.26. Box plots of log tortuosity $(\tau)$ for 3-D tracking by release intake and flow condition........3-19 
Figure 3.27. Velocity and acceleration estimates for individual beads as they pass to the right of the vertical splitter above and below the horizontal splitter at maximum operation level for beads released into all three intakes

Figure 3.28. Bias in bead position estimates due to error in the calibration jig and increase in distance of the bead from the calibration jig.

Figure 3.29. Calculated velocity and acceleration of dropped bead captured with, Redlake camera for unsmoothed and data smoothed using two different methods

Figure 3.30. Calculated velocity and acceleration of dropped bead captured with, Photron camera for unsmoothed and data smoothed using two different methods.

Figure 3.31. Comparison of velocity and acceleration estimates and error of a dropped bead captured with Photron and Redlake cameras simultaneously.

Figure 3.32. Velocity and acceleration estimates of a dropped spherical bead with images captured by the Photron camera.

Figure 3.33. Calculated velocity and acceleration of a bead released into a water jet water tank captured with the Photron camera showing unsmoothed data and data smoothed using two different methods.

\section{Tables}

Table 2.1. Scale of the BON1 physical model and elements to the prototype.

Table 2.2. Summary of data collection in the BON1 MGR physical model describing the region of camera coverage, operation level, number of bead release events, and camera frame rate for tests conducted May 2003 at ERDC.

Table 2.3. Characteristics of beads used during testing in the physical model

Table 2.4. Specification for cameras used during laboratory tests comparing trajectory accuracy relative to camera resolution.

Table 3.1. Percent of beads as they were first detected below the runner within each quadrant by release location and operation level.

Table 3.2. Percent of beads as they were first detected below the runner within each region of the runner by release location and operation level.

Table 3.3. Distribution of beads out from the center of the turbine runner for beads released at the lower $1 \%$ efficiency and maximum operation.

Table 3.4. Summary ANOVA where the independent predictor variables are both factors and the radial distance from the center of the runner hub was the dependent variable

Table 3.5. Time of travel for beads from first detection below the runner to the elbow region of the runner for beads released in each intake and two operation levels.

Table 3.6. Summary ANOVA of tortuosity estimates between intakes and operation conditions for beads tracked below the runner hub in 2-D

Table 3.7. Velocity (fps) and acceleration $\left(\mathrm{ft} / \mathrm{s}^{2}\right)$ estimates calculated for beads passing through the draft tube of the BON1 scale model by release location

Table 3.8. Summary ANOVA of tortuosity estimates between intakes and operation conditions for beads tracked below the runner hub in 3-D 
Table 3.9. Percent distribution of beads as they passed through one of the four regions of the splitter in the lower end of the draft tube for both operating conditions and by intake

Table 3.10. Random error associated with motion analysis of a dropped bead captured with Photron 1280 cameras and Redlake cameras simultaneously.

Table 3.11. Error in estimates of velocity and acceleration relative to viewing area for Redlake and Photron cameras at 500 and 1000 frames/s. 


\subsection{Introduction}

The U.S. Army Corps of Engineers (USACE) makes extensive use of turbine physical models to conduct engineering studies of the hydraulic performance of existing and alternative designs and to identify potential hazards for fish. These 1:25 scale models are constructed of clear Plexiglas so water pathways, internal turbine structures, and moving parts are visible. Researchers have used laser Doppler velocimetry (LDV), high-speed videography, and plastic beads to measure flow field variables and to study the probable paths of fish through the turbine units; to estimate the probability of strike, collision, and exposure to shear; and to make general observations about turbulence and other hydraulic conditions. But our understanding has been limited by the lack of data showing actual bead trajectories in three dimensions (3-D) and the lack of quantified velocity, acceleration, and other kinematics describing the trajectories of beads as they pass through the physical models.

This report describes a study conducted by Pacific Northwest National Laboratory (PNNL) to determine the feasibility of using video imaging to track the trajectories of beads through the draft tubes of physical turbine models and, from those trajectories, to calculate the kinematics of the bead trajectories and the beads' responses to turbulence in the model. This project is part of a research program supported by the U.S. Department of Energy Advanced Hydropower Turbine System Program (AHTS), the goal of which is to increase hydropower production while reducing the risk of injury and death to fish passing through turbines. Video data for the study were collected at the USACE Environmental Research and Development Center (ERDC) in Vicksburg, Mississippi, on May 6-9, 2003.

\subsection{Background}

When water velocities are uniform, fish can move with the flow without being harmed. But if water velocities change abruptly, the resulting shear stress and turbulence forces can damage fish. These quick changes can lead to physical injury and mortality resulting directly from physical injury. Behavioral impairment, such as vestibular disruption, is also possible. These types of injuries may also lead to mortality but indirectly through means such as increased vulnerability of predation by birds and piscivorous fish in the dam's tailrace or further downstream (TSP 2004). Recent laboratory studies have shown that salmon smolts exposed to high levels of shear stress have increased susceptibility to predation (Neitzel et al. 2000). Turbulence occurs throughout the hydropower turbine. It is difficult to obtain direct measurements of turbulence in turbines because of the difficulty and cost of deploying instruments in the turbine environment (Weiland and Carlson 2003). Because of these difficulties, time-sensitive (dynamic) measurements and other aspects of the physical environment of hydroturbines are currently being studied using scale physical models. Progress is also being made using 3-D computational fluid dynamics models.

The USACE has built several physical turbine models at its ERDC in Vicksburg, Mississippi. The turbine models are constructed of Plexiglas so that the water pathway, internal turbine structures, and moving parts are visible. Physical models are used for engineering evaluation of existing structures and design alternatives. The models are also extensively used to evaluate the biological performance of existing and altered structures and operations. 
The Portland and Walla Walla Districts of the USACE have made extensive use of 1:25 scale models of Columbia River hydroturbines to investigate their physical environments and to identify mechanisms and locations of potential hazards for fish. One of the newest of these models is a 1:25 scale model of the turbine runners installed at Bonneville Dam's first powerhouse (BON1). This physical turbine model is unique in that it has two interchangeable runners. These runners are models of the original design and a minimum gap runner (MGR). The MGR is a new runner design that is being used to replace the standard Kaplan runners installed at BON1. The MGR was designed to eliminate the inner gap between the runner and the hub and the outer gap between the runner blade tip and the discharge ring. These gaps are believed to be a risk for mechanical injuries to fish (Cada 2001). The MGR's runner blade leading edges are also blunter (more rounded) so fish are more likely to be diverted around the blade than to directly strike the blade. Reduction of the gaps also increases the efficiency of the turbine across the operating range of the unit thereby permitting more electrical power to be produced from existing civil structures.

Two tools commonly used to study conditions within the turbine models are laser Doppler velocimetry (LDV) and high-speed videography. Researchers at ERDC have been using LDV and twodimensional videography to measure water velocity and turbulence intensity and to track small, plastic, nearly neutrally buoyant beads sent through the physical models. The beads, which at the scale of the physical model are similar in size to yearling juvenile salmon migrants, are used to observe the probable paths of fish through the turbine units, to estimate the probability of strike, collision, and shear exposure, and to make general observations about turbulence and other hydraulic conditions. But our understanding has been limited by the lack of bead 3-D trajectories and quantified velocity, acceleration, and other kinematics describing the trajectories and dynamics of the beads as they pass through the physical turbine model.

Three-dimensional tracking is routinely used in other fields: paired cameras are used to track the movement and behavior of insects such as houseflies (Dahmen and Zeil 1984) and animals such as bats (Rayner and Aldridge 1985), fish (Wilga and Lauder 1999), birds (Tucker 1991), and microscopic organisms (Krenshaw et al. 2000). Three-dimensional cinematography has also been used to track particle flows in liquid (Pan et al. 2002). Until this study, 3-D tracking had not been used to observed larger dimensioned beads in physical turbine models.

\subsection{Goal and Objectives}

Previous image data collected at the ERDC physical models had been collected with single cameras (non-overlapping fields of view), which typically only allow bead trajectory description in two dimensions (2-D).

\subsubsection{Goal}

The goal of this project was to determine the feasibility of using paired high-speed digital cameras with overlapping fields of view to track beads in 3-D as they passed through the draft tube region of the BON1 physical turbine model and to assess the resolution at which these trajectories could be described. 


\subsubsection{Objectives}

1. Assess the feasibility of tracking near neutrally buoyant beads from below the runner and through the draft tube region of a 1:25-scale turbine physical model and characterize the response of the beads to large-scale turbulence.

2. If objective 1 was successfully completed, characterize the large-scale turbulence that occurs in Kaplan turbines by observing the turbulence response of near neutrally buoyant beads through sections of the draft tube of the ERDC 1:25-scale physical turbine model equipped with a MGR runner.

a. Collect 2-D and 3-D bead trajectory data at two turbine operating conditions (discharges): the lower $1 \%$ efficiency and maximum rated output.

b. Collect bead trajectory data in the region below the runner through the draft tube elbow and from the draft tube elbow to the draft tube splitter piers.

c. Describe 3-D particle turbulence response and other aspects of particle motion such as "linearity of bead trajectory" and particle acceleration and velocity.

d. Store bead trajectory data and metadata to archive data sets for 3-D time-sensitive CFD model validation.

\subsection{Overview of this Report}

Chapter two describes methods used to acquire, process, and analyze bead data. Chapter three describes the results obtained by the study. Chapter four discusses the results. Chapter 5 contains conclusions and Chapter 6 provides a list of the references cited in this report. 
Characterization of Bead Trajectories through the Draft Tube of a Turbine Physical Model 


\subsection{Methods}

\subsection{Model Description}

Data acquisition was conducted at the USACE Engineering Research and Development Center (ERDC) located in Vicksburg, Mississippi, during May 6-9, 2003. The turbine model used is a 1:25-scale model of a single Kaplan turbine unit at Bonneville Dam's first powerhouse (BON1); the model was fitted with a MGR runner. The ratio of the model scale to the prototype (full-scale version of the turbine) is provided in Table 2.1. The turbine model is constructed of Plexiglas so that the water pathway and internal turbine structures and moving parts are visible. For purposes of discussion, the overall model can be divided into five zones: 1) forebay, 2) turbine intake extending from the turbine trashracks to the downstream extent of the intake piers, which includes the turbine's three intake bays and in-turbine fish diversion screens (see Figure 2.1), 3) turbine scroll case, which extends from the end of the turbine intake piers to the stay vane-wicket gate cascade (see Figure 2.2), 4) the region from the stay vane-wicket gate cascade to the exit of the turbine draft tube, and 5) the immediate tailrace downstream of the draft tube exit (see Figure 2.3). For this project, data collection was focused on Zone 4. This zone was divided into four regions where data were collected; these regions are designated A, B, C, and D in Figure 2.3). Water was re-circulated through the model using a programmable electric pump. Data-collection areas were selected based on optimization of the optical path and presence of conditions potentially harmful to fish. Optimal viewing areas were the draft tube and runner hub region. The region downstream of the main draft tube splitter, while interesting had presented problems for acquisition of acceptable images due to the numerous air pockets trapped in the glue in the seams connecting the Plexiglas sections of the model. These air pockets are very effective light reflectors, which significantly degraded image quality.

Table 2.1. Scale of the BON1 physical model and elements to the prototype.

\begin{tabular}{|l|l|}
\hline Length & $1: 25$ \\
\hline Velocity & $1: 5$ \\
\hline Time & $1: 5$ \\
\hline
\end{tabular}




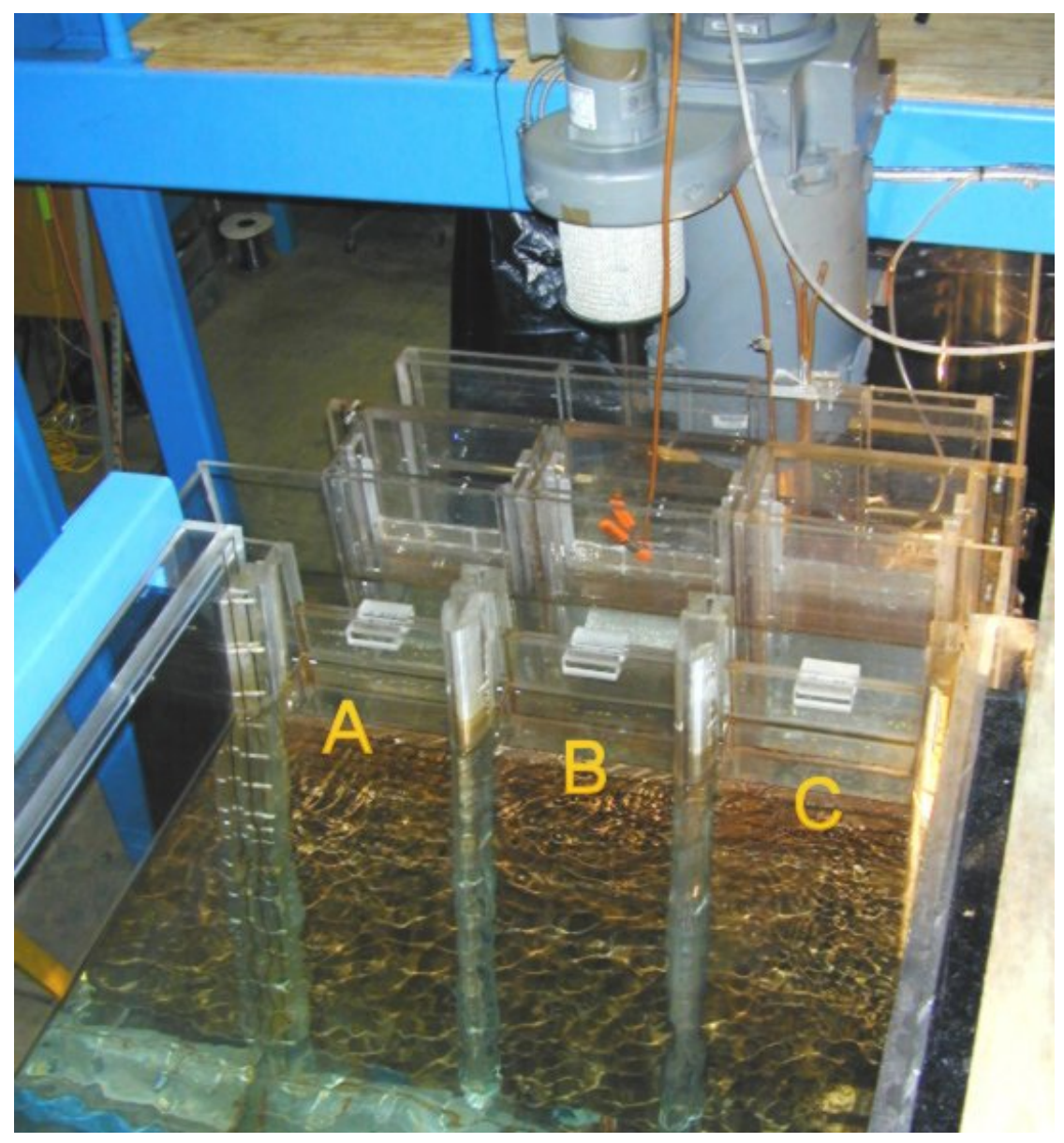

Figure 2.1. Forebay perspective showing the three intake bays $\mathrm{A}, \mathrm{B}$, and $\mathrm{C}$. The $\mathrm{C}$ intake is divided vertically near the scroll case into a fourth intake (D). The bead release tube is shown in the photo in slot B. 


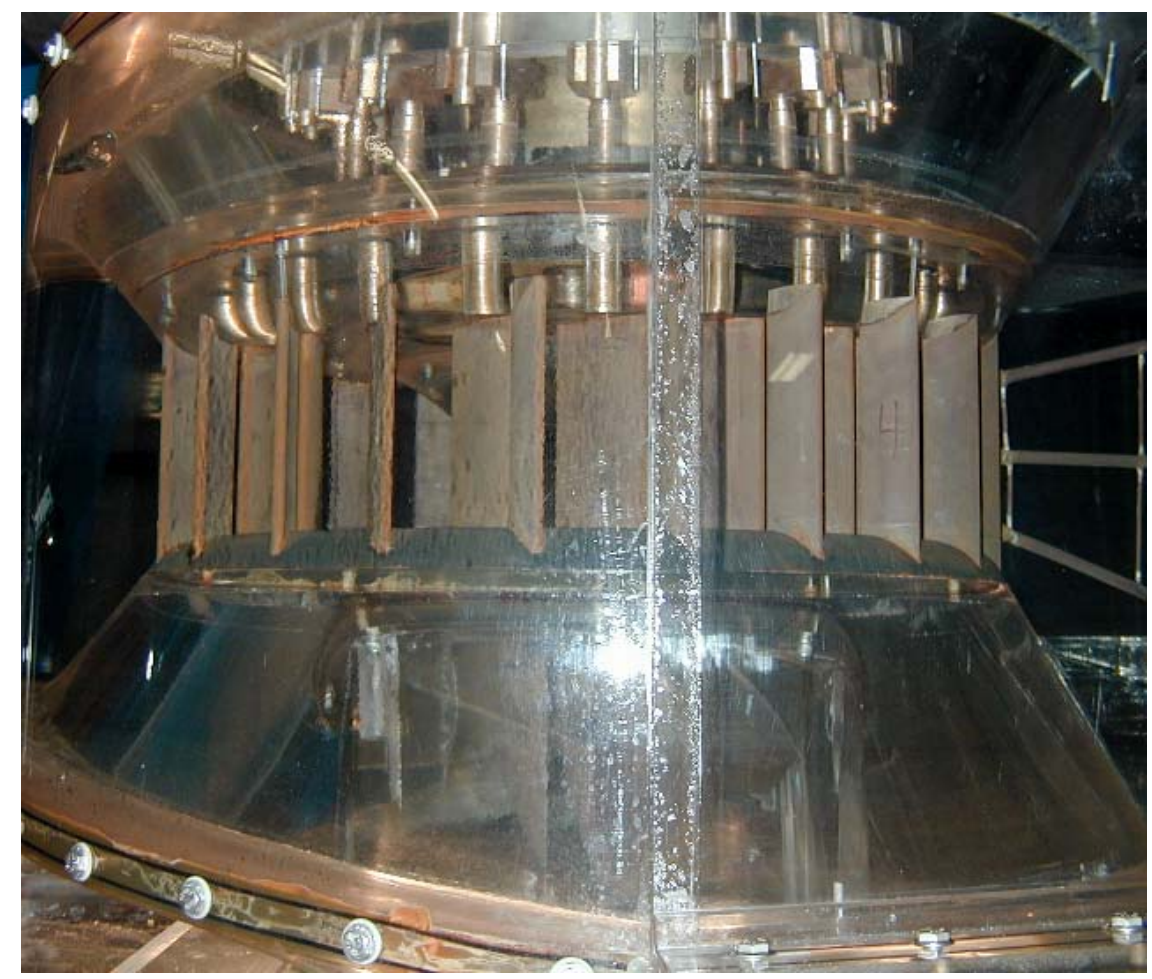

Figure 2.2. The stay vane and wicket gate cascade with the turbine runner.

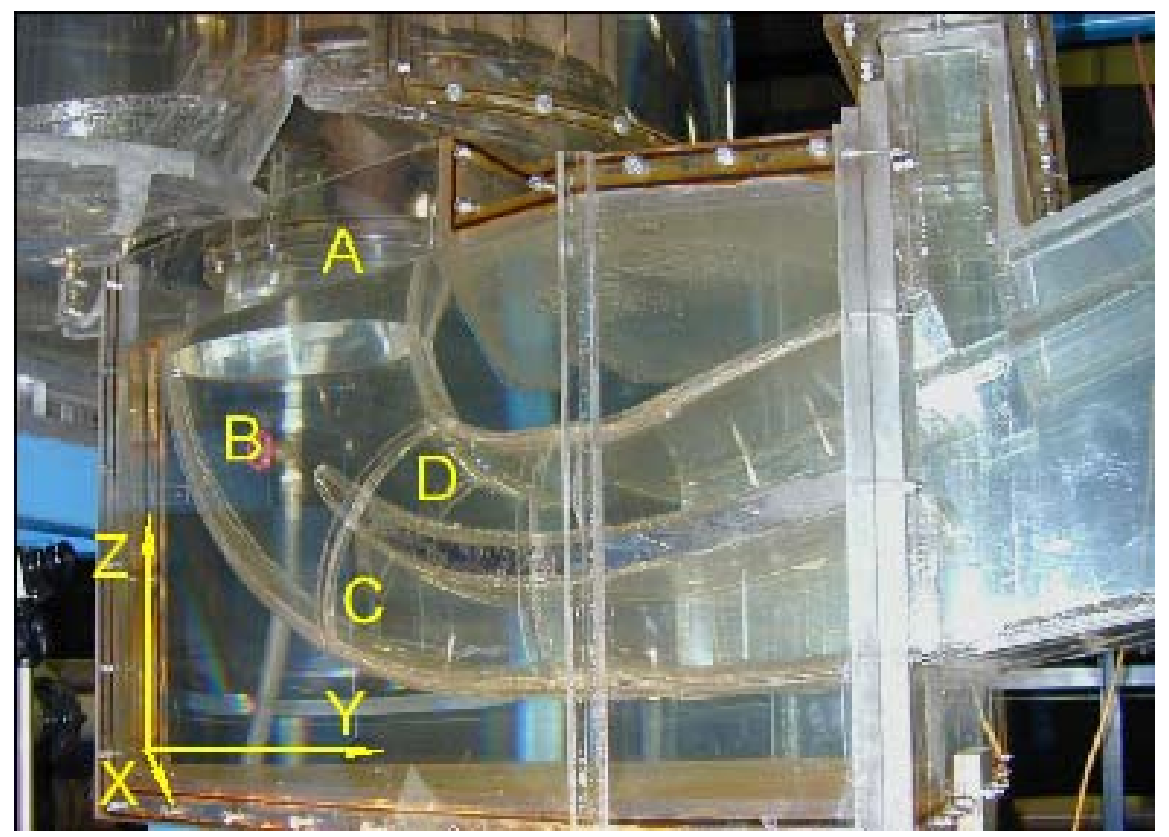

Figure 2.3. Side view of BON1 1:25-scale model showing the general regions the cameras' field of view encompassed: (A) turbine runner and cone region, (B) elbow region, (C) lower splitter, (D) upper splitter region, and orientation of the Cartesian coordinate system used for bead positions. 


\subsection{Test Conditions and Bead Releases}

The data acquisition effort was divided equally between two operating conditions: lower $1 \%$ efficiency, about $29 \mathrm{MW}$, and maximum rated output, about $58 \mathrm{MW}$ (see Figure 2.4). Table 2.2 shows the number of tests run at each turbine operating condition, the region of the model viewed with the cameras, the number of bead releases, and the camera frame rate.

Beads were released in each of the three emergency gate slots (A, B, and C) for both operating conditions (lower $1 \%$ efficiency and maximum operating level). (Note: for the $\mathrm{C}$ intake, beads were actually released into the $\mathrm{D}$ section of the $\mathrm{C}$ intake because of existing release tubes from blade strike testing installed in the $\mathrm{C}$ section of the intake.) The beads were introduced into the model using a gravityfed plastic container connected to a section of vinyl tubing, which was, in turn, attached to a section of copper tubing inserted into the gate slot openings at the center of each slot A, B, and C (Figure 2.5a). The copper tubing was bent at a $90^{\circ}$ angle and pointed downstream so that the point of exit would follow water flow (Figure 2.5b). Approximately 10 to 15 beads were released for each test run. The bead release depth was midway between the surface and the floor of the model. Approximately 5000 beads were released over the four days of testing. About 30 percent of the beads released into the model were tracked for each release location and condition.

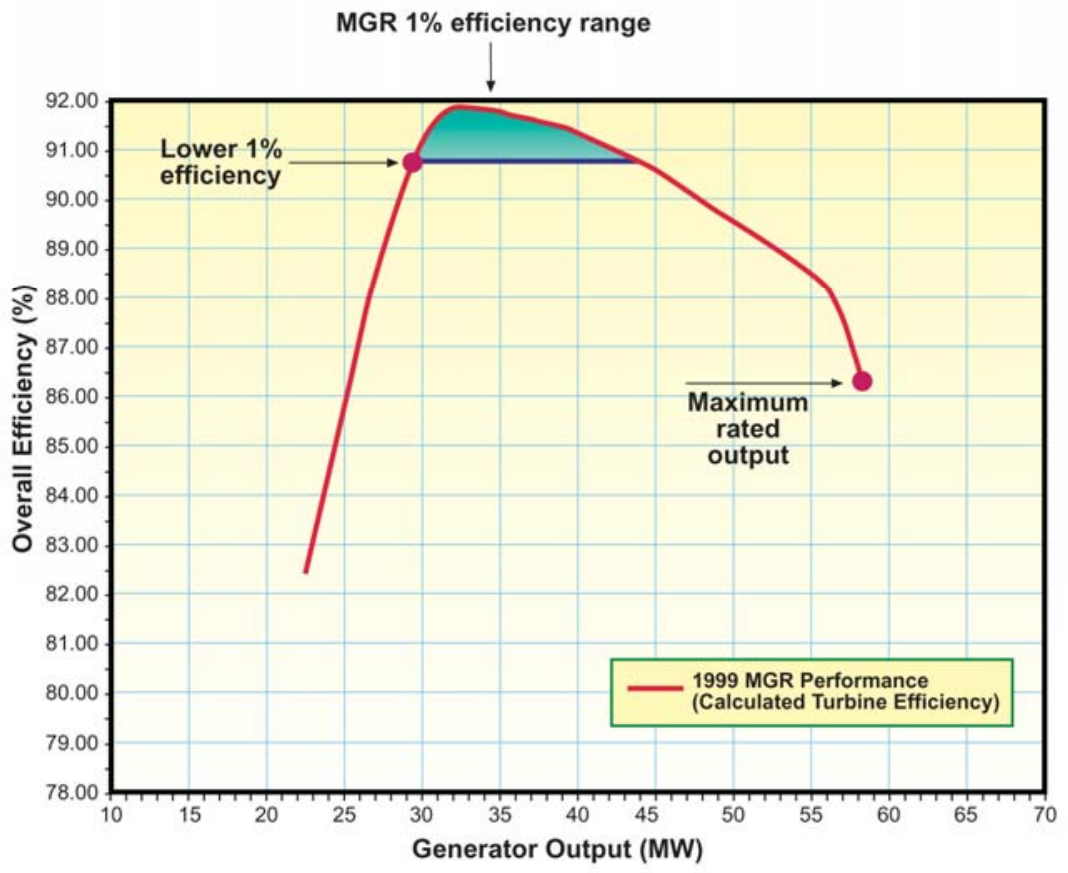

Figure 2.4. 1\% Operating efficiency range for MGR turbines at Bonneville Dam Powerhouse 1. Data was collected at the Lower $1 \%$ efficiency and maximum rated output 
Table 2.2. Summary of data collection in the BON1 MGR physical model describing the region of camera coverage, operation level, number of bead release events, and camera frame rate for tests conducted May 2003 at ERDC.

\begin{tabular}{lccc} 
Camera viewing region in model & $\begin{array}{c}\text { Turbine } \\
\text { operation } \\
\text { condition }\end{array}$ & $\begin{array}{c}\text { No. of bead } \\
\text { release events }\end{array}$ & $\begin{array}{c}\text { Camera frame } \\
\text { rate (frames/s) }\end{array}$ \\
\hline Slot A Draft tube \& splitter region & Lower 1\% & 20 & 500 \\
Slot B Draft tube \& splitter region & Lower 1\% & 20 & 500 \\
Slot C Draft tube \& splitter region & Lower 1\% & 21 & 500 \\
\hline Slot A Lower portion of splitter & Lower 1\% & 10 & 1000 \\
Slot B Lower portion of splitter & Lower 1\% & 10 & 1000 \\
Slot C Lower portion of splitter & Lower 1\% & 10 & 1000 \\
\hline Slot A right side splitter & Lower 1\% & 15 & 500 \\
Slot B right side splitter & Lower 1\% & 15 & 500 \\
Slot C right side splitter & Lower 1\% & 10 & 500 \\
\hline Runner hub slot A & Lower 1\% & 10 & 500 \\
Runner hub slot A & Lower 1\% & 10 & 1000 \\
Runner hub slot B & Lower 1\% & 10 & 500 \\
Runner hub slot B & Lower 1\% & 10 & 1000 \\
Runner hub slot C & Lower 1\% & 10 & 500 \\
Runner hub slot C & Lower 1\% & 10 & 1000 \\
\hline Draft tube elbow slot A & Lower 1\% & 19 & 500 \\
Draft tube elbow slot B & Lower 1\% & 20 & 500 \\
Draft tube elbow slot C & Lower 1\% & 20 & 500 \\
\hline Draft tube elbow slot A & Maximum & 20 & 500 \\
Draft tube elbow slot B & Maximum & 20 & 500 \\
Draft tube elbow slot C & Maximum & 20 & 500 \\
\hline Runner hub slot A & Maximum & 10 & 500 \\
Runner hub slot B & Maximum & 10 & 500 \\
Runner hub slot C & Maximum & 10 & 500 \\
\hline Runner hub slot A & Maximum & 10 & 1000 \\
Runner hub slot B & Maximum & 10 & 1000 \\
Runner hub slot C & Maximum & 10 & 1000 \\
\hline Splitter close-up slot A & Maximum & 20 & 1000 \\
Splitter close-up slot B & Maximum & 20 & 1000 \\
Splitter close-up slot C & Maximum & 20 & 500 \\
\hline Side view splitter horizontal slot A & Maximum & 15 & 500 \\
Side view splitter horizontal slot B & Maximum & 15 & 500 \\
Side view splitter horizontal slot C & Maximum & 15 & \\
\hline & & & \\
\hline & & 10 & \\
\hline & & 10 & \\
\hline
\end{tabular}



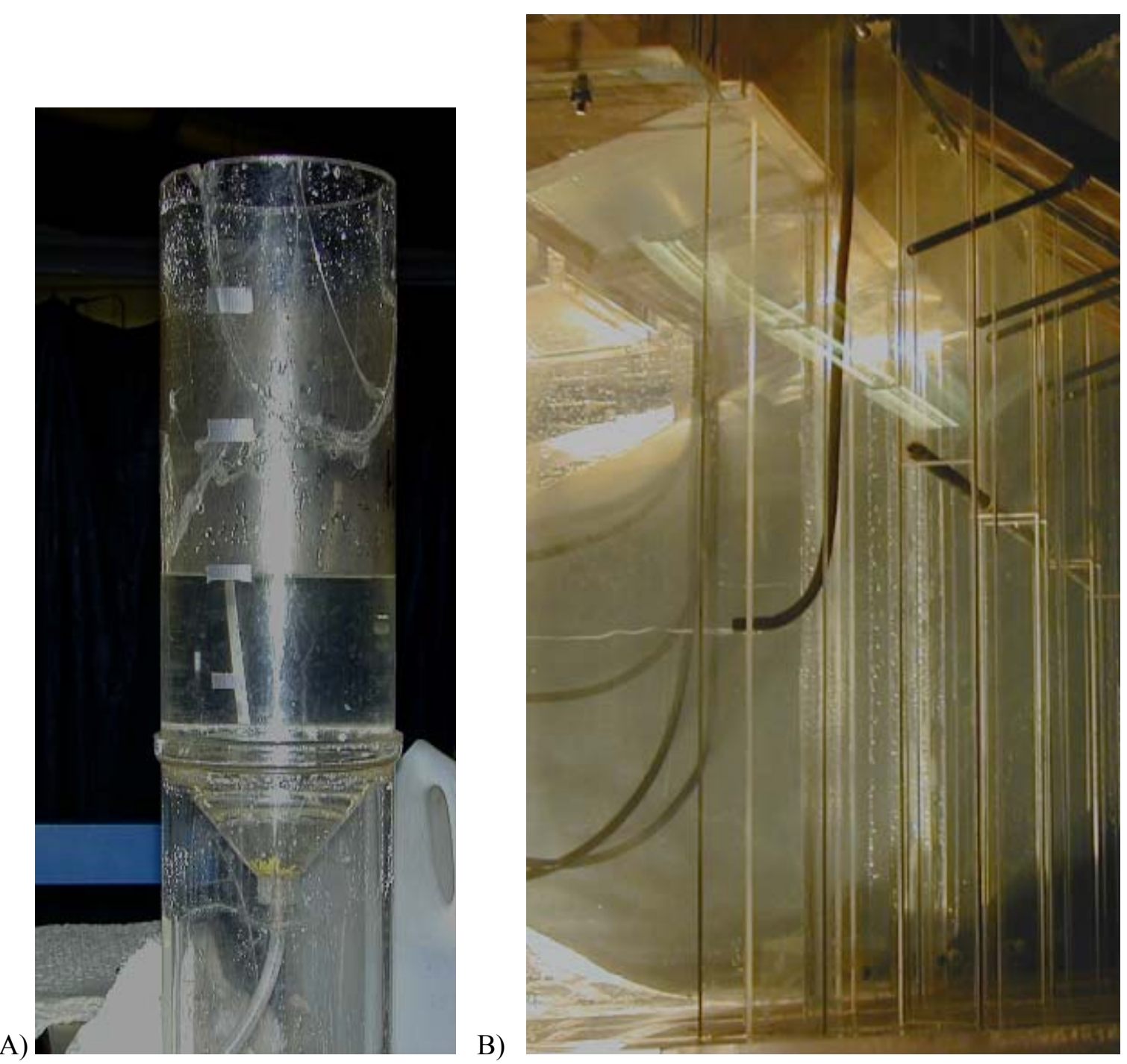

Figure 2.5. A) Bead release canister with beads visible at lower portion of funnel. B) Location of the terminus of copper bead release tube in the turbine intake below the emergency gate slot and downstream of the fish screens.

\subsection{Bead Characteristics}

Small (about $4 \mathrm{~mm}$ ), near neutrally buoyant, plastic, yellow-colored beads were used for all of the tests. The physical characteristics of the beads are given in Table 2.3. Bead dimensions were based on a sample of 10 beads and mass was estimated using a sample of 60 beads. The beads are rectangular shaped in the plan view and elliptical when viewed from the end (concentric cylinders) (Figure 2.6). At the scale of the BON1 physical model, the beads are proportional in size and mass to 110 -mm total-length salmon smolts; however, of course, the beads are not flexible and do not have volitional movement. 
Table 2.3. Characteristics of beads used during testing in the physical model.

\begin{tabular}{|l|l|}
\hline Length & $4.28 \pm 1.02(\mathrm{~mm})$ \\
\hline Height & $3.28 \pm 0.48(\mathrm{~mm})$ \\
\hline Width & $2.23 \pm 0.33(\mathrm{~mm})$ \\
\hline Mass & $23.4 \pm 2.61(\mathrm{mg})$ \\
\hline Specific Gravity & 1.072 \\
\hline Color & yellow \\
\hline
\end{tabular}

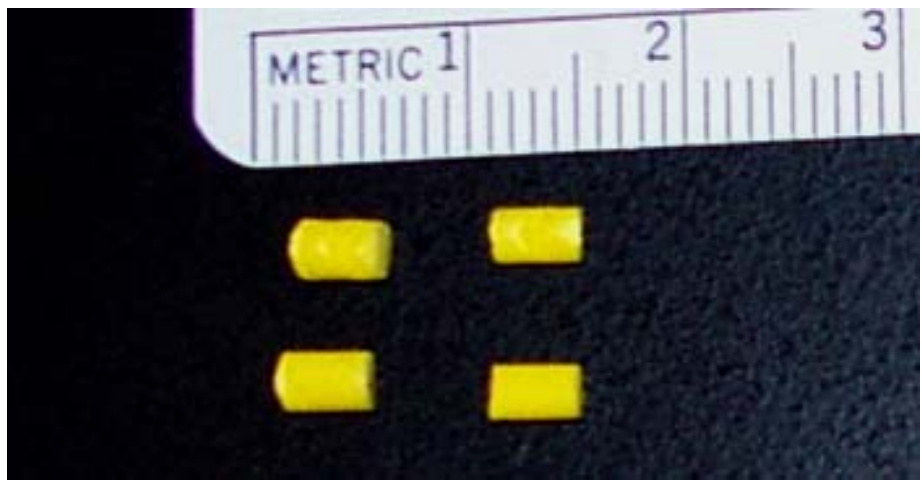

Figure 2.6. Beads used for bead tracking in the physical model.

\subsection{Video System, Calibration of Cameras and Image Processing}

Video images of bead release events were captured using two digital high-speed cameras (Redlake ${ }^{\mathrm{TM}}$ PCI-1000S) fitted with 3.5-mm lenses. Depending on the area viewed, cameras were placed at near right angles to each other to optimize 3-D imaging with the exception of the region directly below the hub where only 2-D data were collected (Figure 2.7). Halogen lights with diffusers were used along with nonreflecting dark cloth at various locations around the model to obtain adequate contrast and reduce reflections. Lights were adjusted for each camera location to ensure optimal image quality. Two recording speeds, 500 and 1000 frames/s, were used for data acquisition. The maximum recording time was $\sim 6 \mathrm{~s}$. Sensor resolution was $320 \times 280$ pixels at 500 frames/s and $320 \times 156$ pixels at 1000 frames/s. The two frame rates were used to test which would provide the best images for determining bead position and calculating velocity and acceleration. There are trade offs between the two frame rates: 500 frames/s had a larger field of view whereas, at 1000 frames/s, faster motion could be detected. The cameras were synchronized so that paired image sequences were obtained. Both cameras were connected to a PC with the camera control program. After the beads passed through the viewing region of the cameras, image acquisition was ended. The video file was then played back to check image quality and the data were saved to an external hard drive in .avi format.

Soft white lights were used with non-reflecting dark cloth at various locations around the model to optimize contrast and reduce reflections within the field of view. Lights were adjusted prior to each bead release to optimize image quality. Both cameras were connected to a $\mathrm{PC}$ and operated using software resident on the PC. Bead and calibration event files were saved in avi format. Depending on the area viewed, cameras were placed at near right angles to each other to optimize 3-D imaging, with the exception of the region directly below the hub where only 2-D data were collected (Figure 2.7). 


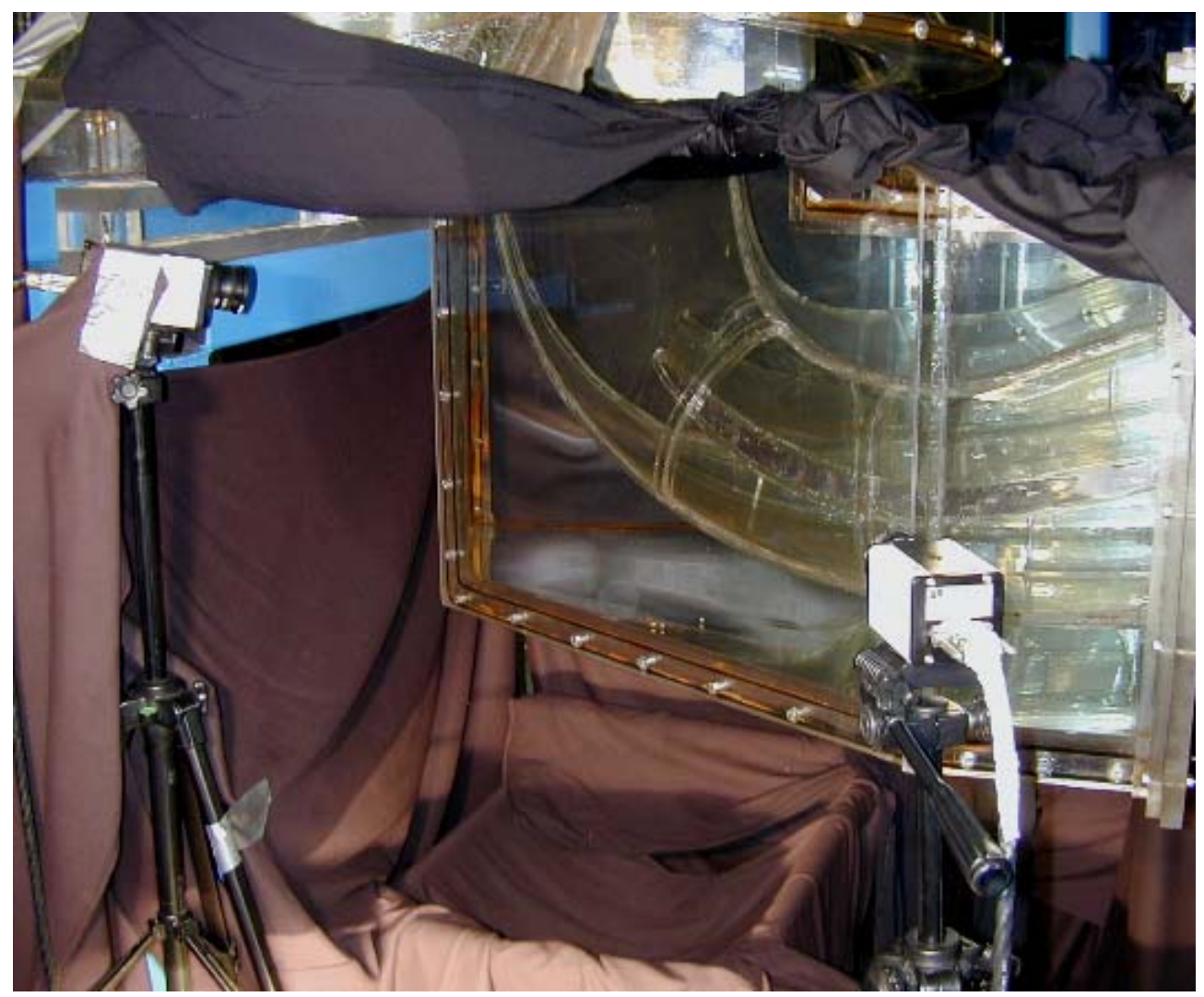

Figure 2.7. Camera positioning in relation to the elbow and splitter region of the model.

In order to accurately track objects in three dimensions using paired cameras, it is necessary to know the orientation of the cameras to each other. This is done by placing a calibration device in the region viewed by both cameras. For each section of the model where bead tracking took place, the orientation of the cameras to each other was determined by placing a calibration jig (Figure 2.8) within the center portion of the field of view for both cameras and acquiring several frames of the resulting image. These images were processed using the Sensors Application Inc. (SAI) software. The nodes of the calibration jig were paired for the two cameras to obtain a calibrated image-oriented reference location for the cameras and viewing area. As an element of bead trajectory image acquisition, the calibration jig was inserted into the model prior to each test run with water in the model under static conditions. The calibration jig was constructed from a Plexiglas base with $1 / 2$-inch-diameter white balls placed in a regular grid pattern on threaded metal uprights. The balls were placed in four rows with 2-inch spacing and three columns with 1-inch spacing. Each row had three 0.1-inch-diameter rods with three balls per rod centered at 1-inch vertical spacing (Figure 2.8). The calibration jig was inserted into the model from the openings at the terminus of the draft tube using a piece of plastic conveyor track that was stiff enough for insertion into the model but flexible enough to bend with the curvature of the draft tube. The jig was positioned so that both cameras could view the maximum number of balls (Figure 2.9). After calibration files were acquired, the jig was removed and the water flow in the model was resumed and left to stabilize before subsequent bead releases. 


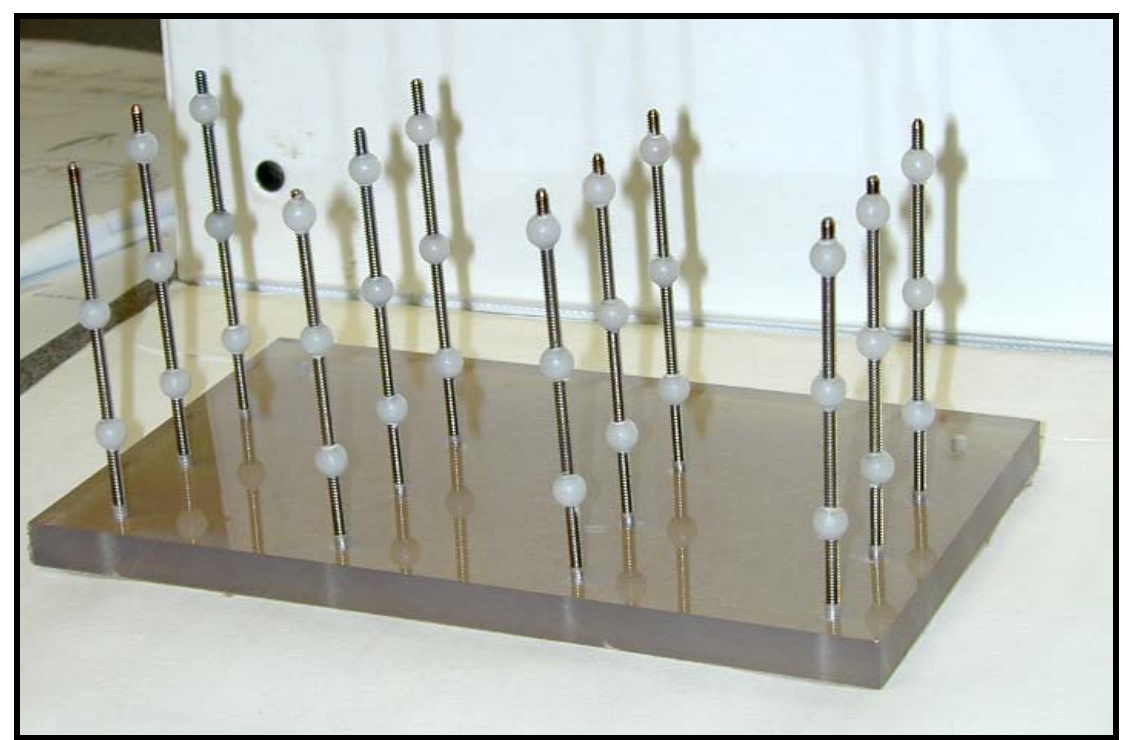

Figure 2.8. Calibration jig used to obtain 3-D measurements within the model

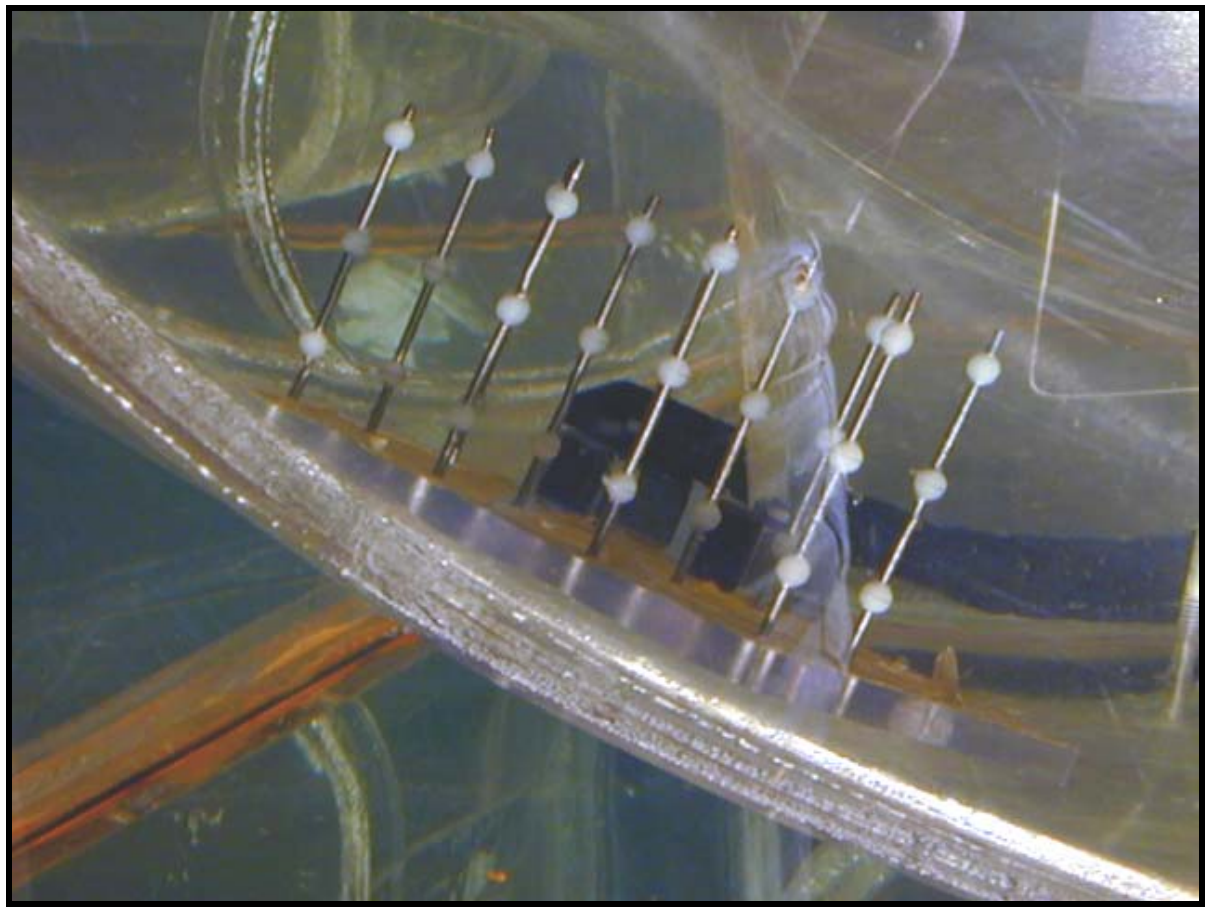

Figure 2.9. Calibration jig positioned upstream of the splitter in the BON1 1:25-scale physical model.

Trajectories of beads in 2-D and 3-D were calculated using the SAI ImageExpress Vision software. Bead trajectories were tracked in 3-D by first identifying the area of overlapping fields of view of the 2-D images from the two cameras and then identifying matching positions on the calibration jig in the two fields of view. Matching the nodes on the calibration jig in the calibration files for both cameras and establishing Cartesian coordinates for jig nodal points enabled us to establish a calibrated stereoscopic view. Paired bead files for both cameras were then opened and beads were tracked using the calibrated 
solutions for the two cameras. Beads were tracked using a combination of automatic and manual methods.

The distribution of beads exiting the runner was observed using a single camera placed directly below the runner region and looking upward. The camera was fastened to a gimbaled bracket mounted on a stationary PVC frame. Data was processed by superimposing a polar grid around an image of the runner region and bead trajectories through this region were determined using the MIDAS 2.0 software program. The outer diameter of the hub was used as a reference dimension for image scaling.

\subsection{Coordinate System}

Each time the cameras were repositioned, recalibration was required. Since the images recorded with the cameras were referenced relative to the calibration jig, the coordinate systems were translated and rotated for each treatment. Therefore, after the bead trajectories were calculated, the data coordinates were translated and rotated relative to the coordinate plane of the model from the coordinate plane of the calibration jig orientations.

The intersecting point between the floor of the draft tube and the base of the upstream end of the vertical splitter was chosen for the common origin $(x=0, y=0, z=0)$ because it was visible in most of the images and was the most distinct point in the draft tube region of the model. A second point at the top of the vertical splitter of known distance from the origin was used as a second point of reference $(x=0, y=0$, $\mathrm{z}=$ height of splitter). Image files were processed for the points at the base and top of the vertical splitter relative to the calibration jig position for each treatment. The position values computed for these two positions were then used for deriving translation and rotation values to adjust tracked bead coordinates into a standard plane relative to the physical model.

The computed coordinates for the base of the vertical splitter $\left(\mathrm{X}_{\mathrm{o}}, \mathrm{Y}_{\mathrm{o}}, \mathrm{Z}_{\mathrm{o}}\right)$ were translated to the origin $(0,0,0)$ so our translation values for all coordinates with each treatment were $T x=-X_{0}, T y=-Y_{0}$, and $\mathrm{Tz}=-\mathrm{Z}_{\mathrm{o}}$ (Figure 2.10). The coordinates computed for the top of the vertical splitter $\left(\mathrm{X}_{1}, \mathrm{Y}_{1}, \mathrm{Z}_{1}\right)$, were then translated $\left(\mathrm{X}^{\prime}{ }_{1}=\mathrm{X}_{1}+\mathrm{Tx}, \mathrm{Y}^{\prime}{ }_{1}=\mathrm{Y}_{1}+\mathrm{Ty}, \mathrm{Z}^{\prime}{ }_{1}=\mathrm{Z}_{1}+\mathrm{Tz}\right)$.

The translated coordinates at the top of the vertical splitter $\left(\mathrm{X}_{1}{ }_{1}, \mathrm{Y}_{1}{ }_{1}, \mathrm{Z}^{\prime}{ }_{1}\right)$ were next rotated on the $\mathrm{Y}$ axis to bring $X$ into vertical alignment with the origin on the vertical splitter $(X=0)$ for the top of the vertical splitter (Figure 2.11), where the angle of rotation $\left(\mathrm{q}_{\mathrm{x}}\right)$ was $q_{x}=\operatorname{abs}\left(\arctan \left(X^{\prime}{ }_{1} / Z^{\prime}{ }_{1}\right)\right)$. The calculations for coordinates rotated on the $\mathrm{Y}$ axis were

$$
\begin{aligned}
& X^{\prime}{ }_{1}=Z^{\prime}{ }_{1} * \sin \left(q_{x}\right)+X^{{ }^{\prime}}{ }_{1} * \cos \left(q_{x}\right) \quad\left(X{ }^{\prime}{ }_{1}=0\right) \\
& Y^{\prime \prime}{ }_{1}=Y^{\prime}{ }_{1} \\
& Z{ }^{\prime}{ }_{1}=Z^{{ }_{1}}{ }_{1} \cos \left(q_{x}\right)-X^{{ }^{\prime}}{ }_{1}{ } \sin \left(q_{x}\right)
\end{aligned}
$$

Finally the coordinates $\left(X{ }_{1}, Y{ }_{1}, Z{ }_{1}\right)$ were rotated on the $\mathrm{X}$ axis to bring $\mathrm{Y}$ into vertical alignment with the origin on the vertical splitter $(\mathrm{Y}=0)$ for the top of the vertical splitter where the angle of rotation $\left(\mathrm{q}_{\mathrm{y}}\right)$ was $\mathrm{q}_{\mathrm{y}}=\arctan \left(\mathrm{Y},{ }_{1}, \mathrm{Z}{ }_{1}{ }\right)$. The calculations for coordinates rotated on the $\mathrm{X}$ axis were 


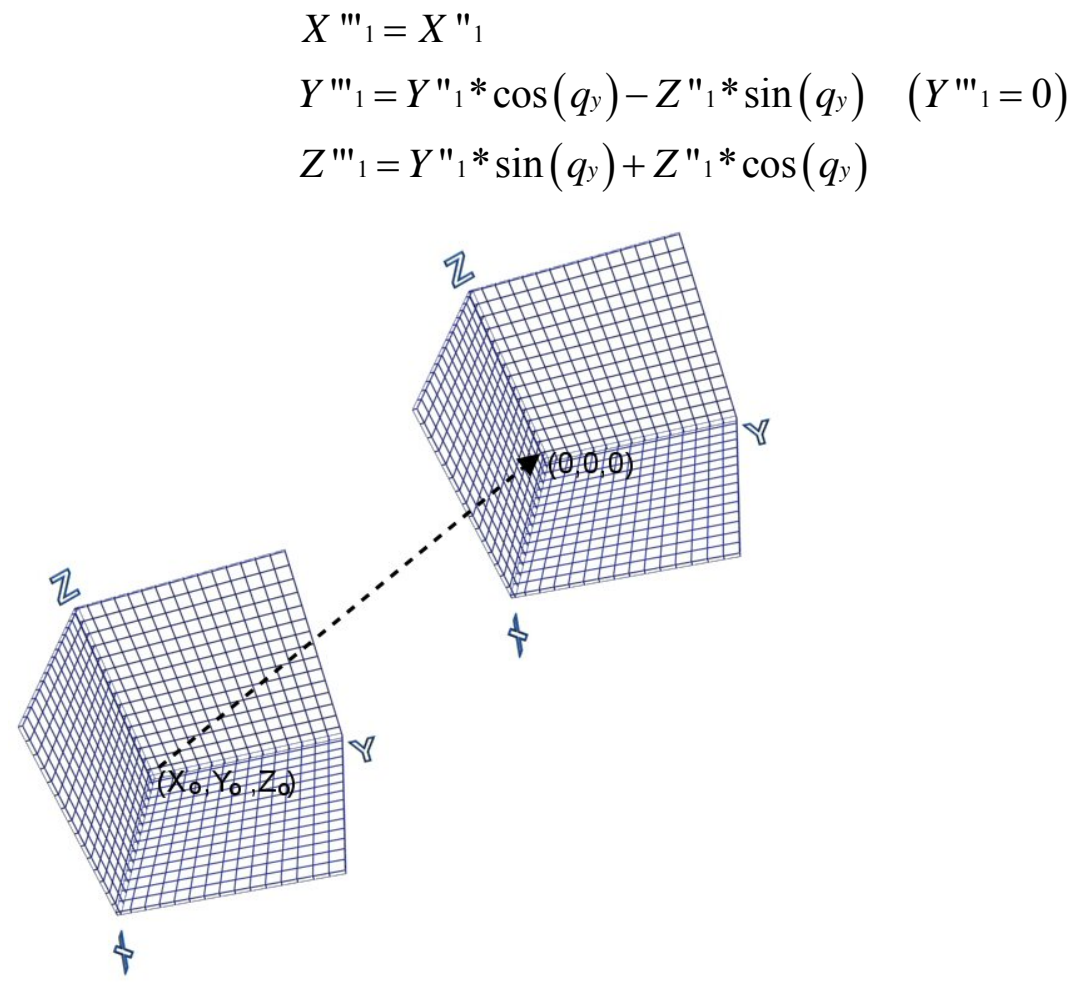

Figure 2.10. Translation of coordinates to the plane of the physical model.

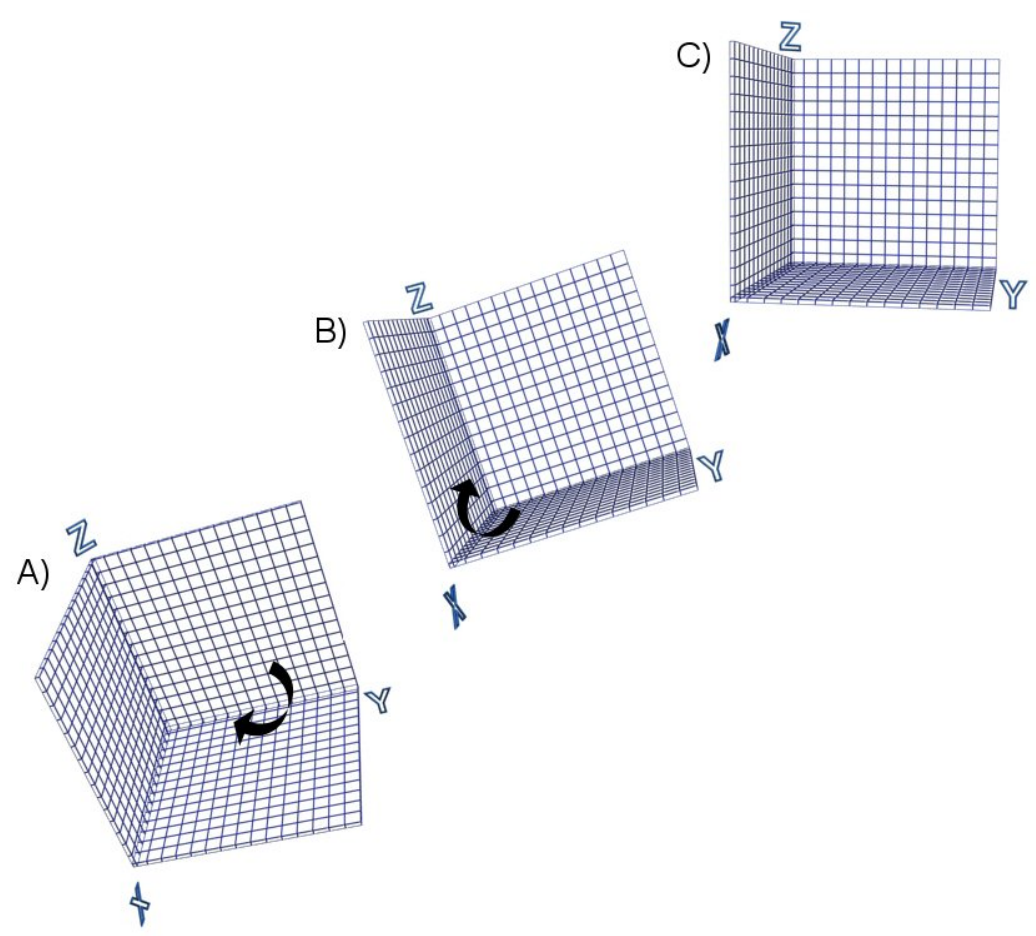

Figure 2.11. Rotation of coordinates to the plane of the physical model by rotating the data on the $\mathrm{X}$ and $\mathrm{Y}$ axis 


\subsection{Bias/Error Analysis}

Bias in bead 3-D position estimates results mainly from error in measurements of the positions of calibration jig nodes and camera resolution (i.e., number of available pixels). Position bias increases with increase in the distance of the bead from the calibration jig's location during calibration. Bead position estimate error is also affected by image distortion caused by the camera lens especially near the edge of the field of view. Additional processing of calibration jig images was used to estimate bead 3-D position estimate bias.

Ideally, to obtain the most accurate position estimates for beads, during calibration the calibration jig would fill the entire field of view of each camera. This positioning of the calibration jig would provide images of jig nodes of known location through the cameras' fields of view. In the physical turbine model it was not possible to achieve optimum placement of the calibration jig due to space constraints, which limited the size of the jig and where and how it could be positioned in the model. The largest possible calibration fixture we could insert into the draft tube of the physical model was $6 \times 4 \times 3$-inches (Figures 2.8 and 2.9). This covered a relatively small section of the portion of the model of interest and the jig could not be moved close to the runner of the model due to the slope of the elbow.

To estimate the bias in position of a bead being tracked through the physical model, the calibration jig (Figure 2.12, bottom) was placed in the middle of a grid of 1-inch by 1-inch squares and images were acquired. A second jig (Figure 2.12, upper right) with nodes of known spacing was then placed on the grid and image data was collected at known locations in the grid system. Images were recorded at 500 and 1000 frames/s and with cameras at two ranges from the center of the calibration jig: close and long range, which bracketed the offsets of the cameras from the middle of the regions of interest during image acquisition in the physical model. At close range, the two cameras were 18 and 14 inches from the center point of the calibration jig and at long range the two cameras were 25 and 28 inches from the center point.

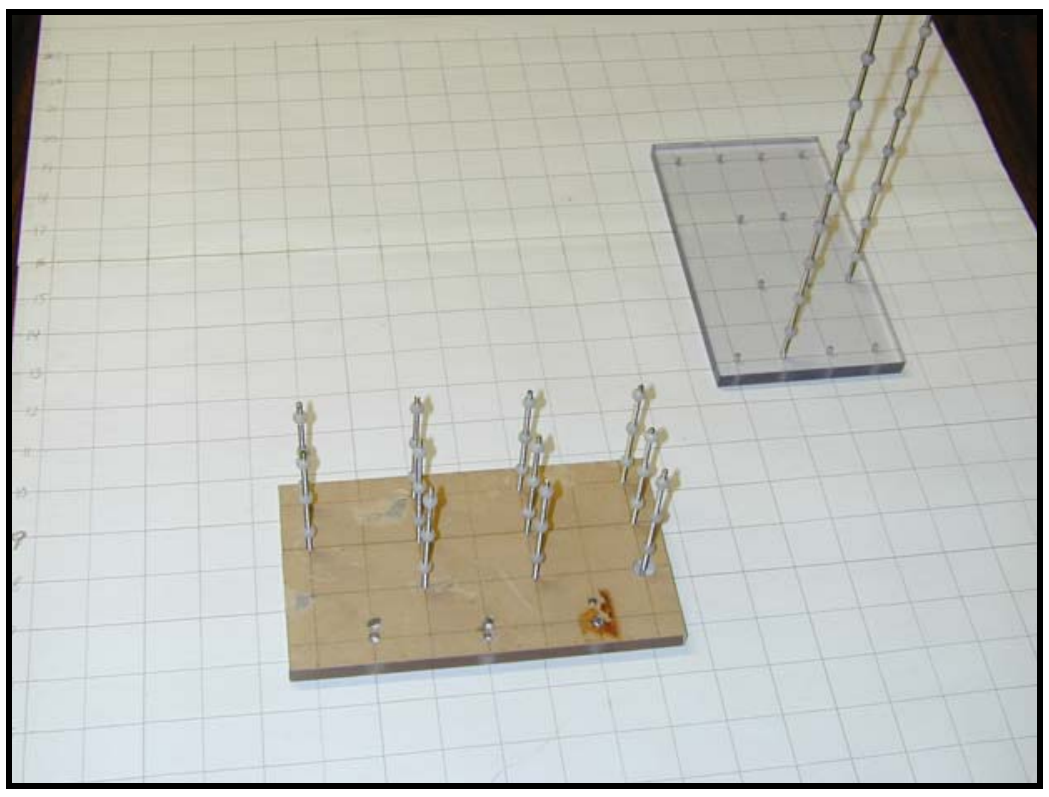

Figure 2.12. Calibration jig (middle bottom) and second jig (upper right) used to estimate bias in location estimates on grid pad. 
Position estimates for every node on the second jig were calculated relative to the grid using the SAI software. We calculated bias in the location of every node relative to its physically measured location as follows:

$$
\text { position bias }=\sqrt{\left(\left(x-x_{1}\right)^{2}+\left(y-y_{1}\right)^{2}+\left(z-z_{1}\right)^{2}\right)}
$$

where $\mathrm{x}, \mathrm{y}$, and $\mathrm{z}$ were the actual location of the node and $\mathrm{x}_{1}, \mathrm{y}_{1}$, and $\mathrm{z}_{1}$ were the calculated locations of the nodes. Position bias of each node was regressed against its actual distance from the center point of the calibration jig.

\subsection{Camera Resolution Testing}

Tests were conducted to determine the effects different parameters (i.e., frame rate, pixel resolution, area of view, etc.) would have on tracking resolution and differences in sources of tracking error (i.e., jitter due to quantization, calibration, tracking method [centroid vs. brightest pixel] etc.). Tests were conducted in a controlled laboratory environment using the same Redake PCI-1000S cameras used for data acquisition at ERDC in the physical model and, in addition, two Photron Fastcam PCI model 1280 video cameras (Table 2.4).

Cameras were used in pairs and synchronized. Both pairs of cameras were placed at a $\sim 30^{\circ}$ angle, relative to each other with an overlapping region of view that would include the trajectory of a dropped bead. A backdrop of black cloth and halogen lighting were used to provide the required image contrast for seeing the beads (Figure 2.13). A calibration grid plate consisting of fiducial marks placed 1 inch on center was used for all tests (Figure 2.14). Two different types of beads were used: 1) beads identical to those used in the physical model at ERDC, and 2) 3/16 inch round beads.

The first series of tests was conducted by dropping five beads in the air so that they passed vertically through the field of view of both sets of cameras. The second set of tests was conducted in water in a 150-gal aquarium that was $6 \mathrm{ft} \times 1.5 \mathrm{ft}$ wide $\mathrm{x} 2.5 \mathrm{ft}$ tall. A small submersible pump was placed at one end of the tank and it had a 1-inch PVC outflow pipe. Groups of three to five beads were released by hand at the pipe terminus. A single Photon camera was situated near the side of the tank and bead paths were recorded as they traveled with the water flow.

Table 2.4. Specification for cameras used during laboratory tests comparing trajectory accuracy relative to camera resolution.

\begin{tabular}{||l|l|l|}
\hline & Redlake PCI 1000S & Photron PCI 1280 \\
\hline 500 frames/s & & \\
\hline Resolution & $320 \times 280$ & $1280 \times 1024$ \\
\hline Shutter speed & $1 / 500^{\text {th }}(1 \mathrm{x})$ & $2 \mathrm{~ms}$ to $7.8 \mu \mathrm{s}$ \\
\hline & & \\
\hline 1000 frames/s & & \\
\hline Resolution & $320 \times 156$ & $1280 \times 512$ \\
\hline Shutter speed & $1 / 1000^{\text {th }}(1 \mathrm{x})$ & $1 \mathrm{~ms}$ to $7.8 \mu \mathrm{s}$ \\
\hline Sensor & $8 \mathrm{bit}$ & $10 \mathrm{bit} \mathrm{CMOS}$ \\
\hline Lens & $6 \mathrm{~mm}$ & $50 \mathrm{~mm}$ \\
\hline
\end{tabular}




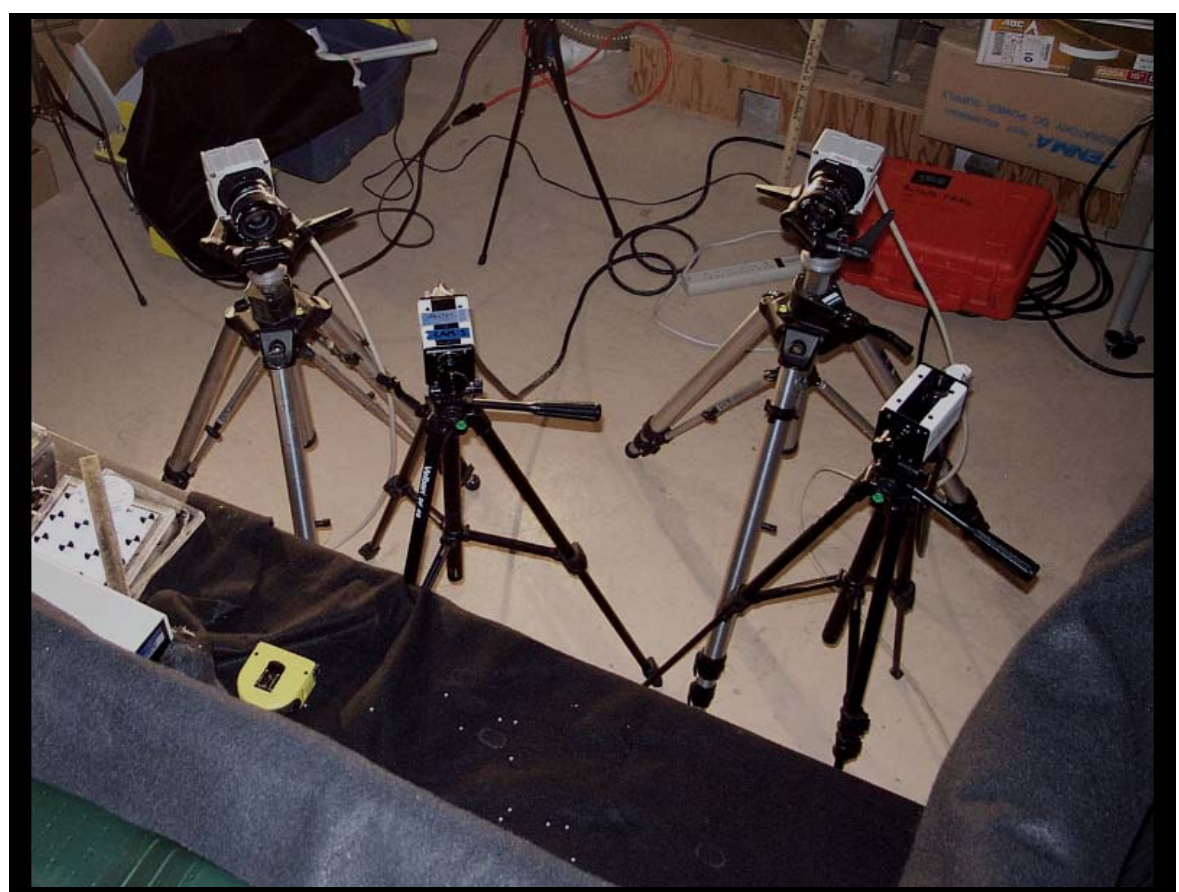

Figure 2.13. Test setup for camera comparison test at PNNL

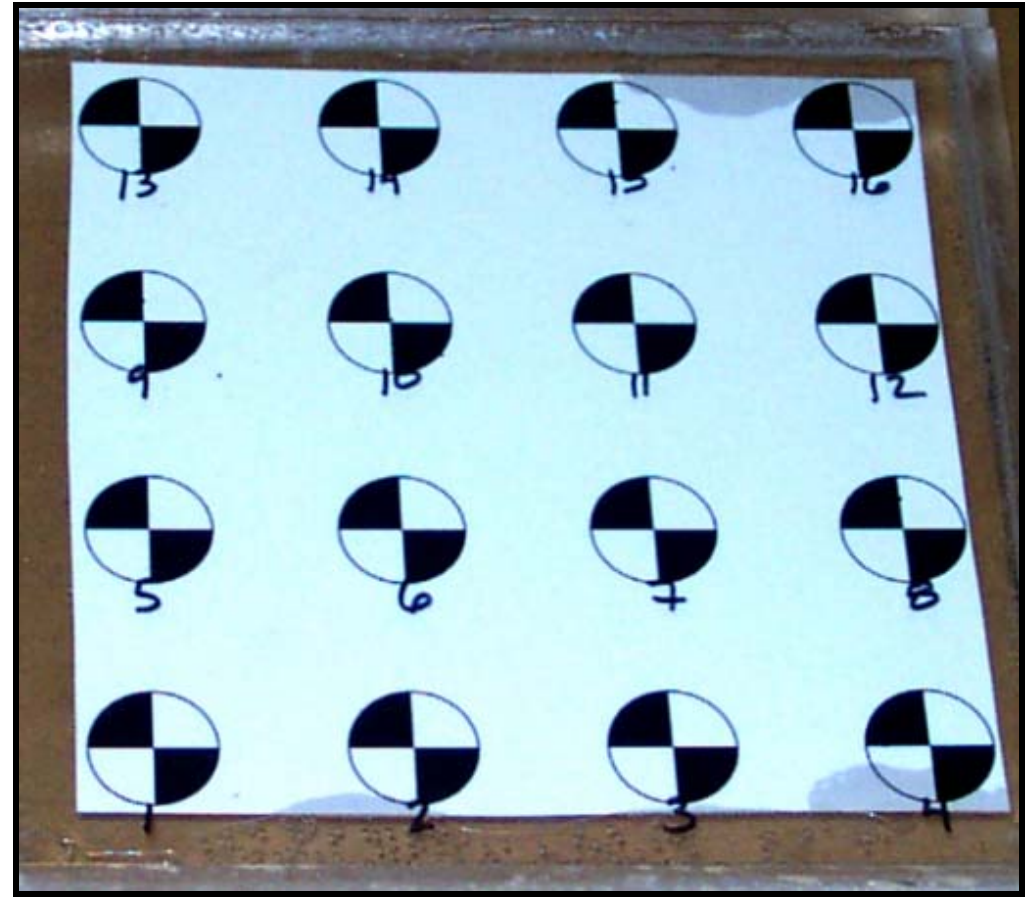

Figure 2.14. Calibration plate with fiducial marks used for camera comparison test at PNNL 


\subsection{Results}

All results are presented at 1:25 model scale unless otherwise noted.

\subsection{Data Smoothing}

Bead trajectories exhibited jitter from pixel-level quantization during image processing and the algorithms used to detect and track the bead; these algorithms focused on the most reflective portion of a bead, which could change from frame to frame. Jitter was almost undetectable when viewing the trajectory (displacement between frames) of the bead but became more apparent when velocity magnitude was estimated (Figure 3.1). Jitter was quite obvious when accelerations were calculated and unrealistic estimates of acceleration were obtained (Figure 3.2). To obtain more realistic estimates of velocity and acceleration, the data were smoothed. Two types of smoothing were compared to determine which provided better results. Data were smoothed by averaging image data over 2 to 20 frames and by skipping (decimating) frames. Skipping five frames provided the best estimates of velocity and acceleration when compared with other model and Sensor Fish acceleration time histories.

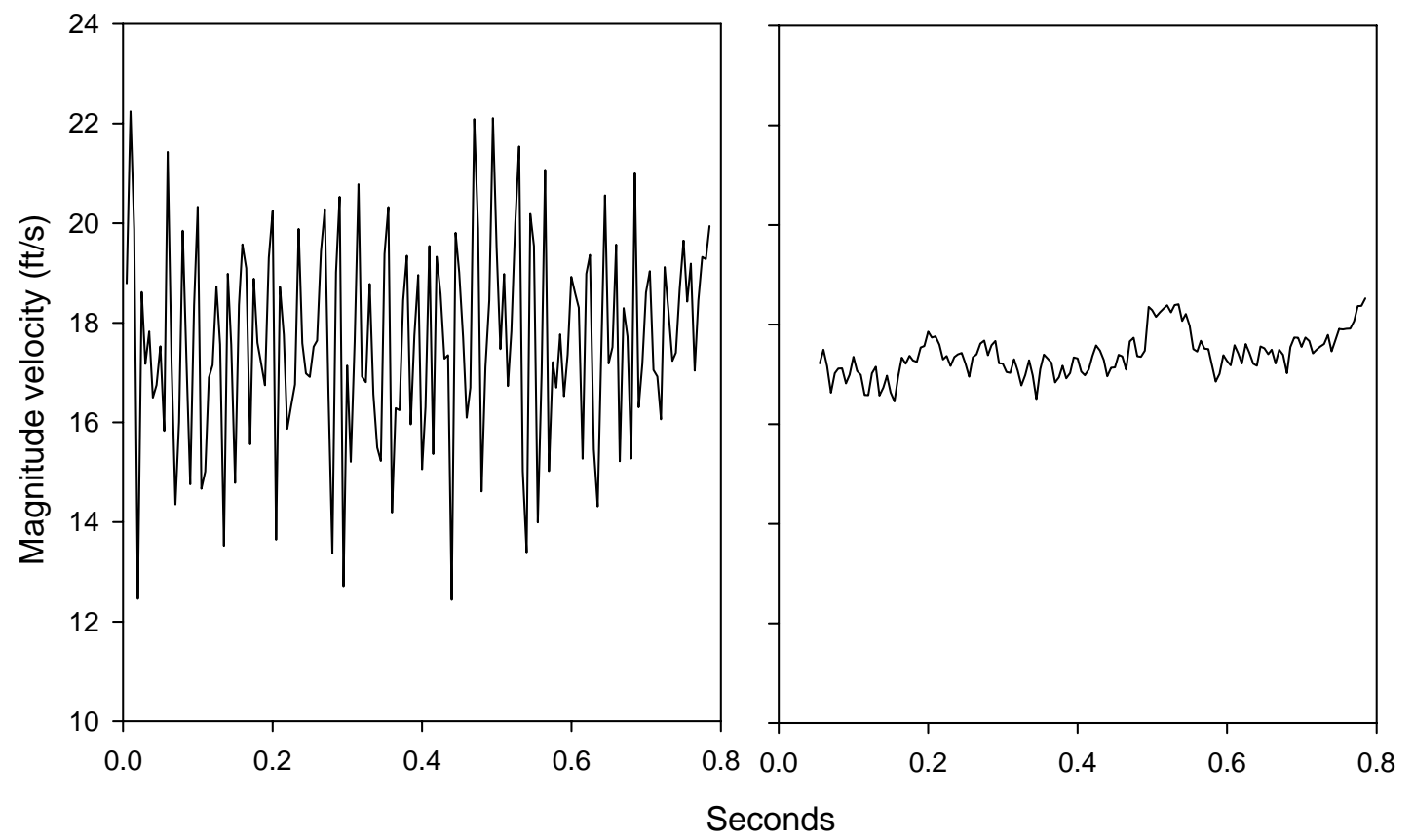

Figure 3.1. Magnitude velocity of a bead tracked through the draft tube region of the model at maximum operation condition prior to smoothing (left) and after smoothing by averaging the frame of interest and the frame 5 frames ahead (right). (Note: The velocity data were converted to prototype scale (multiplied by 5) for direct comparison with Sensor Fish data and other data collected or calculated in prototype scale.) 


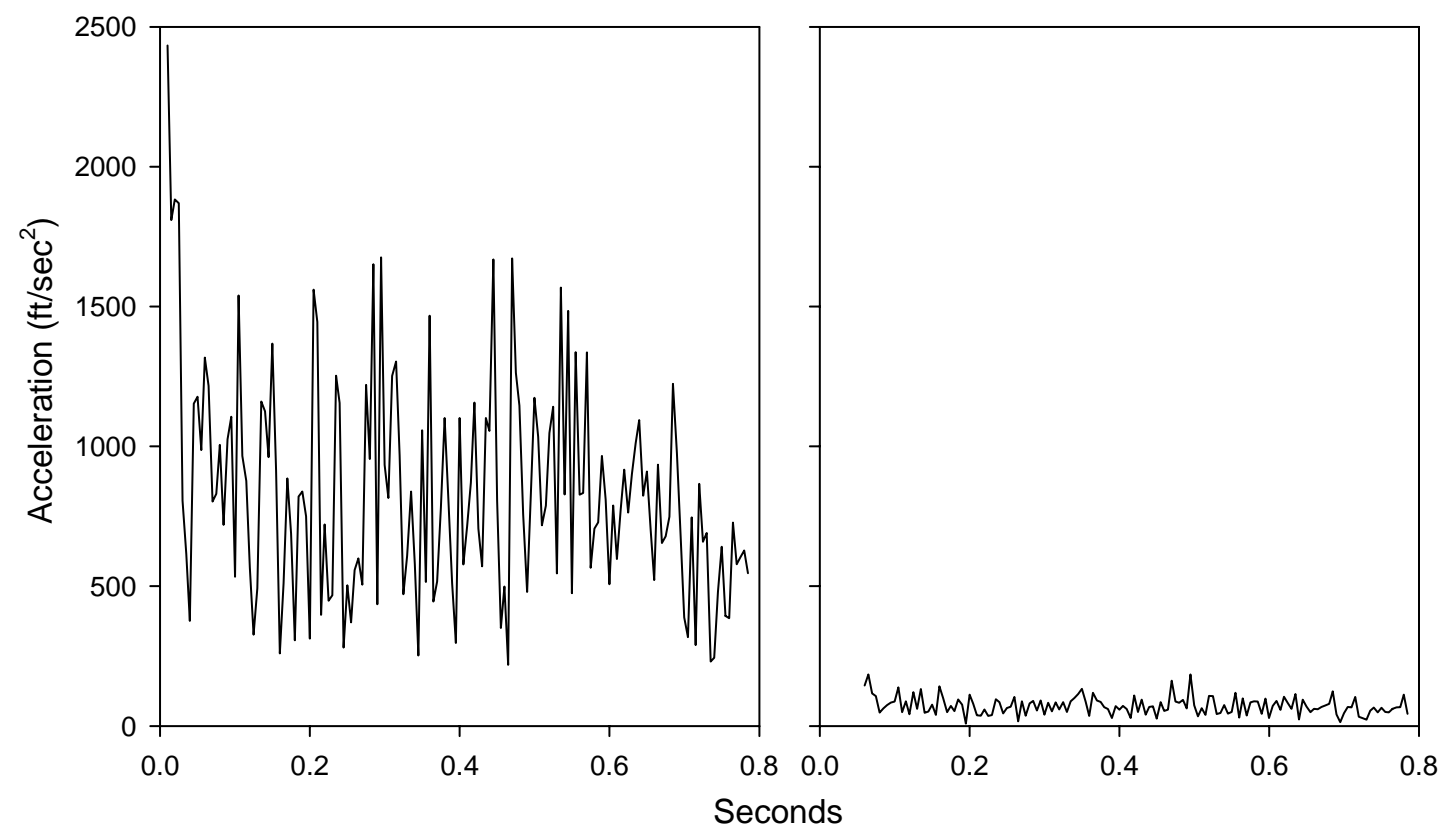

Figure 3.2. Acceleration magnitude of a bead tracked through the draft tube region of the model at maximum operation condition prior to smoothing (left) and after smoothing by averaging the frame of interest and the frame five frames ahead (right). (Note: The acceleration data were converted to prototype scale for direct comparison with Sensor Fish and other data collected or calculated in prototype scale.)

\subsection{Bead Passage Below the Runner}

\subsubsection{Point of First Detection}

Beads released into each of the three intakes at the lower $1 \%$ efficiency and maximum operating levels were not uniformly distributed throughout the plane containing the trailing edges of the runner blades when observed from directly below the MGR runner. The average number of beads first detected was close to what would be expected by chance alone in quadrants I and II, which averaged $25.4 \%$ and $24.7 \%$, respectively, for beads released at both operating conditions. The number detected in quadrants III and IV were skewed with $18.2 \%$ and $31 \%$, respectively. This distribution was also seen at each of the operation levels with $25.0 \%, 24.6 \%, 17.0 \%$, and $33.4 \%$ detected in quadrants I, II, III and IV, respectively, at lower 1\% operating efficiency condition (Figure 3.3). At the maximum operating level condition, $26.0 \%, 24.9 \%, 19.7 \%$ and $29.4 \%$ were detected in quadrants I through IV (Figure 3.4). 


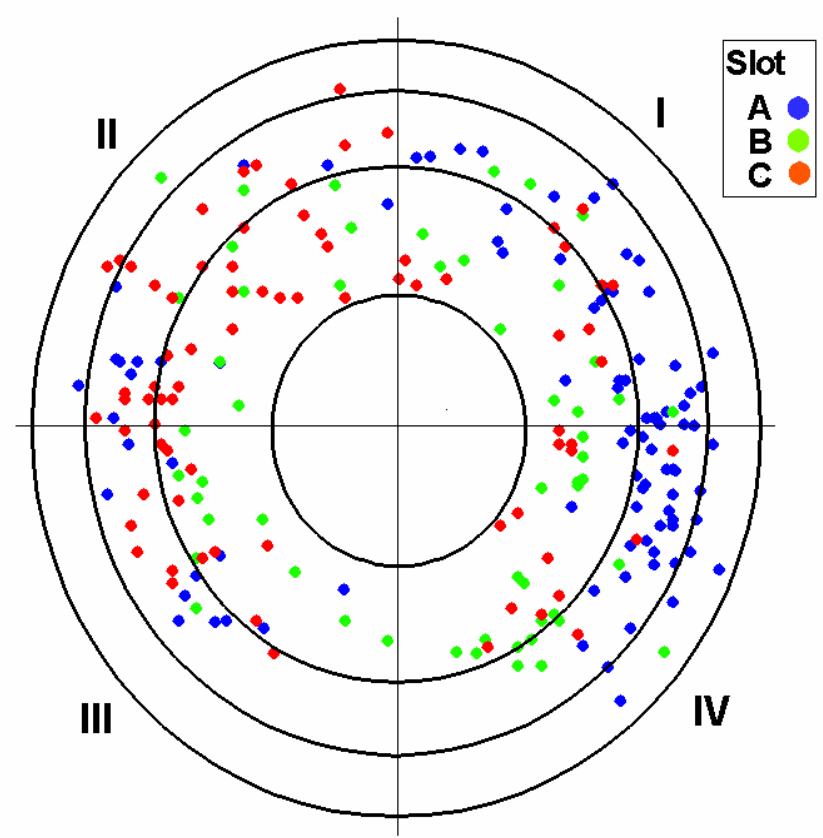

Figure 3.3. Position of first detection of beads below the MGR runner at the lower $1 \%$ operating efficiency for beads released mid-depth in intakes A, B, and C. The underside of the runner was divided into three regions of equal area relative to the runner blades (hub, mid-blade, and tip) and four quadrants (I, II, III, and IV). (Note: perspective is looking up at underside of the runner.)

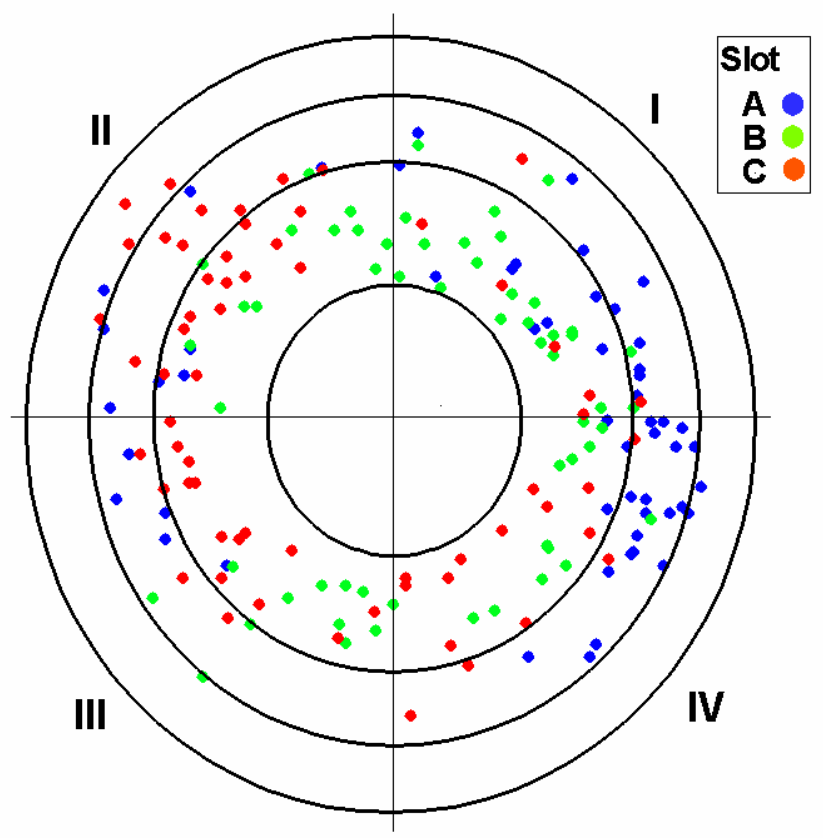

Figure 3.4. Position of first detection of beads below the MGR runner at maximum operating condition for beads released mid-depth in intakes A, B, and C. The underside of the runner was divided into three regions of equal area relative to the runner blades (hub, mid-blade, and tip) and four quadrants (I, II, III, and IV). 
The distribution of beads first detected below the turbine runner was not random $\left(\chi^{2}<0.01\right)$ and varied with release intake and with operating condition for the B intake. The percent distribution was similar at both operating conditions for releases into intakes $\mathrm{A}$ and $\mathrm{C}$. The highest detection for releases at Intake A was in quadrant IV and the lowest detections were in quadrants II and III (Table 3.1 and Figures 3.5 and 3.6). For beads released at intake C, detection was highest in quadrant II and lowest in quadrant I. Distribution among quadrants differed between operating conditions for releases in the B intake. At the lower $1 \%$ operating efficiency, the highest detection was in quadrant IV and the lowest was in quadrant II. At the maximum operating level, the highest detection was in quadrant I and the lowest detection was in quadrant IV.

Table 3.1. Percent of beads as they were first detected below the runner within each quadrant by release location and operation level.

\begin{tabular}{|c|c|c|c|c|c|}
\hline \multirow{2}{*}{$\begin{array}{l}\text { Operation } \\
\text { level }\end{array}$} & \multirow{2}{*}{$\begin{array}{l}\text { Release } \\
\text { location }\end{array}$} & \multicolumn{4}{|c|}{ Quadrant } \\
\hline & & I & II & III & IV \\
\hline \multirow{3}{*}{ Lower 1\% } & $\mathrm{A}$ & 34.0 & 11.7 & 11.7 & 42.6 \\
\hline & B & 24.1 & 18.5 & 20.4 & 37.0 \\
\hline & $\mathrm{C}$ & 14.5 & 44.7 & 21.1 & 19.7 \\
\hline \multirow{3}{*}{ Maximum } & $\mathrm{A}$ & 29.6 & 14.8 & 9.3 & 46.3 \\
\hline & B & 37.3 & 20.4 & 22.0 & 20.3 \\
\hline & $\mathrm{C}$ & 11.1 & 38.1 & 27.0 & 23.8 \\
\hline
\end{tabular}

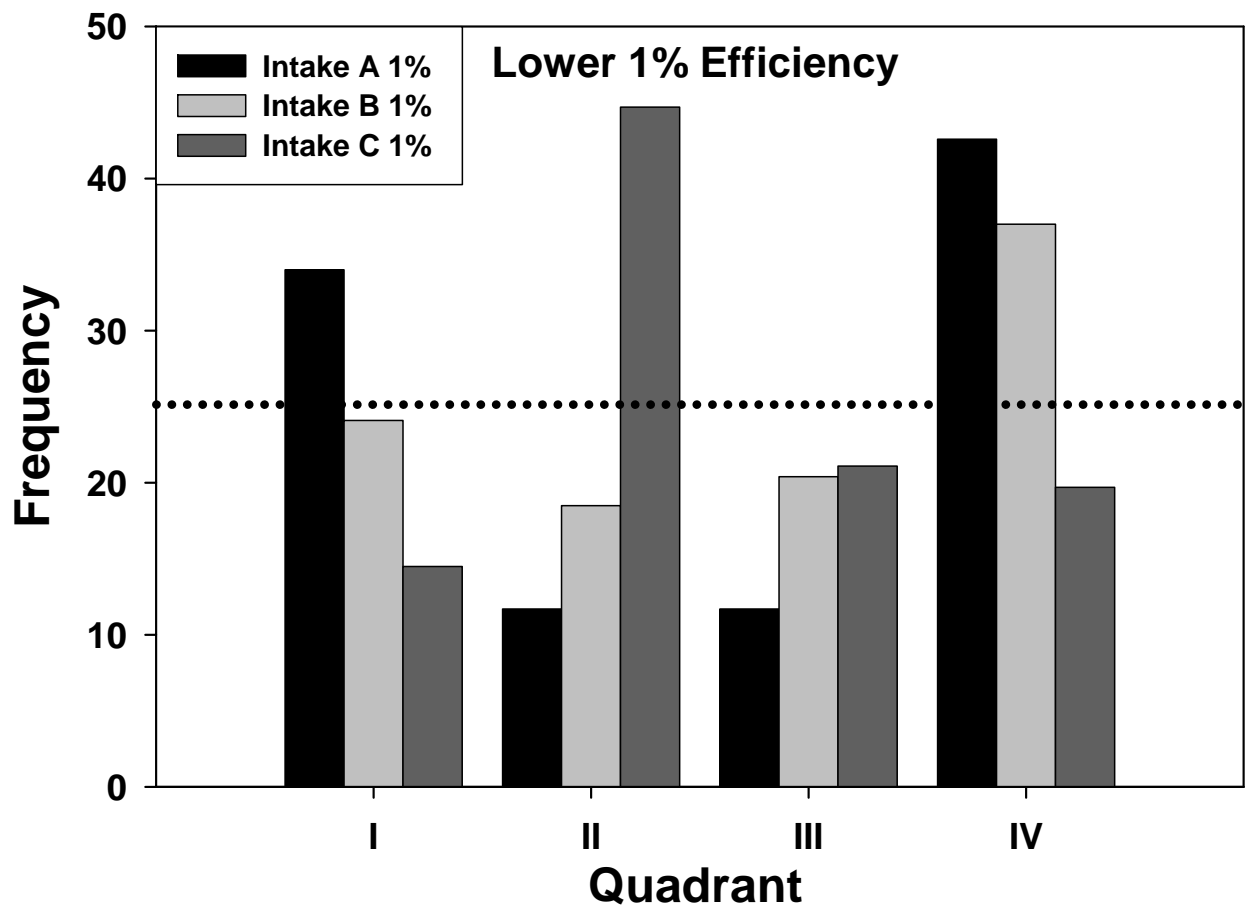

Figure 3.5. Percent distribution of beads by quadrant of first detection below the runner for beads released in the $\mathrm{A}, \mathrm{B}$, and $\mathrm{C}$ intakes at lower $1 \%$ operating efficiency. The dotted line represents the level where bead distribution is random. 


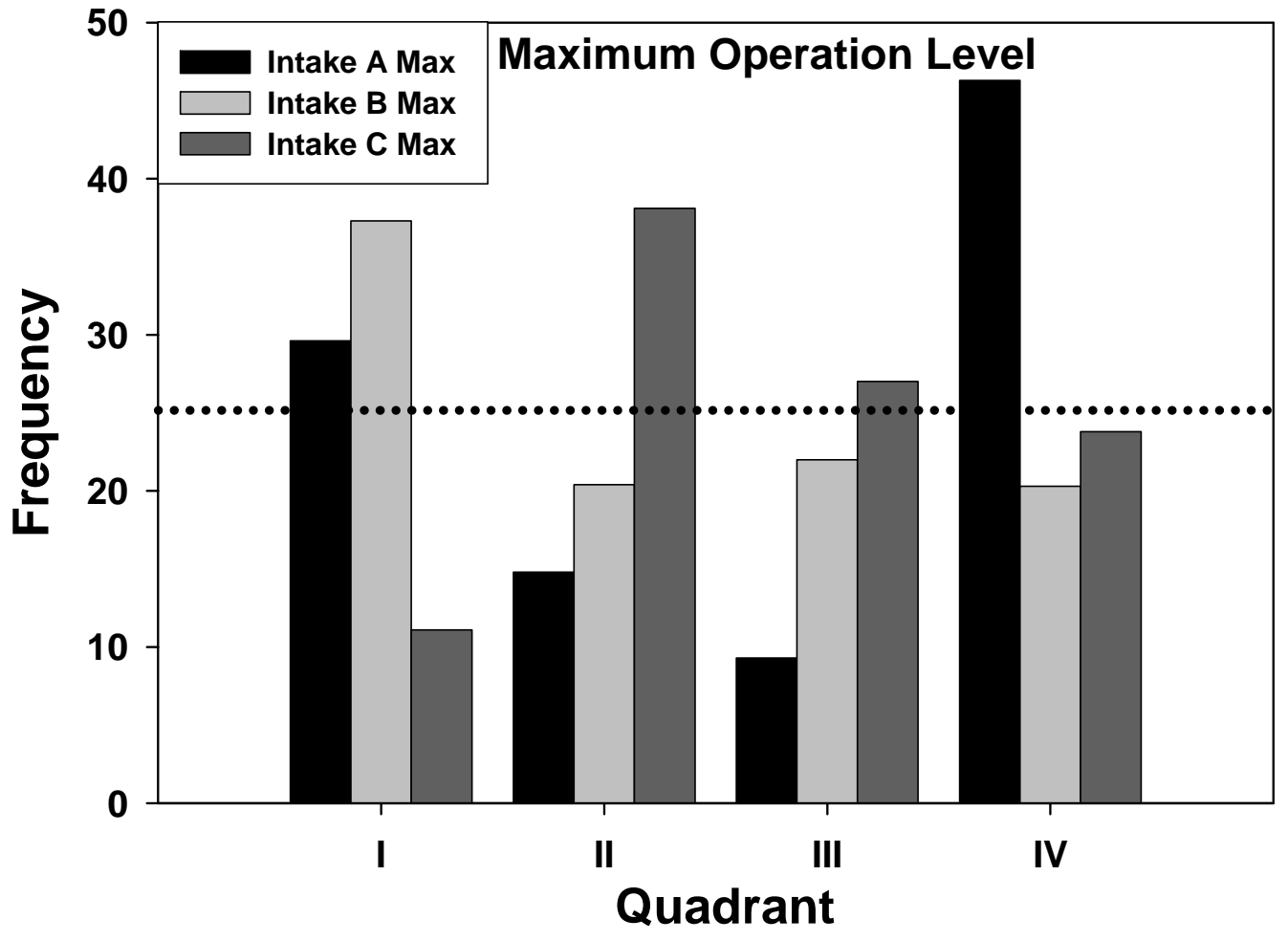

Figure 3.6. Percent distribution of beads by quadrant of first detection below the runner for beads released in the $\mathrm{A}, \mathrm{B}$, and $\mathrm{C}$ intakes at maximum operation level. The dotted line represents the level where bead distribution is random.

The radial distribution of beads out from the hub was highest in the mid-blade region for beads released at mid-depth into the A intake and in the hub region for beads released at mid-depth in both the $\mathrm{B}$ and $\mathrm{C}$ intakes. For all release locations, first detection was lowest in the radial segment near the tips of the runner blades (Table 3.2).

Table 3.2. Percent of beads as they were first detected below the runner within each region of the runner by release location and operation level.

\begin{tabular}{|c|c|c|c|c|}
\hline \multirow{2}{*}{$\begin{array}{l}\text { Operation } \\
\text { level }\end{array}$} & \multirow{2}{*}{$\begin{array}{l}\text { Release } \\
\text { location }\end{array}$} & \multicolumn{3}{|c|}{ Region } \\
\hline & & Hub & Mid-blade & Tip \\
\hline & $\mathrm{A}$ & 22.4 & 63.8 & 13.8 \\
\hline Lower $1 \%$ & $\mathrm{~B}$ & 68.5 & 27.8 & 3.7 \\
\hline & $\mathrm{C}$ & 59.2 & 36.8 & 4.0 \\
\hline & A & 27.8 & 66.7 & 5.5 \\
\hline Maximum & $\mathrm{B}$ & 86.4 & 11.9 & 1.7 \\
\hline & $\mathrm{C}$ & 69.8 & 23.8 & 6.4 \\
\hline
\end{tabular}

The position of beads when first detected below the runner was also analyzed for radial distance from the runner hub for the three release intakes and two operating conditions. The data were converted to prototype scale and to cylindrical coordinates $(\theta, \boldsymbol{r})$ where $\theta$ is an angle in radians and $\boldsymbol{r}$ is the radial distance from the center of the runner. 
In lower $1 \%$ operation efficiency tests, beads released from the $\mathrm{B}$ and $\mathrm{C}$ intake were detected closer to the hub (median distance of 6.7 and $7.5 \mathrm{ft}$ from the center of the hub at prototype scale, respectively) than beads released into the A intake, where the median distance was $8.8 \mathrm{ft}$ from the center of the hub (Figure 3.7 and Table 3.3). The number of beads detected near the tip of the runner was low for all three release locations, where the tip of the runner was at a radial distance of $11.25 \mathrm{ft}$.
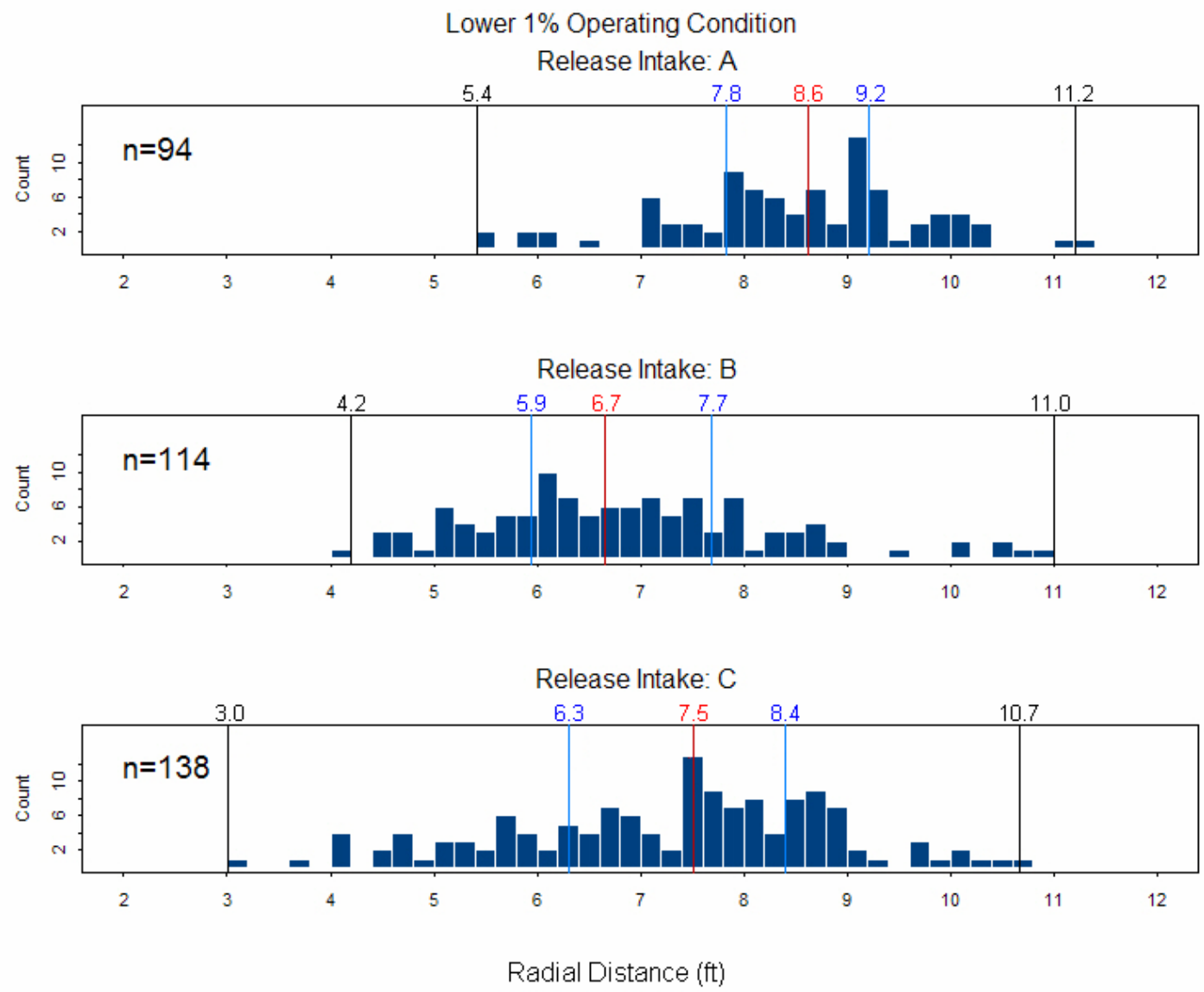

Figure 3.7. Radial distribution of beads first detected, relative to the hub, below the runner for beads released in the $\mathrm{A}, \mathrm{B}$, and $\mathrm{C}$ intakes at the lower $1 \%$ operating efficiency. The vertical lines mark the quartile distribution of beads (from left to right) minimum, $25^{\text {th }}$ percentile, median, $75^{\text {th }}$ percentile, and maximum. Data were converted to prototype scale.

At the highest operating condition, beads released into the A intake were observed at a radial distance of $4.4 \mathrm{ft}$ from the center of the hub, at prototype scale, and the median distance of first detection was $8.4 \mathrm{ft}$, which was significantly higher than median distances for beads released into the $\mathrm{B}$ and $\mathrm{C}$ intakes (6.4 and $6.9 \mathrm{ft}$ from the center of the hub, respectively (Figure 3.8 and Table 3.3). Beads released into the $\mathrm{B}$ and $\mathrm{C}$ intakes were detected on average closer to the hub with median radial distances of $6.4 \mathrm{ft}$ and $6.9 \mathrm{ft}$ from the center of the hub, respectively. For all three release locations, the radial locations were closer to the hub at maximum operation level and farther away from the tips of the runner blades. 
Table 3.3. Distribution of beads out from the center of the turbine runner for beads released at the lower $1 \%$ efficiency and maximum operation.

\begin{tabular}{|c|c|c|c|c|c|c|c|c|}
\hline & Beads & Operation & Release & \multicolumn{5}{|c|}{ Quartile } \\
\hline Treatment & Released & Level & Intake & $\min$ & $25 \%$ & $50 \%$ & $75 \%$ & $\max$ \\
\hline 1 & 94 & & $A$ & 5.42 & 7.83 & 8.62 & 9.22 & 11.21 \\
\hline 2 & 114 & Lower 1\% & $B$ & 4.20 & 5.94 & 6.66 & 7.69 & 11.00 \\
\hline 3 & 138 & & C & 3.01 & 6.32 & 7.51 & 8.40 & 10.67 \\
\hline 4 & 55 & & $A$ & 4.36 & 7.55 & 8.40 & 9.11 & 10.09 \\
\hline 5 & 120 & Maximum & B & 4.10 & 5.55 & 6.36 & 7.22 & 9.97 \\
\hline 6 & 134 & & C & 3.99 & 6.08 & 6.90 & 7.68 & 10.65 \\
\hline
\end{tabular}
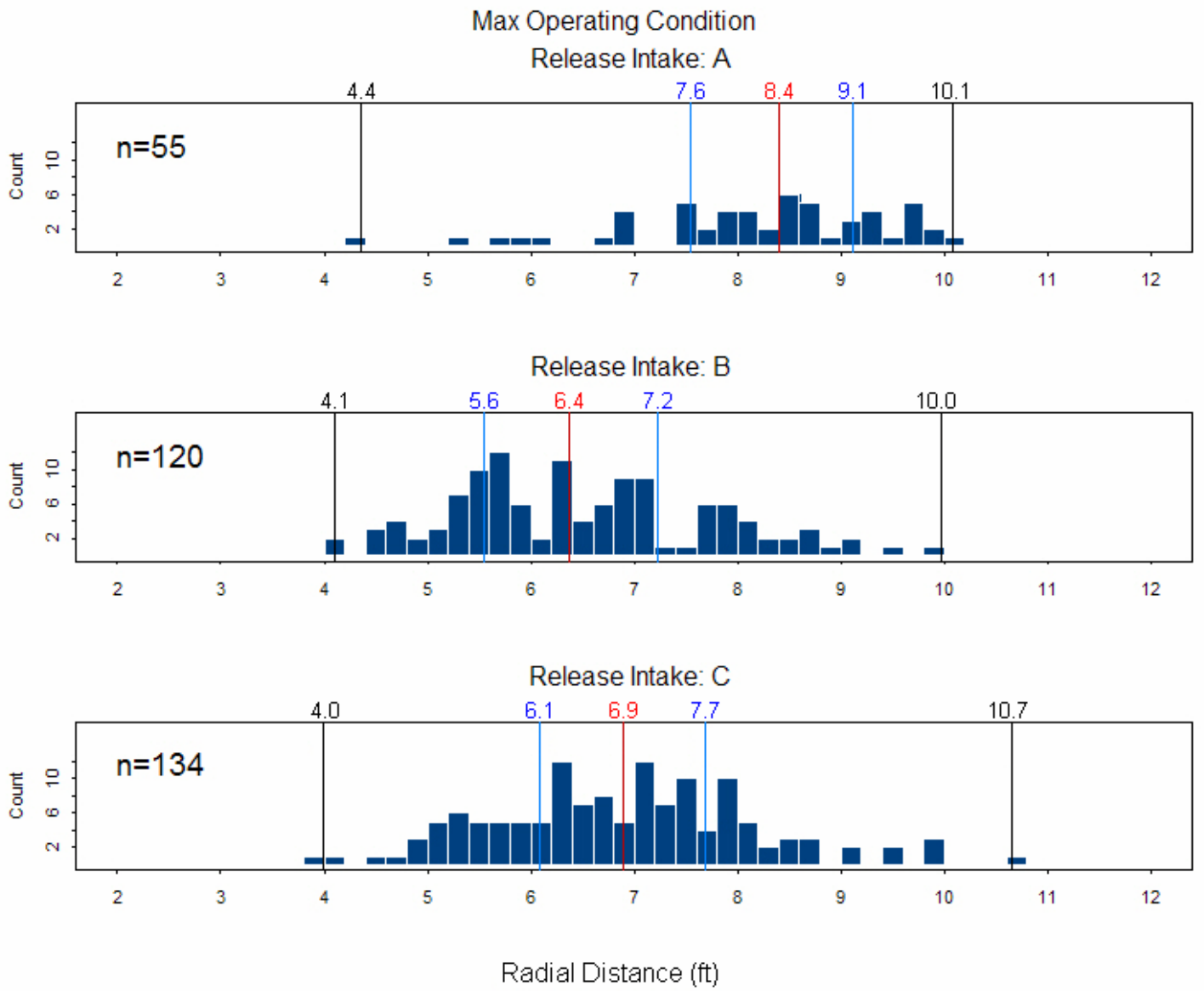

Figure 3.8. Radial distribution of beads first detected, relative to the hub, below the runner for beads release in the $\mathrm{A}, \mathrm{B}$, and $\mathrm{C}$ intakes at maximum operation level. The vertical lines mark the quartile distribution of beads: (from left to right) minimum, $25^{\text {th }}$ percentile, median, $75^{\text {th }}$ percentile, and maximum. Data were converted to prototype scale.

Beads released into intake A had the greatest radial distance from the hub $(\boldsymbol{r})$ followed by $\mathrm{C}$ and $\mathrm{B}$ in that order. This is confirmed in Table 3.4 where the same general ranking of release intakes by $\boldsymbol{r}$ values is 
confirmed and shown to be statistically significant. Also in Table 3.4, the high level of discharge produced significantly higher $\boldsymbol{r}$ values than the low level of discharge.

Table 3.4. Summary ANOVA where the independent predictor variables are both factors and the radial distance from the center of the runner hub was the dependent variable. The parameter estimates were computed as a deviation from the reference level for that factor where $\mathrm{C}$ was taken as the reference level and so its estimate is 0 .

\begin{tabular}{|l|c|c|c|c|c|c|c|c||}
\hline Parameter & Level1 & DF & Estimate & StdErr & LowerCL & UpperCL & ChiSq & Prob ChiSq \\
\hline Intercept & & 1 & 6.902 & 0.097 & 6.711 & 7.093 & 5029.390 & $<.0001$ \\
\hline Intake & $\mathrm{A}$ & 1 & 1.253 & 0.137 & 0.984 & 1.522 & 83.330 & $<.0001$ \\
\hline Intake & $\mathrm{B}$ & 1 & -0.391 & 0.120 & -0.625 & -0.157 & 10.720 & 0.001 \\
\hline Ref: Intake & $\mathrm{C}$ & 0 & 0.000 & 0.000 & 0.000 & 0.000 & & \\
\hline flow & Low & 1 & 0.353 & 0.106 & 0.146 & 0.560 & 11.180 & 0.001 \\
\hline Ref: flow & High & 0 & 0.000 & 0.000 & 0.000 & 0.000 & & \\
\hline
\end{tabular}

\subsubsection{Bead Trajectory}

The 2-D trajectories of beads below the hub and into the elbow region of the draft tube varied with release location and operation level (Figures 3.9-3.11). The trajectories of the beads at maximum operation level were more direct than those of beads released at the lower $1 \%$ level. Many beads released into the $\mathrm{B}$ intake and to a lesser degree into the $\mathrm{C}$ intake spiraled as they passed beneath the runner at the lower 1\% operating efficiency operating point (Figure 3.9 and 3.10) but spiraling was not observed at the maximum operating level for either release location where bead trajectories had a much smaller angular component.
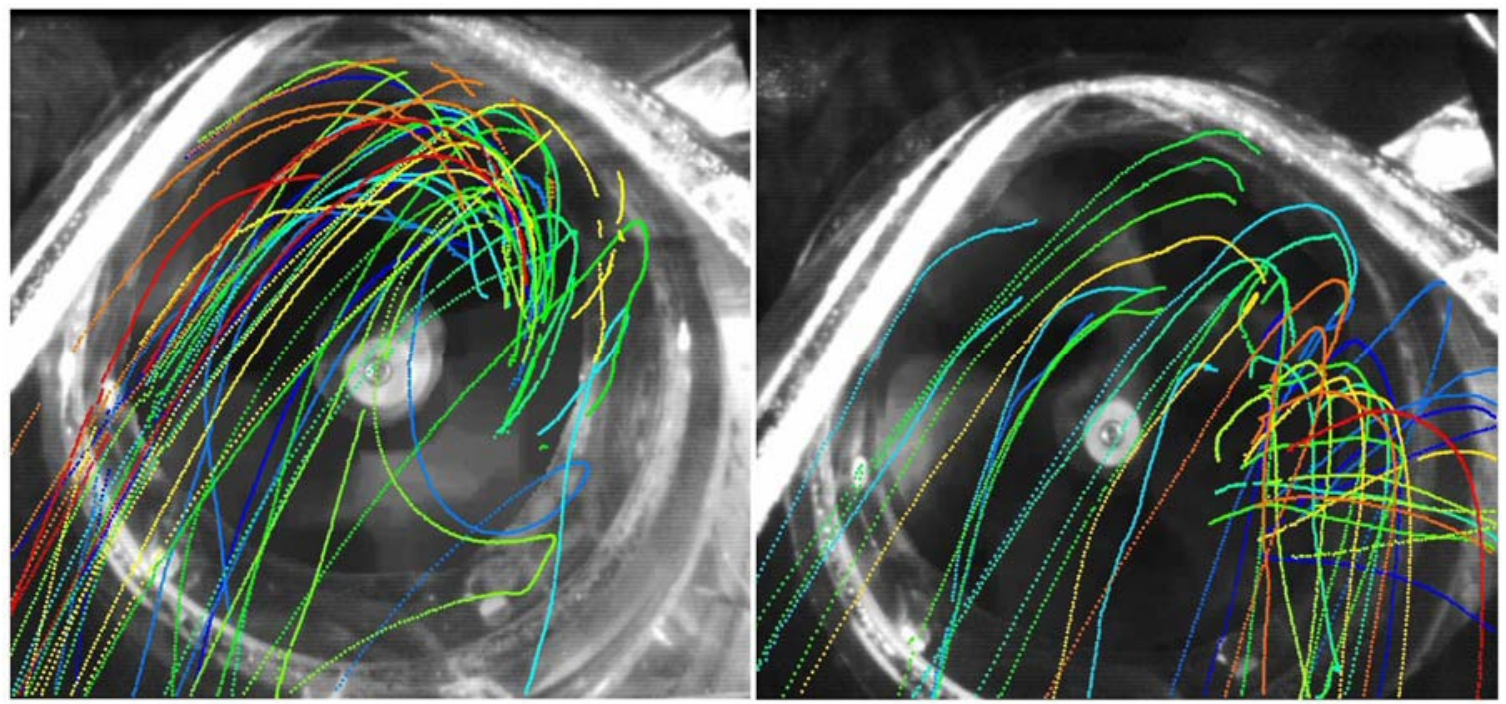

Figure 3.9. Trajectory of beads from point of first detection below the runner into the elbow of the draft tube for beads released into the A intake at lower 1\% operating efficiency (left) and maximum operating condition (right). 

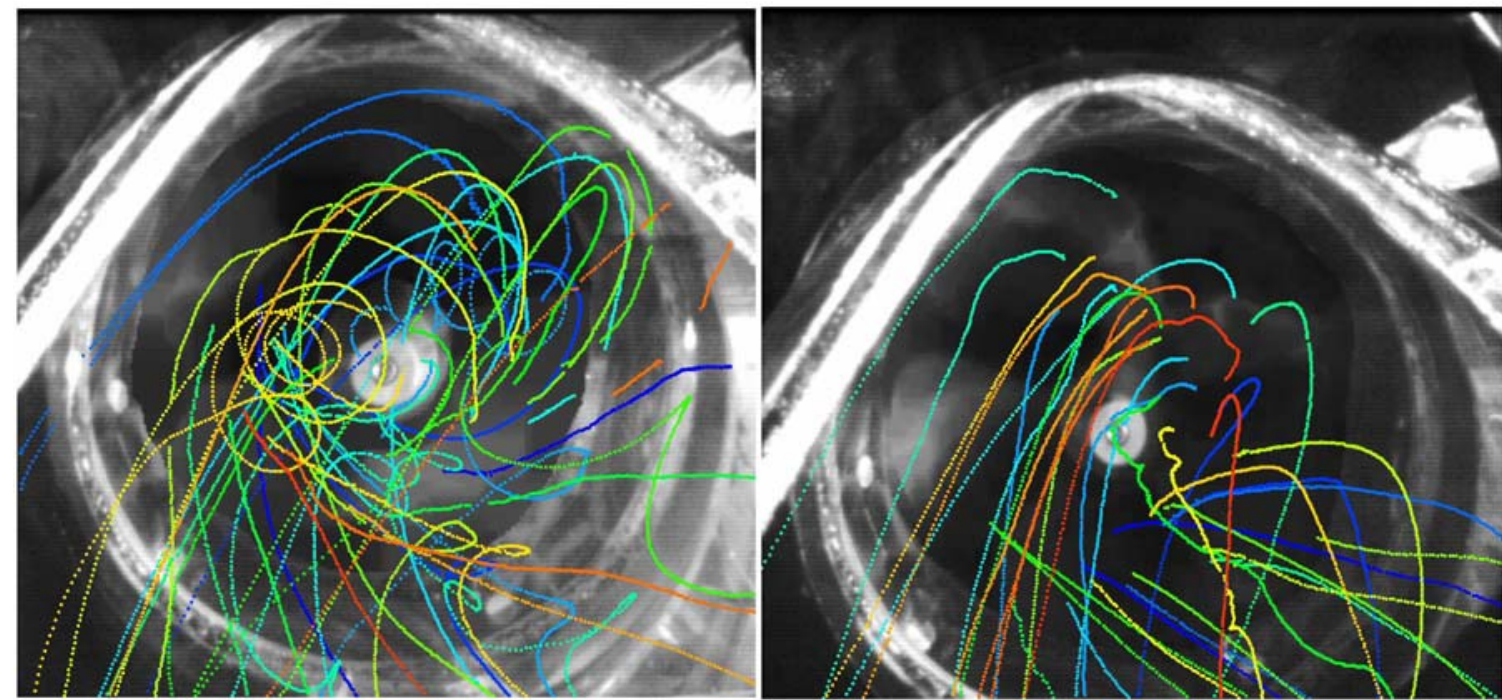

Figure 3.10. Trajectory of beads from point of first detection below the runner into the elbow of the draft tube for beads released into the B intake at lower 1\% operating efficiency (left) and maximum operating condition (right).
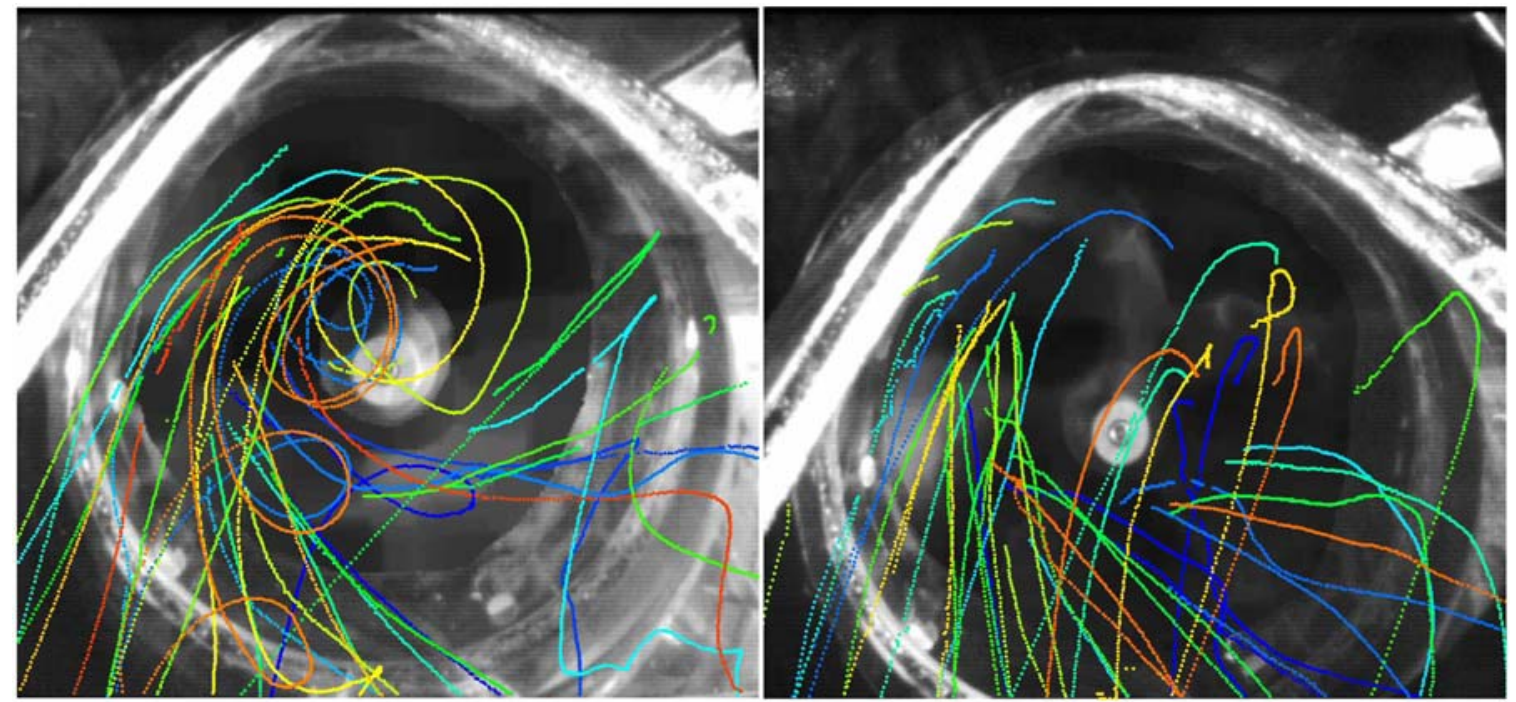

Figure 3.11. Trajectory of beads from point of first detection below the runner into the elbow of the draft tube for beads released into the $\mathrm{C}$ intake at lower $1 \%$ operating efficiency (left) and maximum operating condition (right).

Bead passage trajectory below the hub was significantly more linear $(\mathrm{P}<0.05)$, with a lower index value (more linear trajectory) at the maximum operating level than at the lower $1 \%$ operating efficiency, and intake had a significant effect on track linearity. Beads released into the B intake at the lower 1\% operating efficiency had a significantly longer path $(\mathrm{P}<0.01)$ during passage through the cameras' field of view below the turbine runner (vs. a direct path) than releases at any other intake or operating condition. Trajectory linearity was not significantly different for beads released into intake A at either operating level and intake $\mathrm{C}$ at the lower $1 \%$ operating efficiency turbine operating condition. Beads released into the $\mathrm{B}$ and $\mathrm{C}$ intakes at maximum operating conditions had significantly more linear paths below the 
runner than from the other release locations (Figure 3.12). The time of passage from directly below the runner into the elbow region of the physical model for these observations varied from $1.35 \mathrm{~s}$ for beads released into the $\mathrm{C}$ intake at the maximum operation level to $2.93 \mathrm{~s}$ for beads released into the $\mathrm{B}$ intake at the lower $1 \%$ efficiency (Table 3.5).

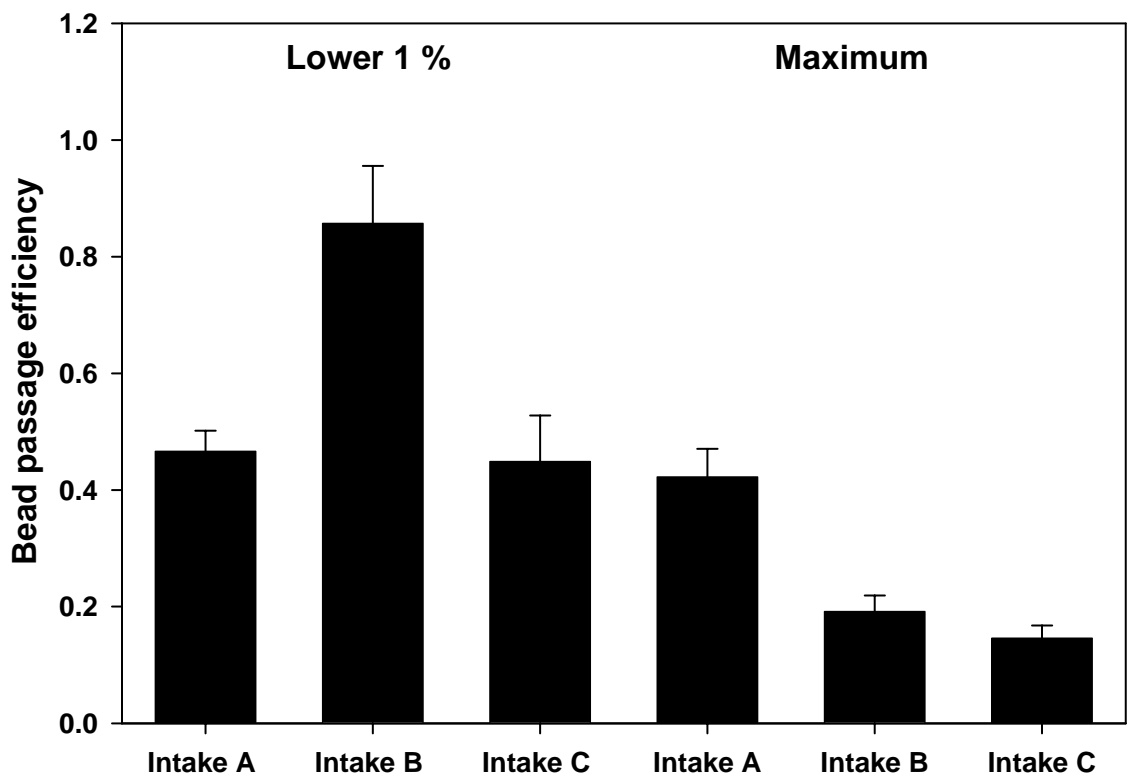

Figure 3.12. Bead passage efficiency (trajectory linearity) from beneath the turbine runner into the elbow region of the draft tube. The lower the index value, the more linear the trajectory of the bead.

Table 3.5. Time of travel for beads from first detection below the runner to the elbow region of the runner for beads released in each intake and two operation levels.

\begin{tabular}{|c|c|c|}
\hline & \multicolumn{2}{|c|}{ Time of travel (s) and 95\% CI } \\
\hline Intake & Lower 1\% Efficiency & Maximum Operation \\
\hline A & $2.84 \pm 0.07$ & $1.68 \pm 0.07$ \\
\hline B & $2.93 \pm 0.14$ & $1.48 \pm 0.07$ \\
\hline C & $2.42 \pm 0.18$ & $1.35 \pm 0.07$ \\
\hline
\end{tabular}

Another measure of the linearity of a trajectory in 2-D is tortuosity

$$
\tau=\frac{\sum_{i=2}^{n} \sqrt{\left(x_{i}-x_{i-1}\right)^{2}+\left(y_{i}-y_{i-1}\right)^{2}}}{\sqrt{\left(x_{n}-x_{1}\right)^{2}+\left(y_{n}-y_{1}\right)^{2}}}
$$

This is the ratio of the sum of point-to-point distances in trajectory composed by $n$ points in the XY plane, by the straight line distance from the first to the last point in the trajectory. The 2-D tortuosity equation can be generalized to 3-D by incorporating additional terms in the sums under the radicals. It follows that 


$$
1 \leq \tau<\infty
$$

and

$$
0 \leq \log (\tau)<\infty
$$

Values of $\tau$ (tortuosity) are bounded below at unity (1) for perfectly straight trajectories and approach $\infty$ for trajectories with increasing curvilinearity or tortuosity.

Tortuosity differed significantly by release intake with $\mathrm{C}$ showing the lowest overall tortuosity value (i.e., greatest degree of linearity) when computed from trajectory data in 2-D (Figure 3.13 and Table 3.6). Lower tortuosity values were also calculated at the maximum operation level.
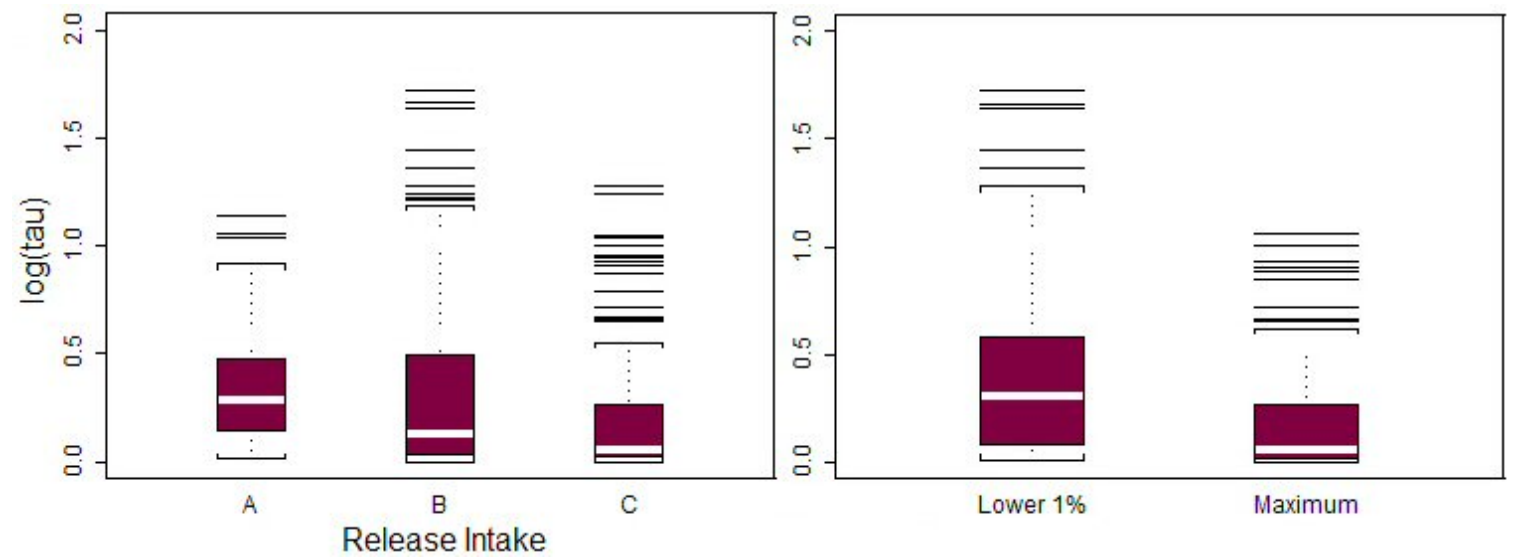

Figure 3.13. Box plots of log tortuosity $(\tau)$ for 2 -D tracking by release intake (left) and flow condition (right).

Table 3.6. Summary ANOVA of tortuosity estimates between intakes and operation conditions for beads tracked below the runner hub in 2-D. The parameter estimates were computed as a deviation from the reference level for that factor where $\mathrm{C}$, and lower $1 \%$ efficiency, was taken as the reference level and so its estimate is 0 .

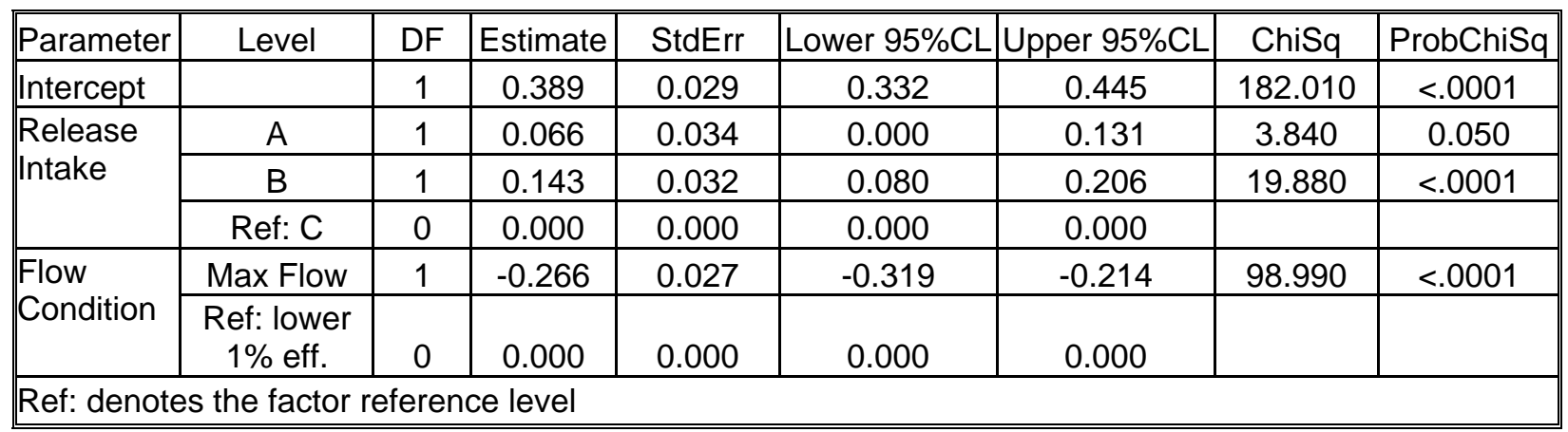




\subsection{Passage through the Elbow Region}

Trajectories for the majority of beads passing through the draft tube elbow region were through the left side of the model viewed from upstream. To summarize the trajectories of beads from the runner to the draft tube vertical splitter wall, the model was divided into three sections from left to right: 1) $1.5 \mathrm{ft}$ or more to the left of the splitter, 2) $1.5 \mathrm{ft}$ to the left to $1.5 \mathrm{ft}$ to the right of the splitter, and 3) $1.5 \mathrm{ft}$ or more to the right of the splitter).

At the lower $1 \%$ operating efficiency condition, most beads passing more than $1.5 \mathrm{ft}$ to the left of the vertical splitter wall displayed linear trajectories, although a few, mainly above the splitter, displayed erratic behavior (Figure 3.14). Many of the beads that passed within $1.5 \mathrm{ft}$ to either side of the vertical splitter changed direction as they came near or in contact with the splitter, although the trajectory of most beads changed before making direct contact with the splitter (Figure 3.15). Trajectories of beads passing greater than $1.5 \mathrm{ft}$ to the right side of the vertical splitter had more tortuous tracks than beads passing to the left side of the vertical splitter, and these beads passing on the right also had higher average rates of acceleration (Figure 3.16).

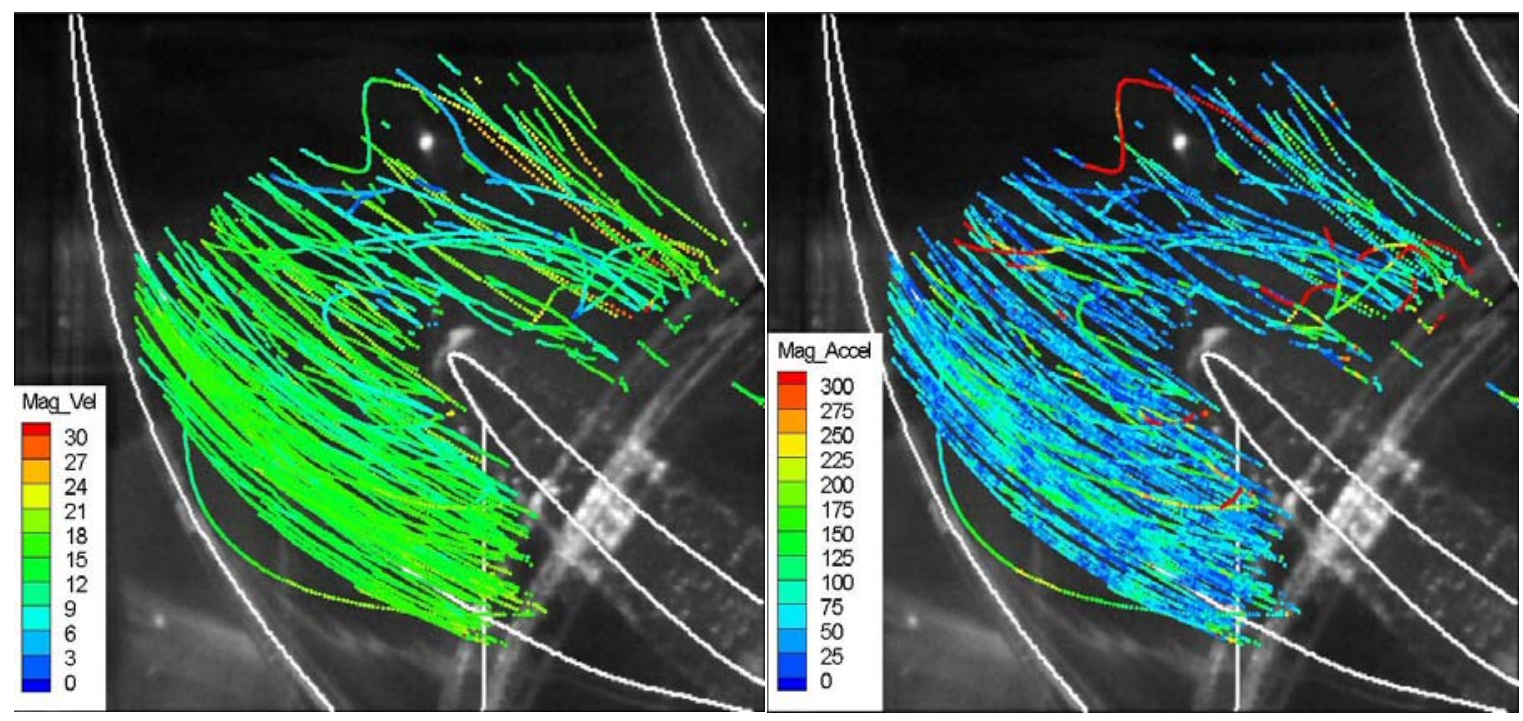

Figure 3.14. Velocity and acceleration estimates for individual beads as they passed $1.5 \mathrm{ft}$ or greater to the left of the vertical splitter above and below the horizontal splitter at the lower $1 \%$ efficiency for beads released into all three intakes. Estimates of velocity and acceleration are calculated to prototype scale. 


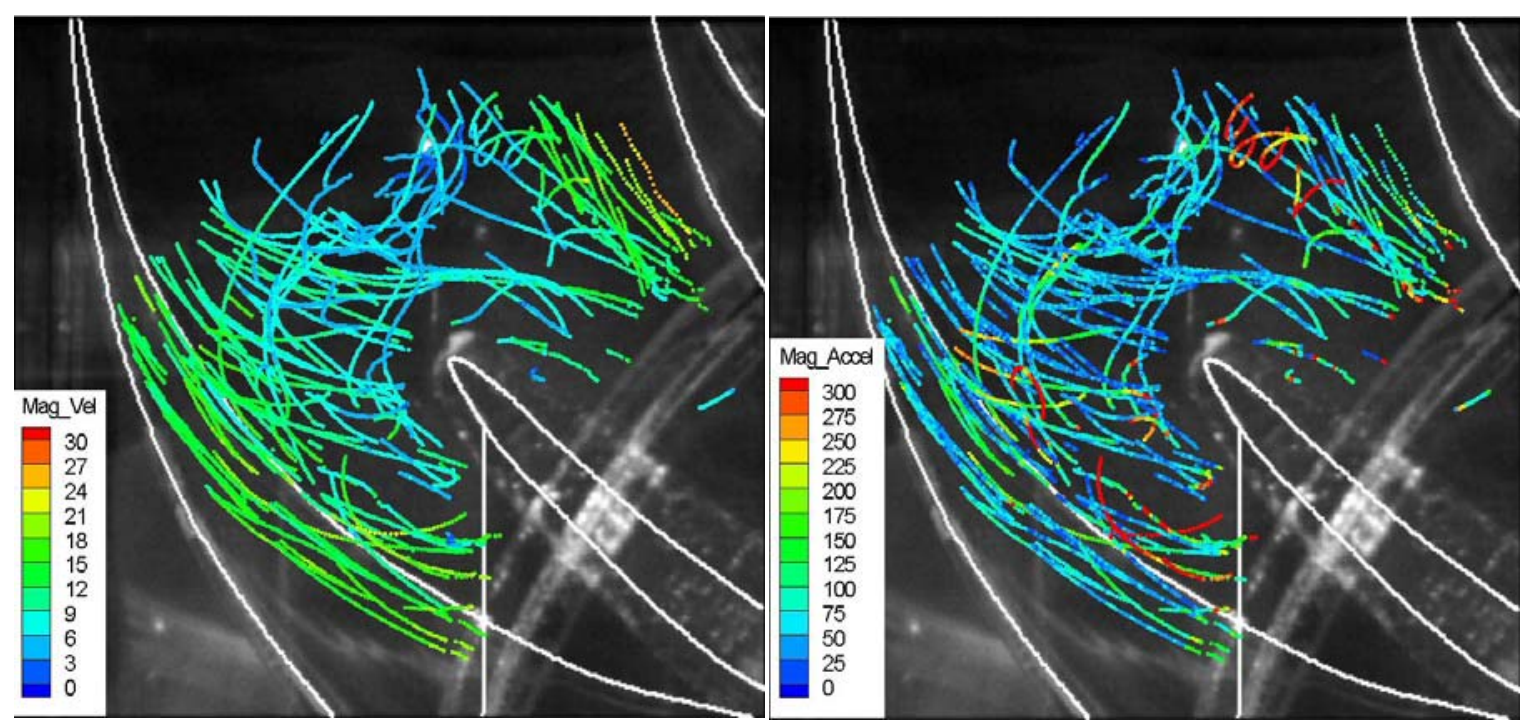

Figure 3.15. Velocity and acceleration estimates for individual beads as they passed within $1.5 \mathrm{ft}$ to the left or right of the vertical splitter above and below the horizontal splitter at the lower $1 \%$ efficiency for beads released into all three intakes. Estimates of velocity and acceleration are calculated to prototype scale.

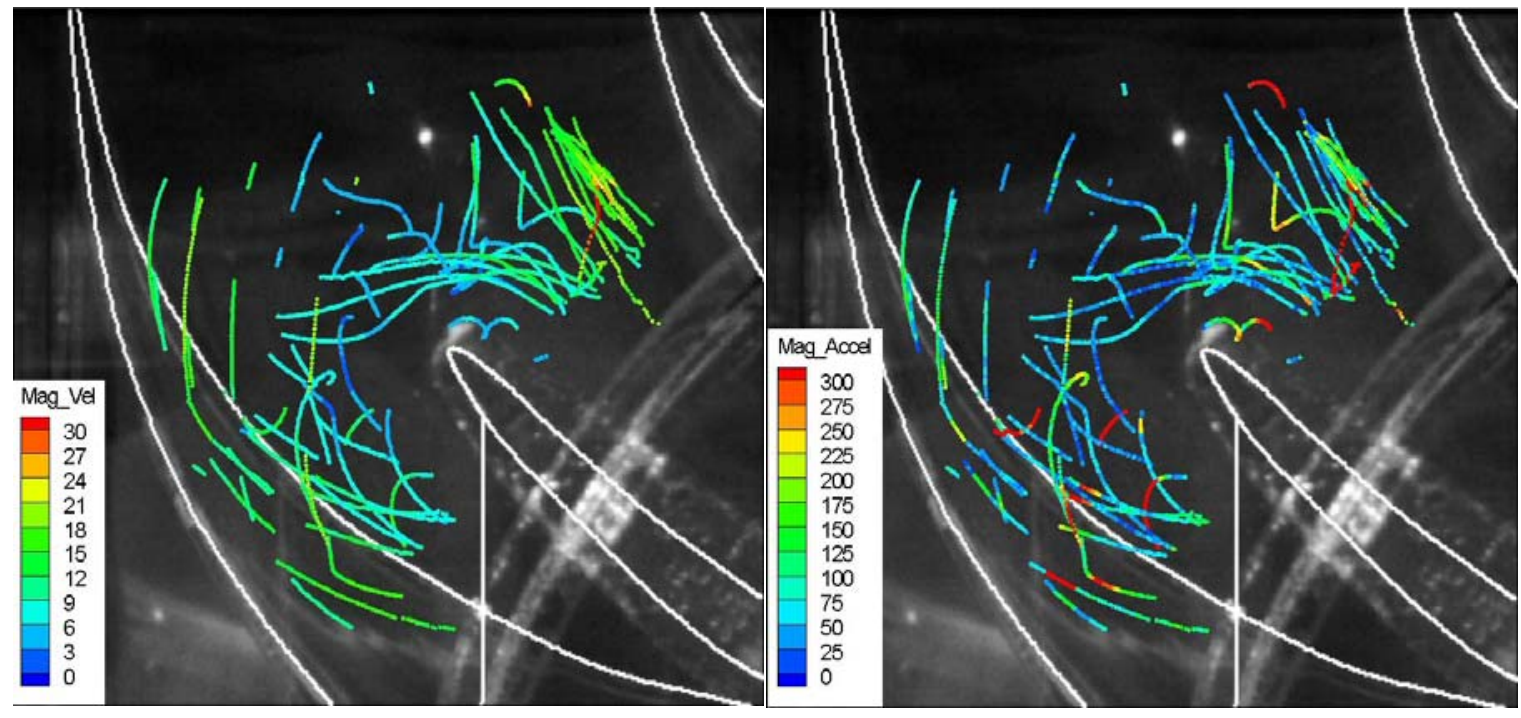

Figure 3.16. Velocity and acceleration estimates for individual beads as they passed $1.5 \mathrm{ft}$ or greater to the right of the vertical splitter above and below the horizontal splitter at the lower $1 \%$ efficiency for beads released into all three intakes. Estimates of velocity and acceleration are calculated to prototype scale. (Note the strike of the bead on top of the horizontal splitter).

At maximum operating condition, all of the beads passing more than $1.5 \mathrm{ft}$ to the left of the vertical splitter displayed fairly linear trajectories (Figure 3.17.) For these beads, maximum acceleration estimates were lower than for beads released into the other two intake bays or for any beads released at the lower $1 \%$ efficiency operating condition. Some of the beads passing within $1.5 \mathrm{ft}$ to either side of the vertical splitter changed direction as they came near or in contact with the splitter but only in the area directly in front of the horizontal splitter (Figure 3.18). Trajectories of beads passing greater than $1.5 \mathrm{ft}$ to the right 
side of the vertical splitter displayed fairly linear tracks except for the ones passing directly in front of the horizontal splitter (Figure 3.19).

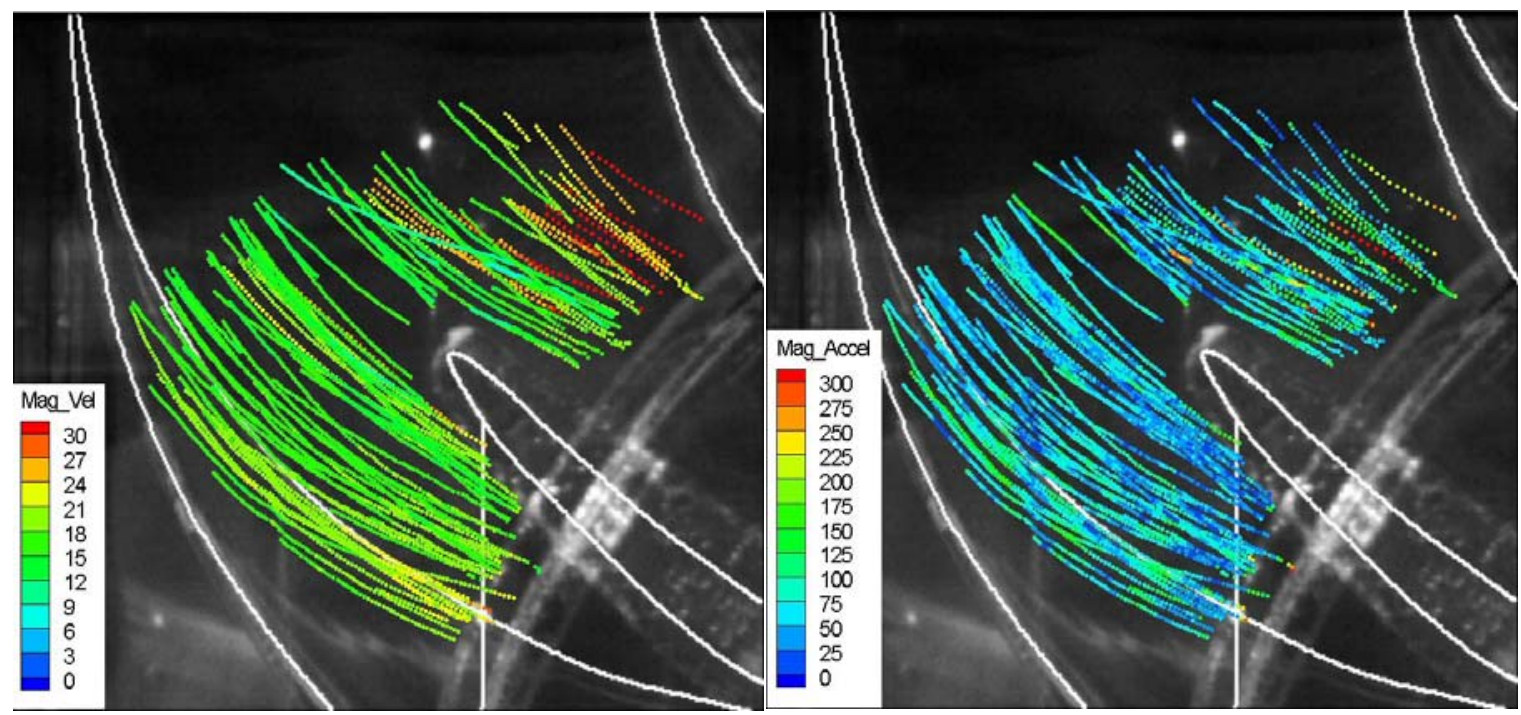

Figure 3.17. Velocity and acceleration estimates for individual beads as they passed $1.5 \mathrm{ft}$ or greater to the left of the vertical splitter above and below the horizontal splitter at maximum operation for beads released into all three intakes. Estimates of velocity and acceleration are calculated to prototype scale.

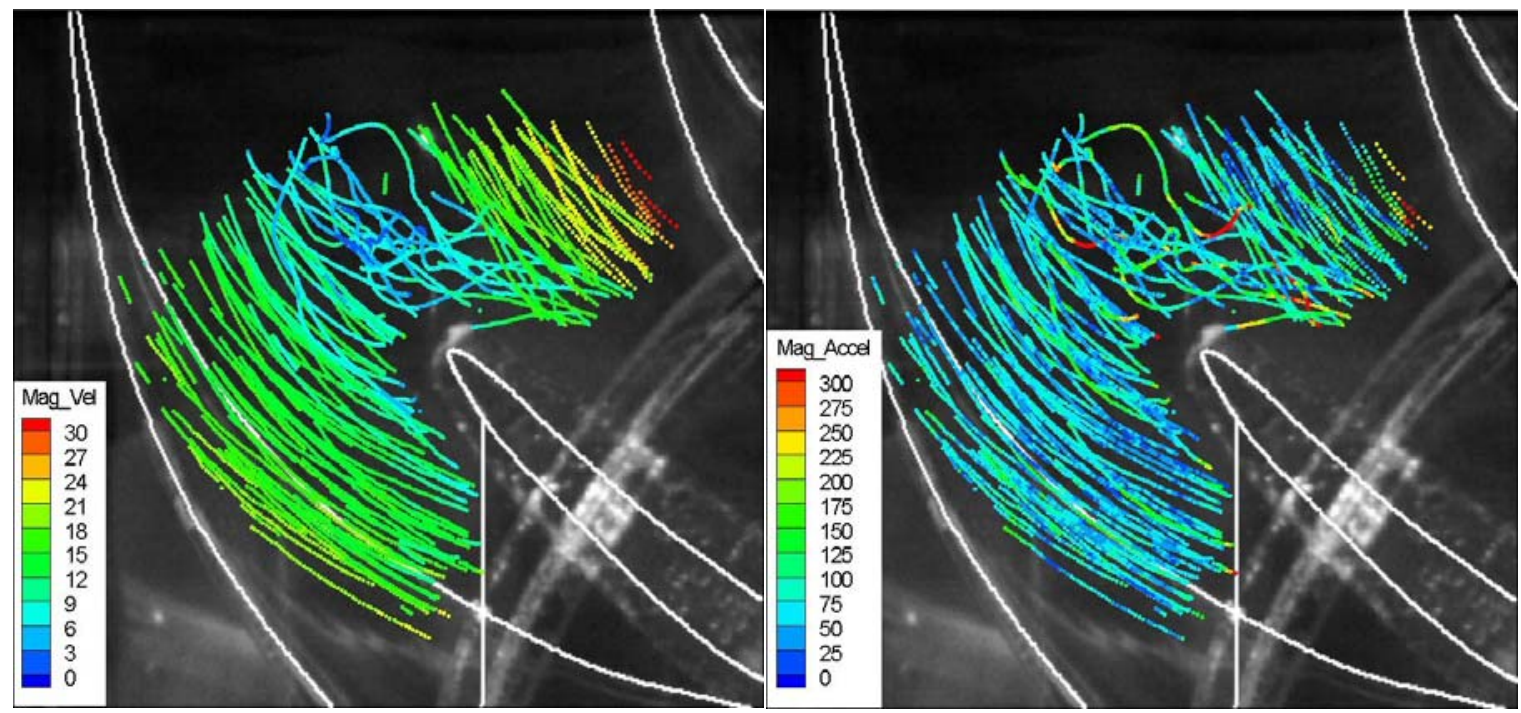

Figure 3.18. Velocity and acceleration estimates for individual beads as they passed within $1.5 \mathrm{ft}$ to the left or right of the vertical splitter above and below the horizontal splitter at maximum operation for beads released into all three intakes. Estimates of velocity and acceleration are calculated to prototype scale. 


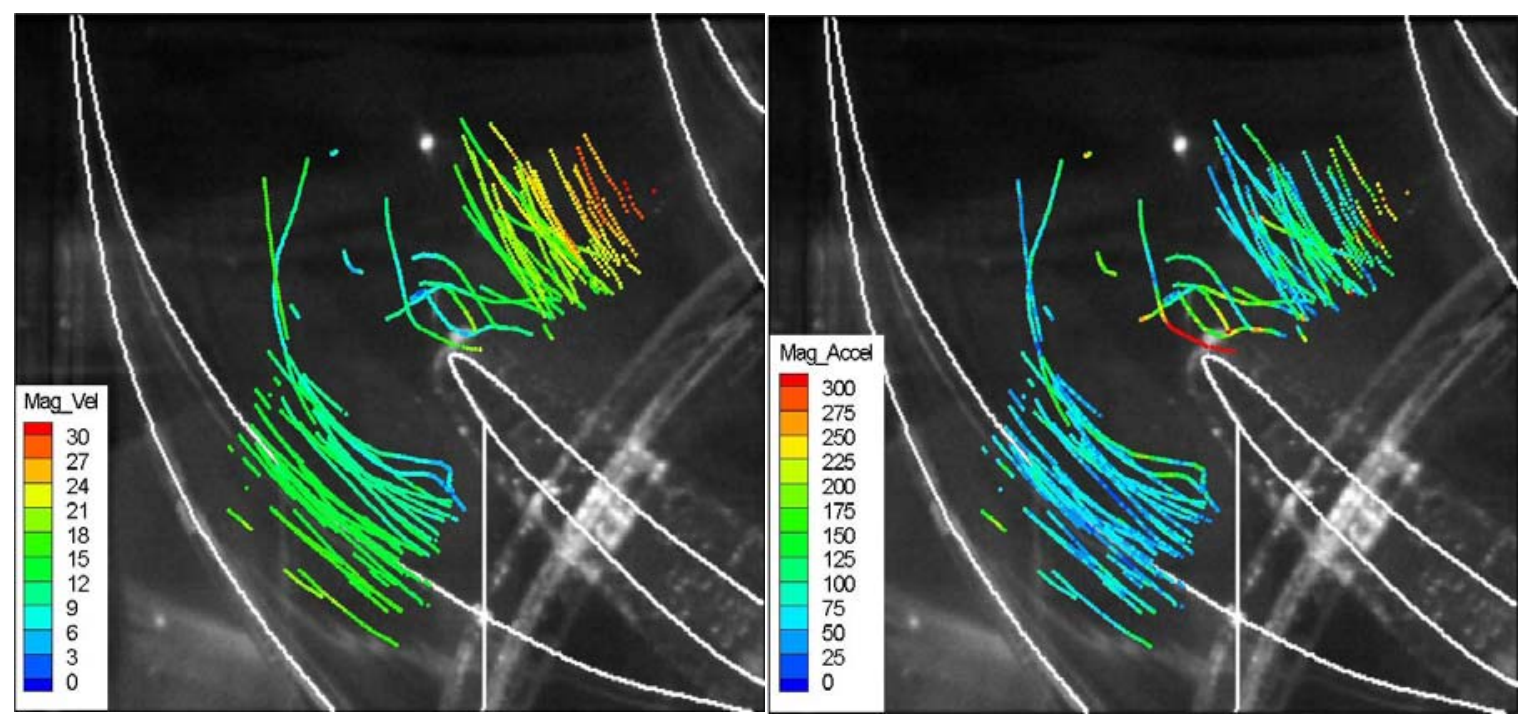

Figure 3.19. Velocity and acceleration estimates for individual beads as they passed $1.5 \mathrm{ft}$ or greater to the right of the vertical splitter above and below the horizontal splitter at maximum operation for beads released into all three intakes. Estimates of velocity and acceleration are calculated to prototype scale.

Velocity estimates ranged from as low as $0.2 \mathrm{fps}$ where the bead came to a near stop to $41.0 \mathrm{fps}$. Acceleration estimates ranged from $0.9 \mathrm{ft} / \mathrm{s}^{2}$ to nearly $550 \mathrm{ft} / \mathrm{s}^{2}$ (Table 3.7 ).

Table 3.7. Velocity (fps) and acceleration $\left(\mathrm{ft} / \mathrm{s}^{2}\right)$ estimates calculated for beads passing through the draft tube of the BON1 scale model by release location. (Note: measurements were calculated at prototype scale).

\begin{tabular}{|c|c|c|c|c|c|c|c|}
\hline \hline \multirow{2}{*}{$\begin{array}{c}\text { Operation } \\
\text { level }\end{array}$} & Intake & \multicolumn{3}{|c|}{ Velocity } & \multicolumn{3}{c|}{ Acceleration } \\
\cline { 3 - 8 } & Min. & Mean & Max & Min. & Mean & Max. \\
\hline $\begin{array}{l}\text { Lower 1\% } \\
\text { efficiency }\end{array}$ & $\mathrm{A}$ & 1.0 & 12.1 & 28.3 & 1.7 & 58.0 & 543.1 \\
\cline { 2 - 8 } & $\mathrm{B}$ & 0.2 & 9.2 & 32.7 & 0.9 & 75.9 & 549.6 \\
\cline { 2 - 8 } & $\mathrm{C}$ & 0.6 & 9.9 & 34.9 & 1.0 & 90.9 & 542.6 \\
\hline \multirow{3}{*}{ Maximum } & $\mathrm{A}$ & 1.9 & 15.0 & 30.9 & 2.3 & 65.2 & 295.0 \\
\cline { 2 - 8 } & $\mathrm{B}$ & 1.1 & 13.2 & 35.9 & 3.3 & 74.3 & 461.6 \\
\cline { 2 - 8 } & $\mathrm{C}$ & 0.3 & 12.7 & 41.0 & 2.9 & 87.0 & 545.8 \\
\hline \hline
\end{tabular}

Cross-sectional average velocity and acceleration contour plots for regions $6.25 \mathrm{ft}$ to the left of the splitter, in line with the splitter, and $6.25 \mathrm{ft}$ to the right of the splitter showed that the flows through the model are turbulent. Contour plots of acceleration for all three cross-sectional views at the lower $1 \%$ operation efficiency condition showed areas of high acceleration (in red) (Figures 3.20-3.22). Areas of higher acceleration were also found at the maximum operation level condition but mainly within the splitter region (Figures 3.23-3.25). 


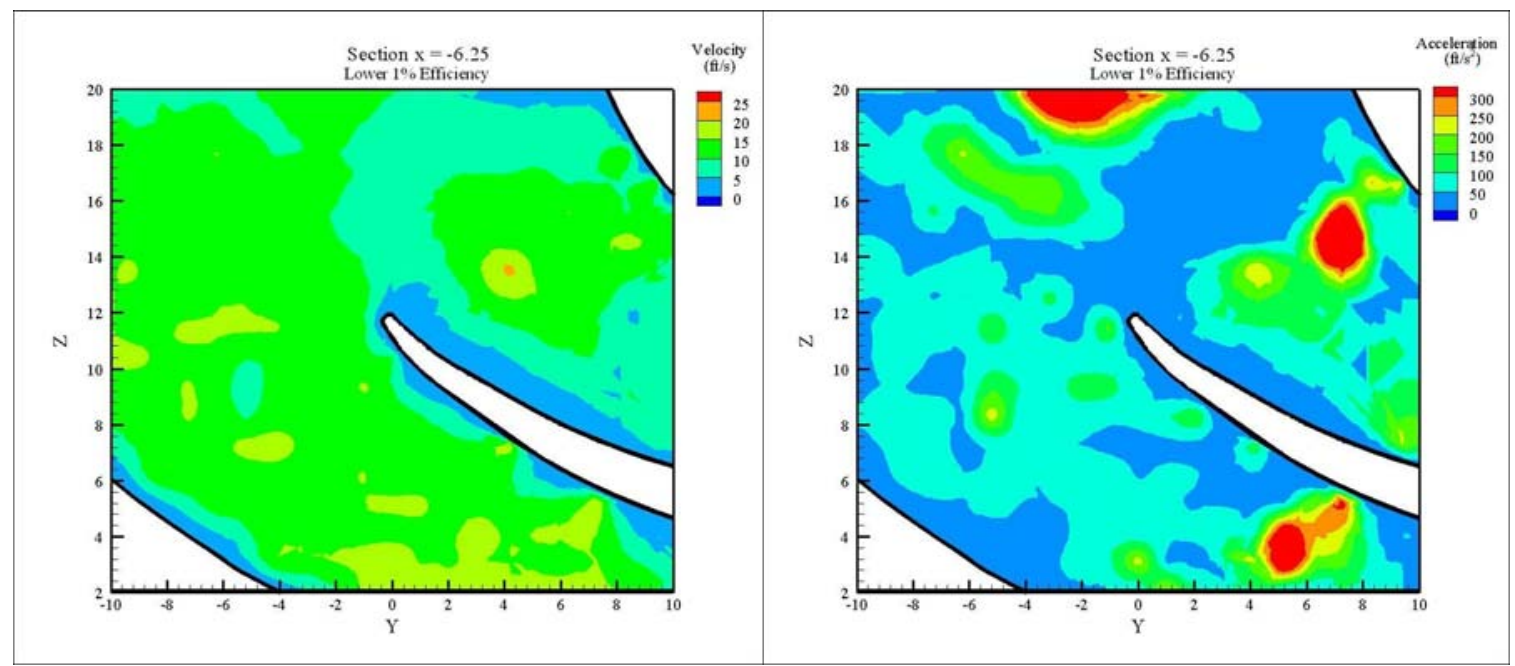

Figure 3.20. Average velocity and acceleration contour plots for beads as they passed through a plane of the model $6.25 \mathrm{ft}$ to the left of the vertical splitter above and below the horizontal splitter at lower $1 \%$ efficiency for beads released into all three intakes. Estimates of velocity and acceleration are calculated to prototype scale.

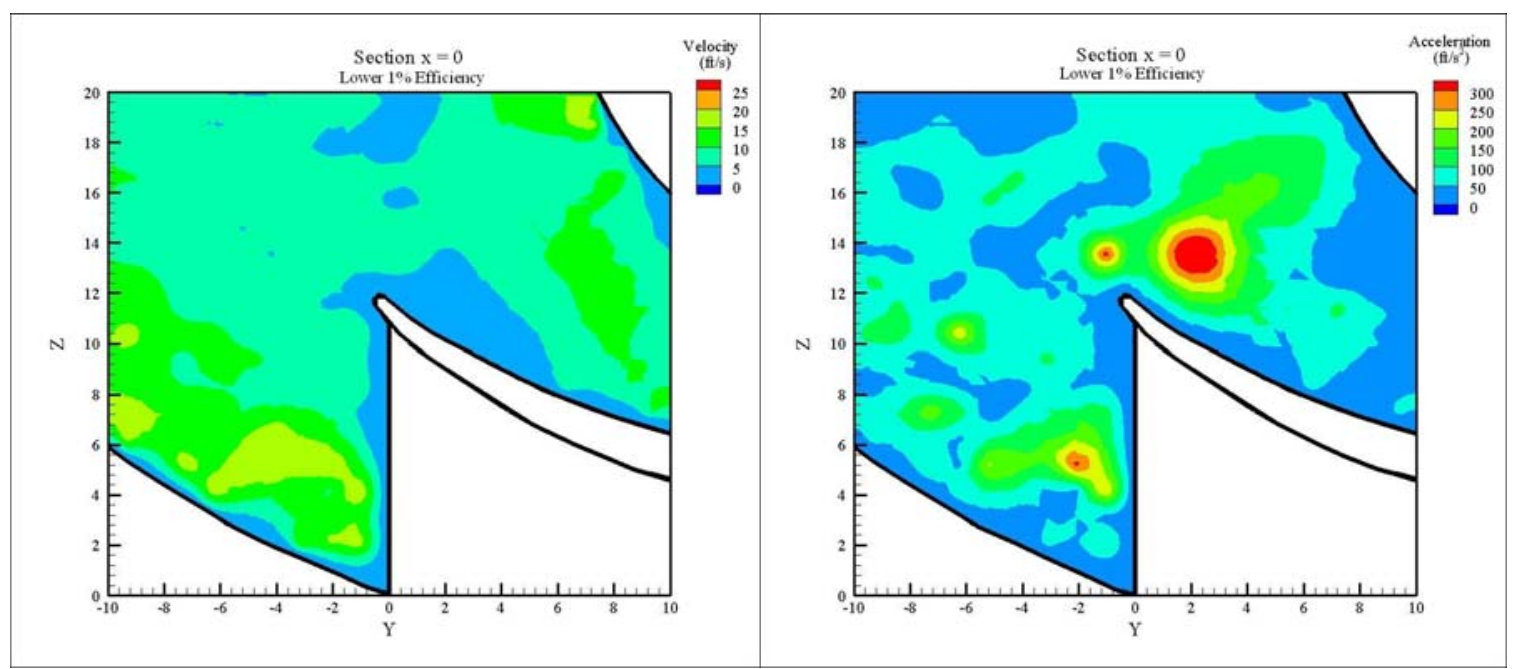

Figure 3.21. Average velocity and acceleration contour plots for beads as they passed through a plane in line with the vertical splitter above and below the horizontal splitter at the lower $1 \%$ efficiency for beads released into all three intakes. Estimates of velocity and acceleration are presented at prototype scale. 


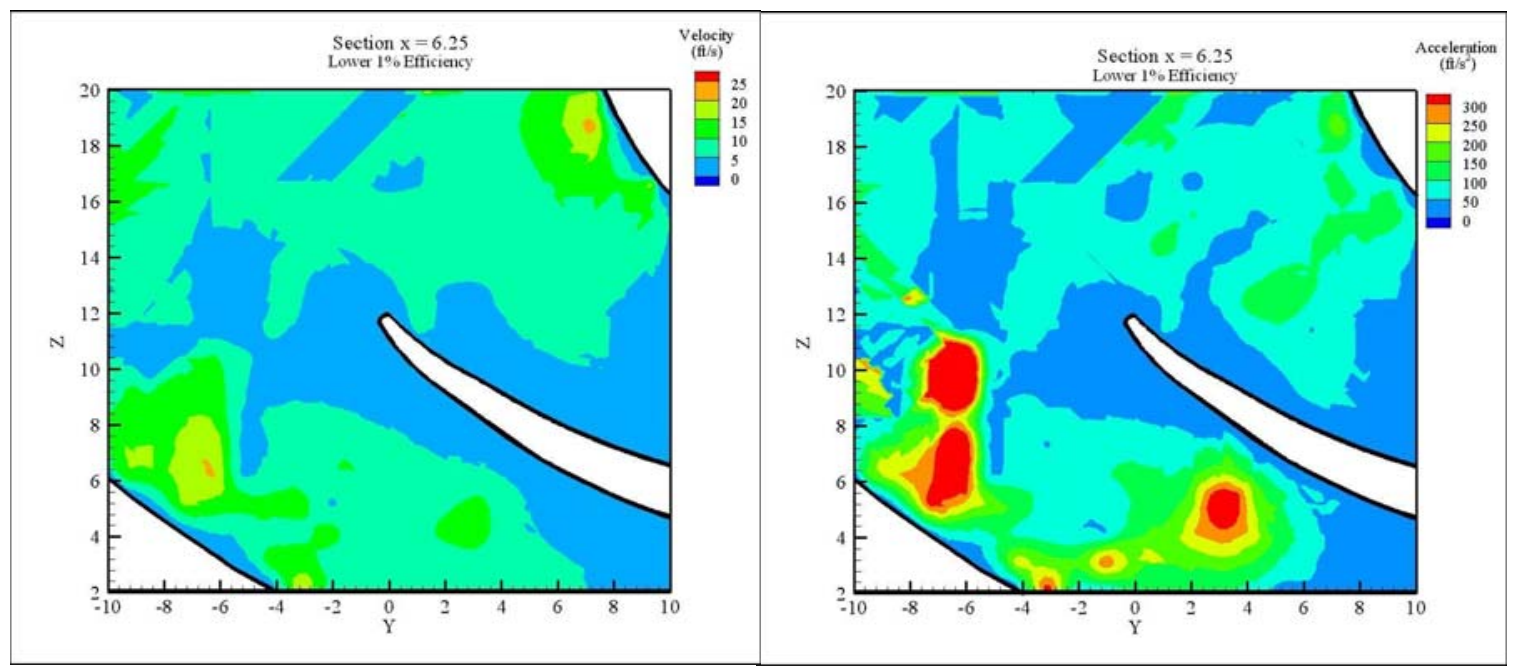

Figure 3.22. Average velocity and acceleration contour plots for beads as they passed through a plane $6.25 \mathrm{ft}$ to the right of the vertical splitter above and below the horizontal splitter at the lower $1 \%$ efficiency for beads released into all three intakes. Estimates of velocity and acceleration are calculated to prototype scale.

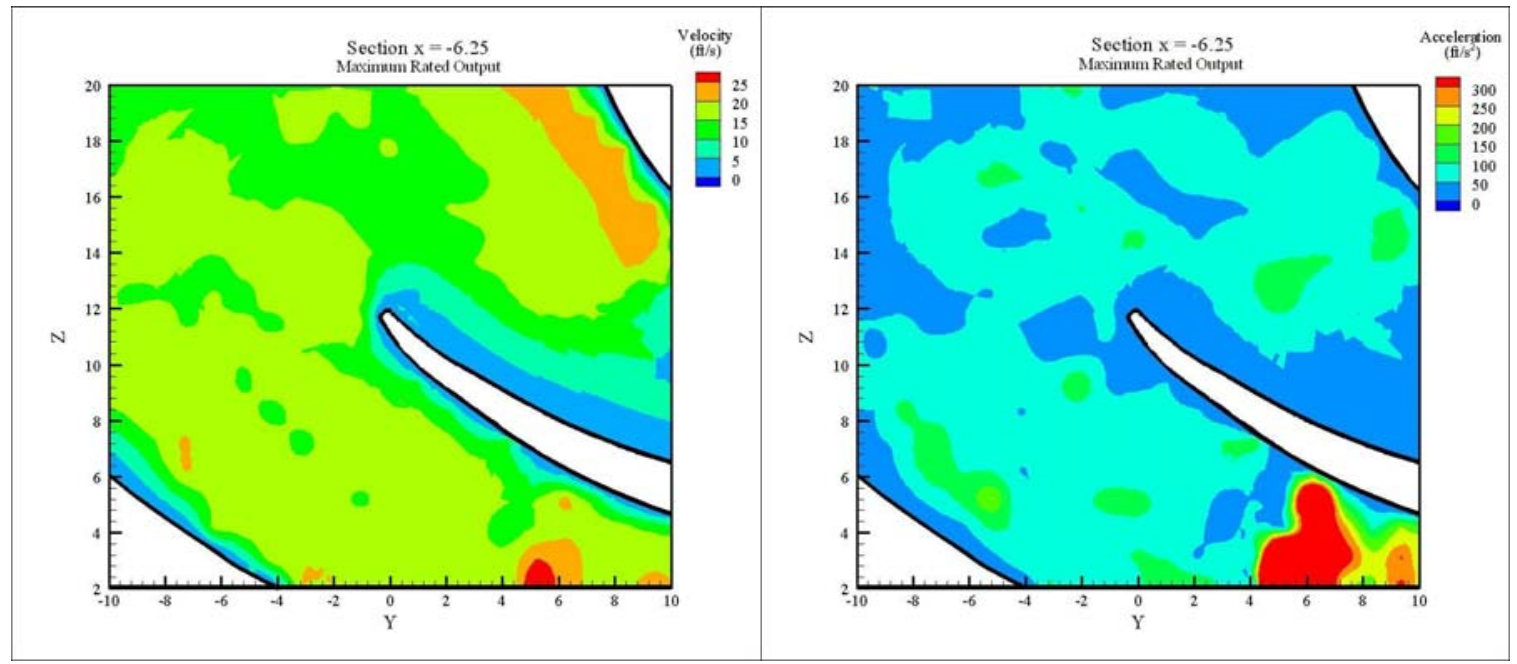

Figure 3.23. Average velocity and acceleration contour plots for beads as they passed through a plane $6.25 \mathrm{ft}$ to the left of the vertical splitter above and below the horizontal splitter at maximum operation level for beads released into all three intakes. Estimates of velocity and acceleration are calculated to prototype scale. 


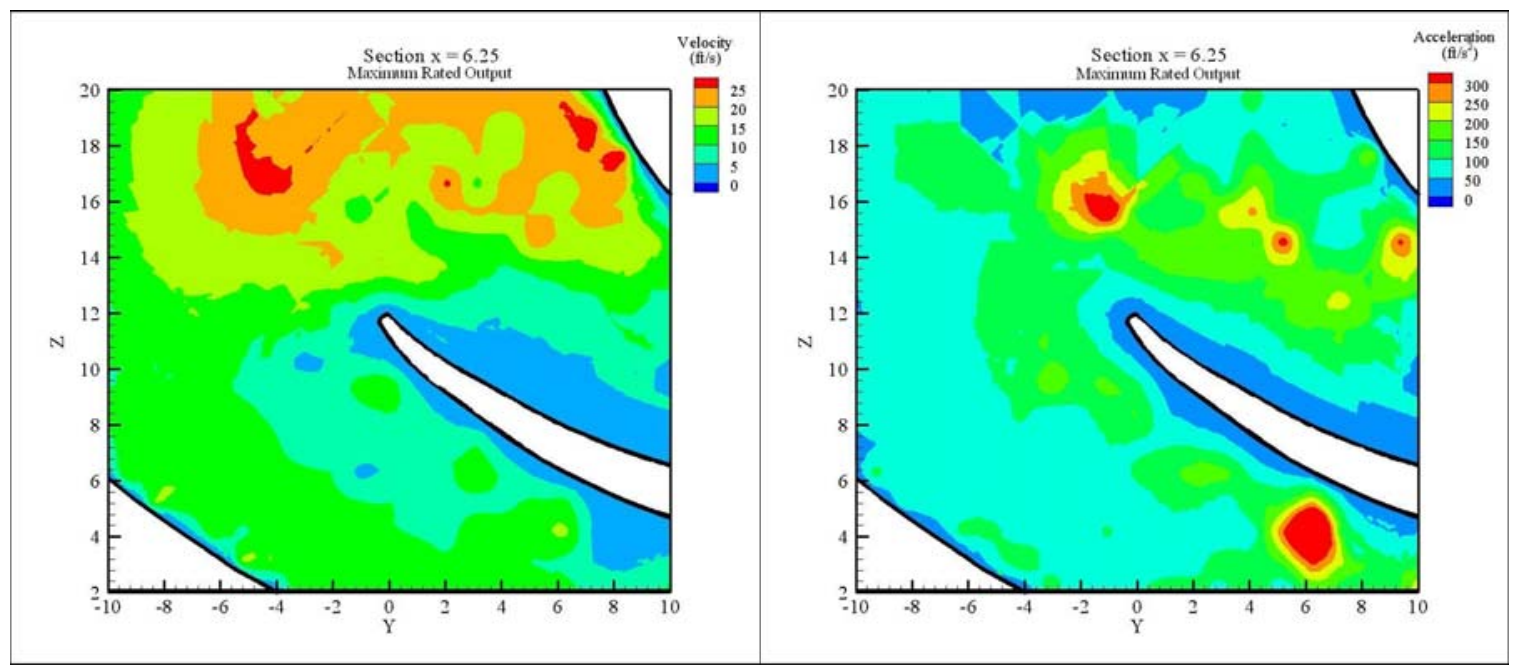

Figure 3.24. Average velocity and acceleration contour plots for beads as they passed through a plane in line with the vertical splitter above and below the horizontal splitter at maximum operation level for beads released into all three intakes. Estimates of velocity and acceleration are calculated to prototype scale.

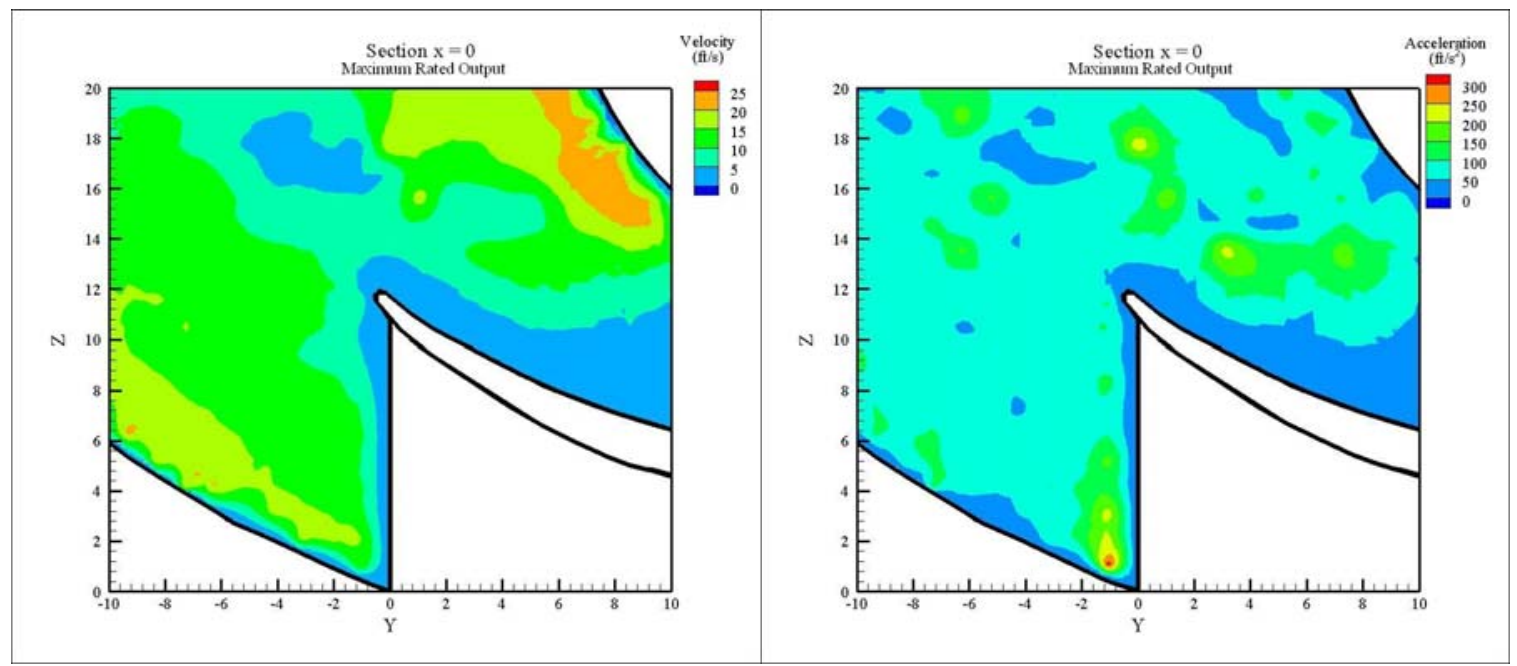

Figure 3.25. Average velocity and acceleration contour plots for beads as they passed through a plane $6.25 \mathrm{ft}$ to the right of the vertical splitter above and below the horizontal splitter at maximum operation level for beads released into all three intakes. Estimates of velocity and acceleration are calculated to prototype scale.

Tortuosity differed significantly by release intake with A showing the lowest overall tortuosity value and intake $\mathrm{C}$ having the highest tortuosity values (Figure 3.26 and Table 3.8). Lower tortuosity values were seen at the maximum operation level than at the lower $1 \%$ efficiency operating condition. 


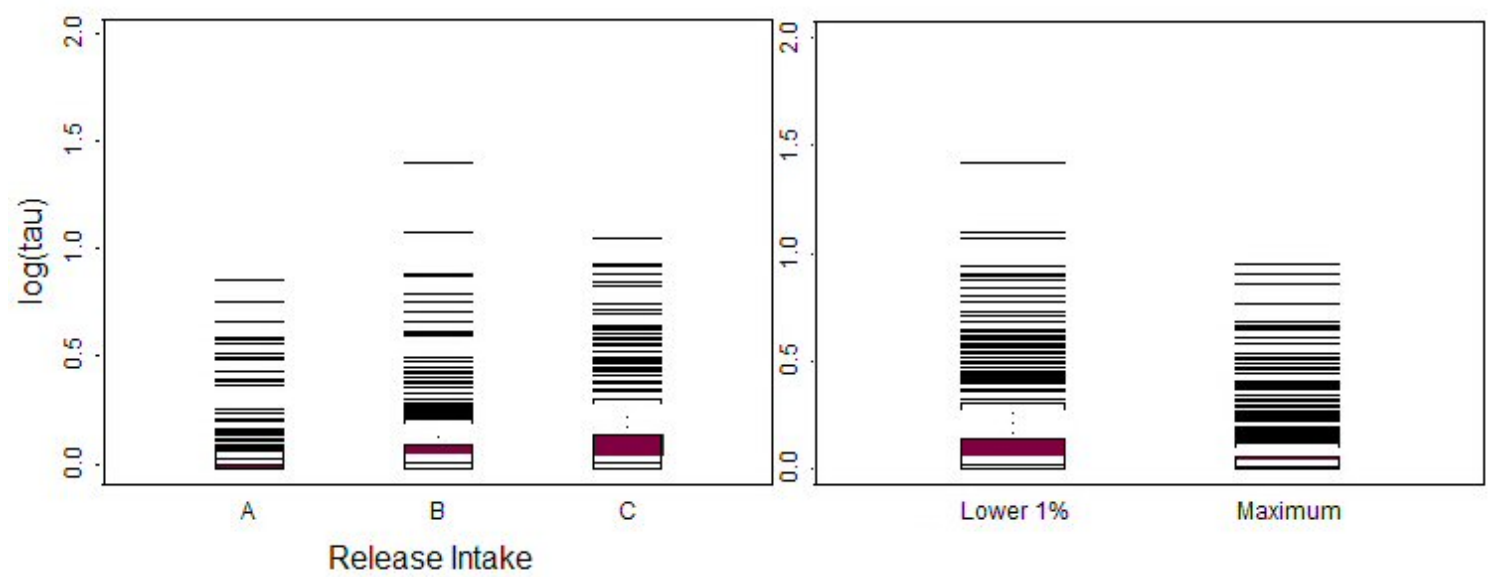

Figure 3.26. Box plots of log tortuosity $(\tau)$ for 3-D tracking by release intake (left) and flow condition (right).

Table 3.8. Summary ANOVA of tortuosity estimates between intakes and operation conditions for beads tracked below the runner hub in 3-D. The parameter estimates were computed as a deviation from the reference level for that factor where $\mathrm{C}$, and the lower $1 \%$ efficiency, was taken as the reference level and so its estimate is 0 .

\begin{tabular}{|l|l|c|c|c|c|c|c|c||}
\hline Parameter & Level & DF & Estimate & StdErr & Lower95\%CL & Upper95\%CL & ChiSq & ProbChiSq \\
\hline Intercept & & 1 & 0.213 & 0.013 & 0.188 & 0.237 & 286.740 & $<.0001$ \\
\hline \multirow{2}{*}{$\begin{array}{l}\text { Release } \\
\text { Intake }\end{array}$} & $\mathrm{A}$ & 1 & -0.091 & 0.014 & -0.119 & -0.064 & 42.840 & $<.0001$ \\
\cline { 2 - 9 } & $\mathrm{B}$ & 1 & -0.027 & 0.015 & -0.055 & 0.002 & 3.350 & 0.067 \\
\cline { 2 - 9 } & Ref: C & 0 & 0.000 & 0.000 & 0.000 & 0.000 & & \\
\hline $\begin{array}{l}\text { Flow } \\
\text { Condition }\end{array}$ & Max Flow & 1 & -0.090 & 0.012 & -0.113 & -0.066 & 54.980 & $<.0001$ \\
\cline { 2 - 8 } & $\begin{array}{l}\text { Ref: 1\% } \\
\text { Max Flow }\end{array}$ & 0 & 0.000 & 0.000 & 0.000 & 0.000 & & \\
\hline
\end{tabular}

\subsection{Bead Passage through Splitter Region}

The distribution of beads as they passed into the splitter region of the draft tube was skewed to the lower left side of the draft tube looking downstream at both operating conditions tested (Table 3.9), but there were significant differences in distribution between the two operating conditions. At the lower $1 \%$ operating efficiency the beads were concentrated to the left side of the draft tube, looking downstream, with $77.2 \%$ of the beads passing through the left side of the vertical splitter. At the maximum operation condition, the beads were concentrated to the bottom half of the draft tube at the splitter, with $74.4 \%$ of beads passing under the horizontal splitter. 
Table 3.9. Percent distribution of beads as they passed through one of the four regions of the splitter in the lower end of the draft tube for both operating conditions and by intake

\begin{tabular}{|l|c|c|c|c|c|c|c|c||}
\hline \hline & \multicolumn{4}{|c|}{ Lower 1\% efficiency } & \multicolumn{3}{c||}{ Maximum operation } \\
\hline Intake & $\begin{array}{c}\text { Lower } \\
\text { left }\end{array}$ & $\begin{array}{c}\text { Upper } \\
\text { left }\end{array}$ & $\begin{array}{c}\text { Lower } \\
\text { right }\end{array}$ & $\begin{array}{c}\text { Upper } \\
\text { right }\end{array}$ & $\begin{array}{c}\text { Lower } \\
\text { left }\end{array}$ & $\begin{array}{c}\text { Upper } \\
\text { left }\end{array}$ & $\begin{array}{c}\text { Lower } \\
\text { right }\end{array}$ & $\begin{array}{c}\text { Upper } \\
\text { right }\end{array}$ \\
\hline Combined & 52.3 & 24.9 & 10.3 & 12.5 & 40.8 & 9.1 & 33.6 & 16.5 \\
\hline & & & & & & & & \\
\hline $\mathrm{A}$ & 69.4 & 20.1 & 0.8 & 9.7 & 60.3 & 1.5 & 35.5 & 2.7 \\
\hline $\mathrm{B}$ & 43.6 & 34.7 & 9.8 & 11.9 & 32.0 & 13.1 & 31.5 & 23.4 \\
\hline $\mathrm{C}$ & 42.3 & 22.5 & 19.7 & 15.5 & 25.1 & 13.3 & 33.9 & 27.7 \\
\hline
\end{tabular}

The distribution of beads at the splitter showed that most of the beads released into the A intake passed through the lower left quadrant (left of the vertical splitter and below the horizontal splitter) of the draft tube at both operating conditions. This was also true for beads released into the $\mathrm{B}$ and $\mathrm{C}$ intakes at the lower 1\% operating efficiency. However at the maximum operating level, the distribution of beads released into the $\mathrm{B}$ and $\mathrm{C}$ intakes was nearly evenly distributed between the lower left and right quarters of the splitter.

We were unable to calibrate the cameras at the lower $1 \%$ operating efficiency condition because of too few paired points in the calibration files resulting from low light levels. Without a calibration, the acquired data could only be used to compute 2-D trajectories. We were able to calibrate the cameras for data collected at the maximum operation level though detection of the edges of the vertical splitter wall in acquired images was faint. To resolve this issue, we estimated the position of the vertical splitter to produce the coordinates necessary for rotating the data into the plane of the physical model. It is apparent from the figures that we were not able to derive the exact location of the vertical splitter (Figure 3.27). The bead tracks above the horizontal splitter have realistic tracks but the bead tracks below the horizontal splitter are incorrect. The calculated trajectories of those beads do not follow the contour of the model; as the bead moved from left to right, the calculated trajectory of the bead became too positive in the Z-axis (vertical). These differences were verified by watching video records of the bead events. Although the absolute trajectories of the beads do not comport to the physical model, relative trajectories, velocity, and acceleration of the beads are correct. 


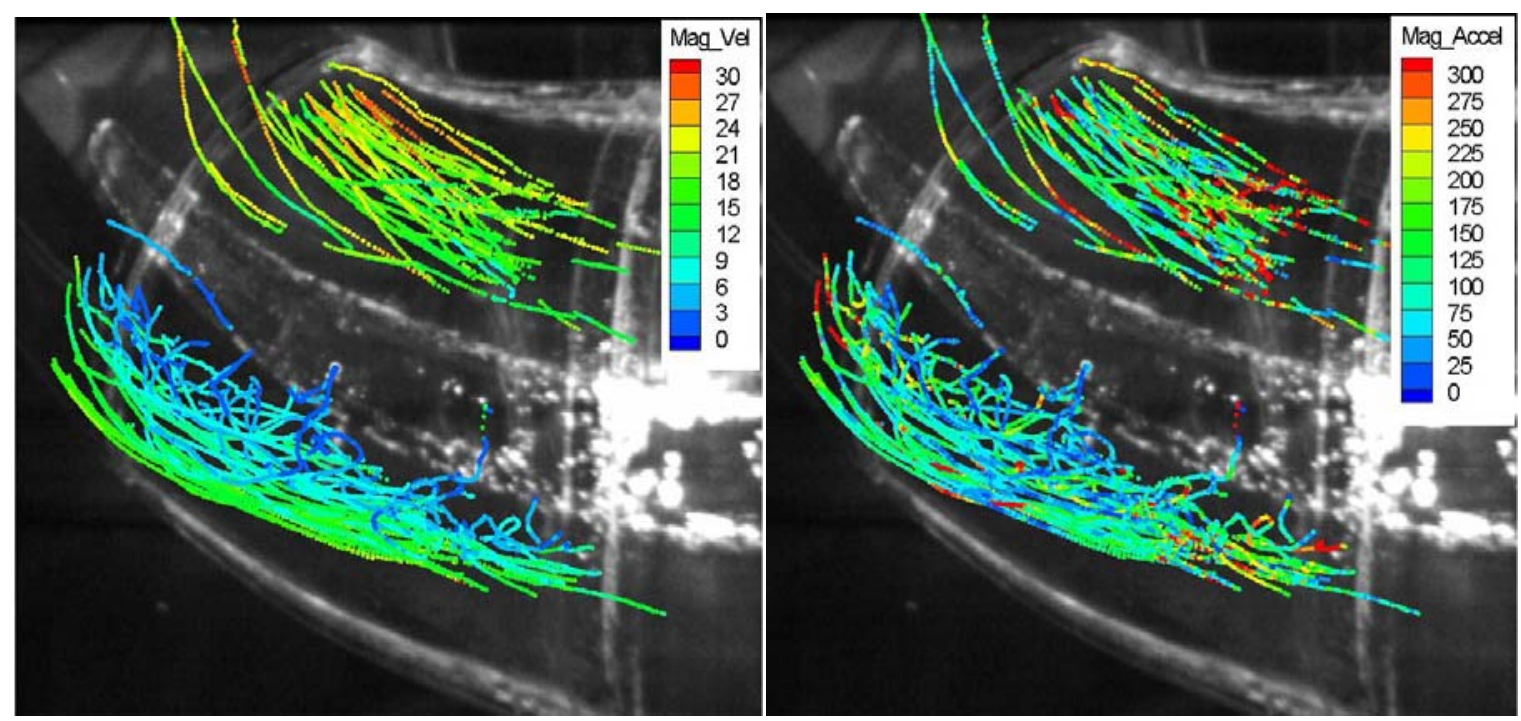

Figure 3.27. Velocity and acceleration estimates for individual beads as they pass to the right of the vertical splitter above and below the horizontal splitter at maximum operation level for beads released into all three intakes. Estimates of velocity and acceleration are calculated to prototype scale.

The trajectories of the beads passing above the horizontal splitter are relatively straight with some beads showing high velocity and acceleration magnitudes. Beads passing through the region below the horizontal splitter experienced lower velocities and acceleration than beads passing above the splitter in most instances but many of these beads spiraled and moved erratically when they passed near the splitter wall. The trajectories of beads near the floor of the draft tube were more linear than those of beads passing above the floor.

\subsubsection{Bead Strikes}

We observed several bead strikes on the vertical and horizontal splitter piers. When strikes occurred, the trajectory of the bead would often become less linear during the remainder of its passage through the draft tube. In a few cases, a single bead would be retained in "confused" flow in the splitter region for short periods ( 0.25 to $1 \mathrm{~s})$. Beads that were observed traveling in close proximity to the walls near the splitter region would exhibit non-linear paths and longer periods in the draft tube.

\subsubsection{Estimated Bias in Position Estimates of Beads}

Bias in calculated bead position estimates increased, as expected, with distance from the calibration jig (Figure 3.28). When the bead was within 8 inches of the center of the calibration jig, calculations of the actual bead position were in error by about 0.4 inches and 0.2 inches at 500 and 1000 frames/s, respectively. Bias in bead position increased when the viewing area of the cameras was increased by moving the cameras farther from the calibration jig. The error was about 0.8 inches at 14 inches distance from the center of the calibration jig. For tests conducted in the BON1 model, the greatest distance a bead was tracked from the calibration jig was about 10 inches. The largest error in bead location was about $4 \%$. This had minimal effect on the calculation of velocity and acceleration because of the high frame rate at which images were collected. At these frame rates, adjacent bead images were so close that less than one pixel separated them. 


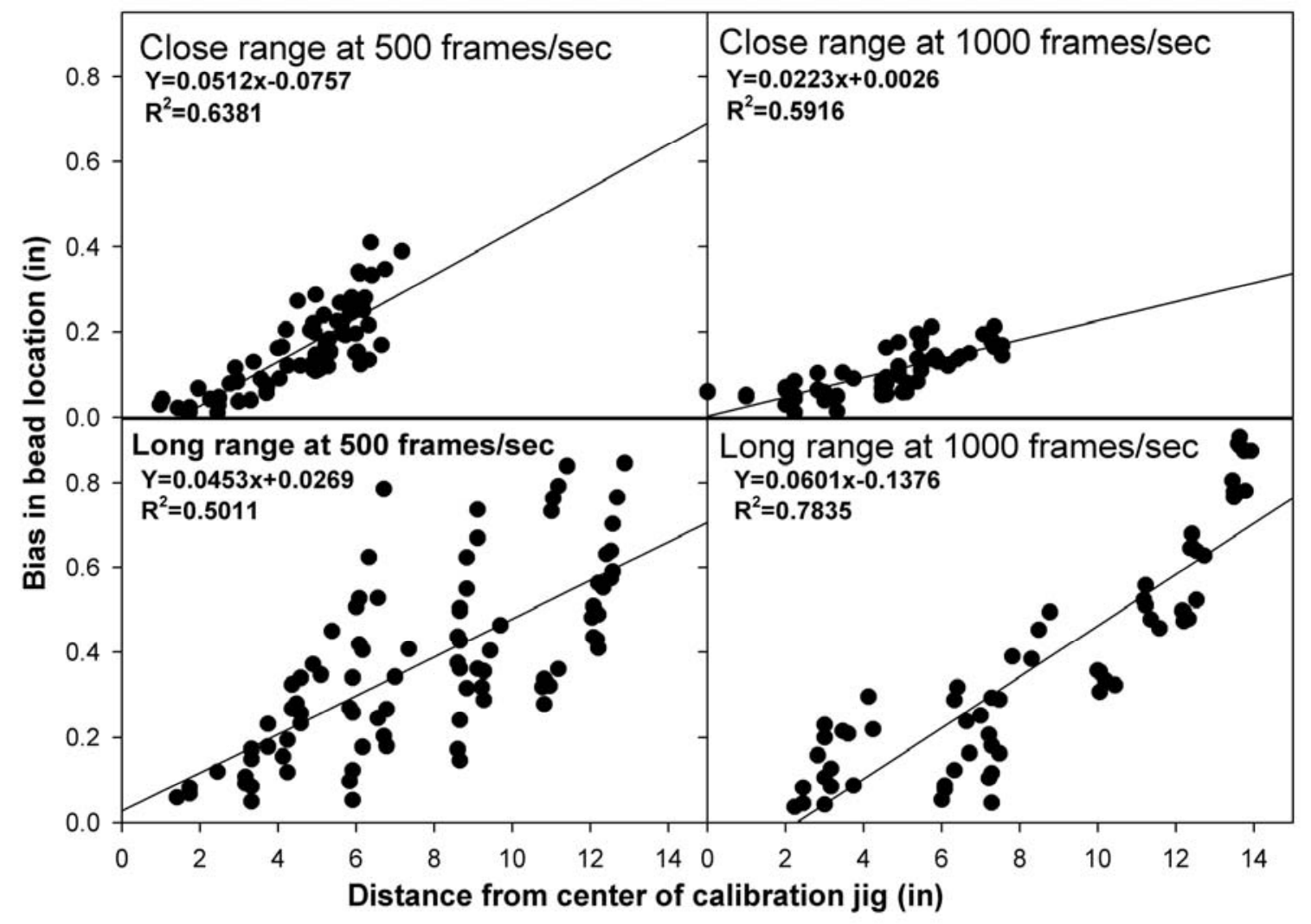

Figure 3.28. Bias in bead position estimates due to error in the calibration jig and increase in distance of the bead from the calibration jig.

\subsection{Camera Resolution Comparison of Bead Tracking with Photron 1280 Camera and Redlake PCl-1000S Cameras}

\subsubsection{Free-Falling Beads in the Air}

\subsubsection{Smoothing Methods}

Velocity and acceleration were computed from bead trajectories using three methods: un-smoothed, \pm 2 points simple averaging, and skip-5 points differentiation. The latter two methods of smoothing were used because velocities and accelerations estimated using these methods were found to be more accurate when applied to estimating these quantities for free-falling beads where the bead velocities and acceleration were better known. Simple averaging ( \pm 2 points) at a given point replaces the center point with the average of five points, the reference point and the two before and the two following the reference point. Point differentiation (skip-5) uses every fifth position estimate, which results in smaller differentiation error. Table 3.10 lists the errors associated with motion analysis of a free-falling bead using the three methods. Only random errors associated with video tracking are considered assuming systematic errors are relatively small compared with the random errors. The skip-5 method has the smallest error, which is shown in the velocity and acceleration plots (Figures 3.29-30). 
Table 3.10. Random error associated with motion analysis of a dropped bead captured with Photron 1280 cameras and Redlake cameras simultaneously.

\begin{tabular}{|l|c|c|c|c|c|c|}
\hline \multirow{2}{*}{} & \multicolumn{3}{|c|}{ Redlake Camera } & \multicolumn{3}{c||}{ Photron 1280 Camera } \\
\cline { 2 - 7 } & $\Delta \mathrm{y}(\mathrm{m})$ & $\Delta \mathrm{v}(\mathrm{m} / \mathrm{s})$ & $\Delta \mathrm{a}\left(\mathrm{m} / \mathrm{s}^{\wedge} 2\right)$ & $\Delta \mathrm{y}(\mathrm{m})$ & $\Delta \mathrm{v}(\mathrm{m} / \mathrm{s})$ & $\Delta \mathrm{a}\left(\mathrm{m} / \mathrm{s}^{\wedge} 2\right)$ \\
\hline Un-smoothed & 0.00166 & 1.66 & 1660 & 0.00039 & 0.39 & 390 \\
\hline Simple averaging & 0.00166 & 0.74 & 332 & 0.00039 & 0.17 & 76 \\
\hline Skip-5 & 0.00166 & 0.166 & 16.6 & 0.00039 & 0.039 & 3.9 \\
\hline \hline
\end{tabular}
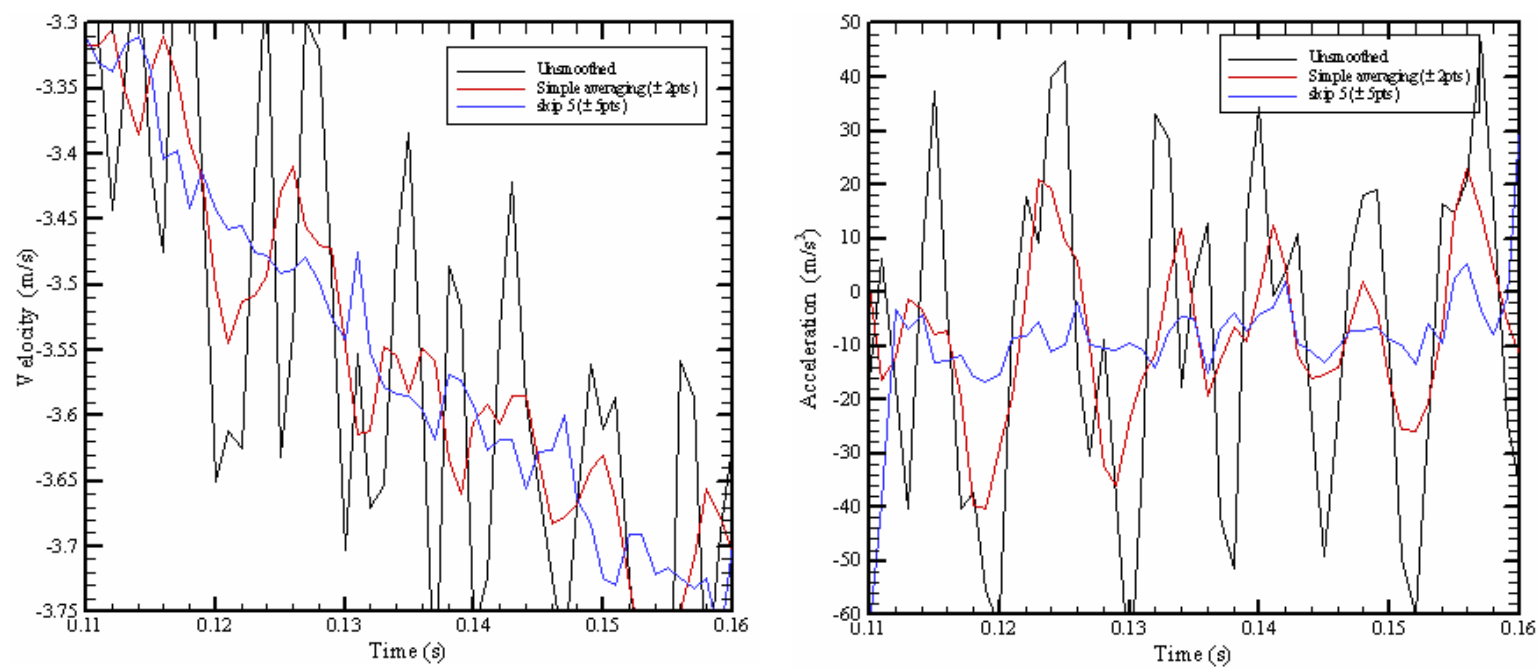

Figure 3.29. Calculated velocity and acceleration of dropped bead captured with, Redlake camera for unsmoothed and data smoothed using two different methods.
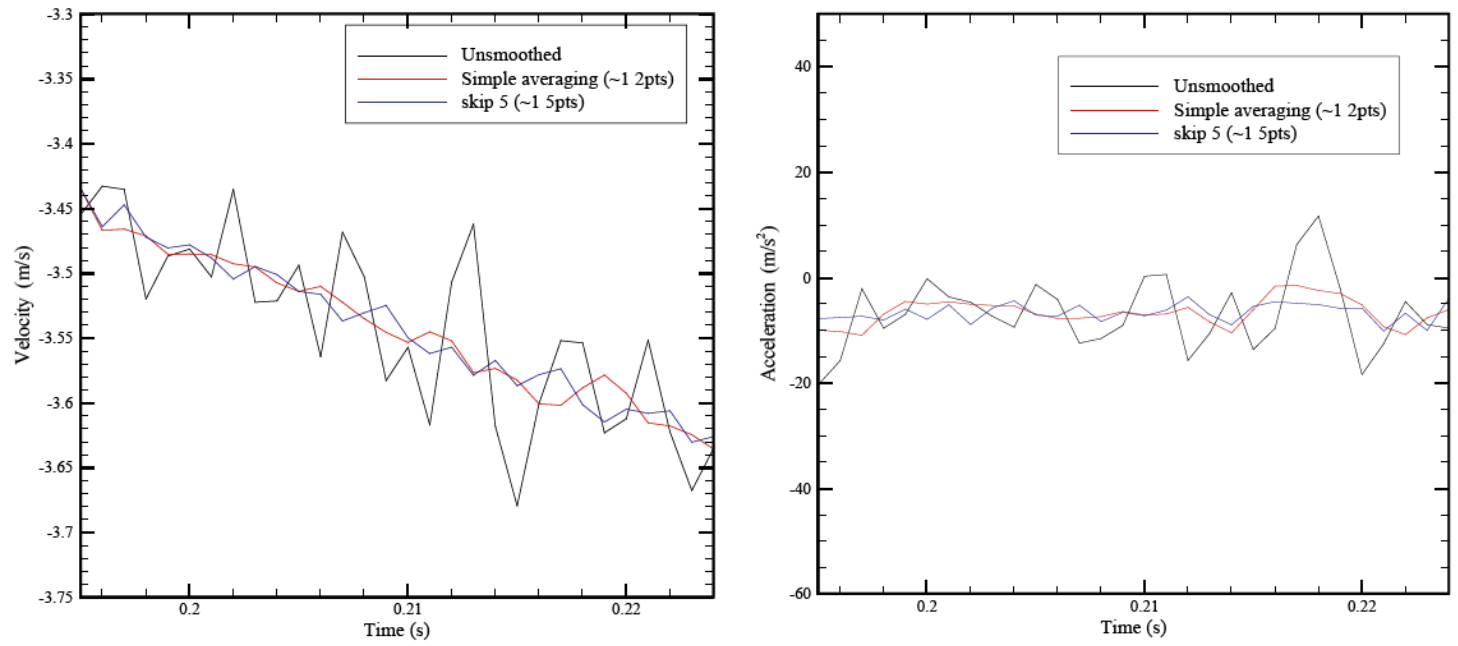

Figure 3.30. Calculated velocity and acceleration of dropped bead captured with, Photron camera for unsmoothed and data smoothed using two different methods.

\subsubsection{Comparison of Results from the Two Cameras}

Since the skip-5 method provided smoothed data with the least error, the results using the skip-5 method were used to compare the resolution of the Redlake and Photron cameras. An example is plotted in Figure 3.31. As expected from the random error analysis, the Photron cameras with their higher frame 
rates and higher dimensioned CCD arrays provided much more accurate velocity and acceleration estimates with less error than estimates calculated from images collected with the Redlake camera, which systematically overestimated the true physical quantity.
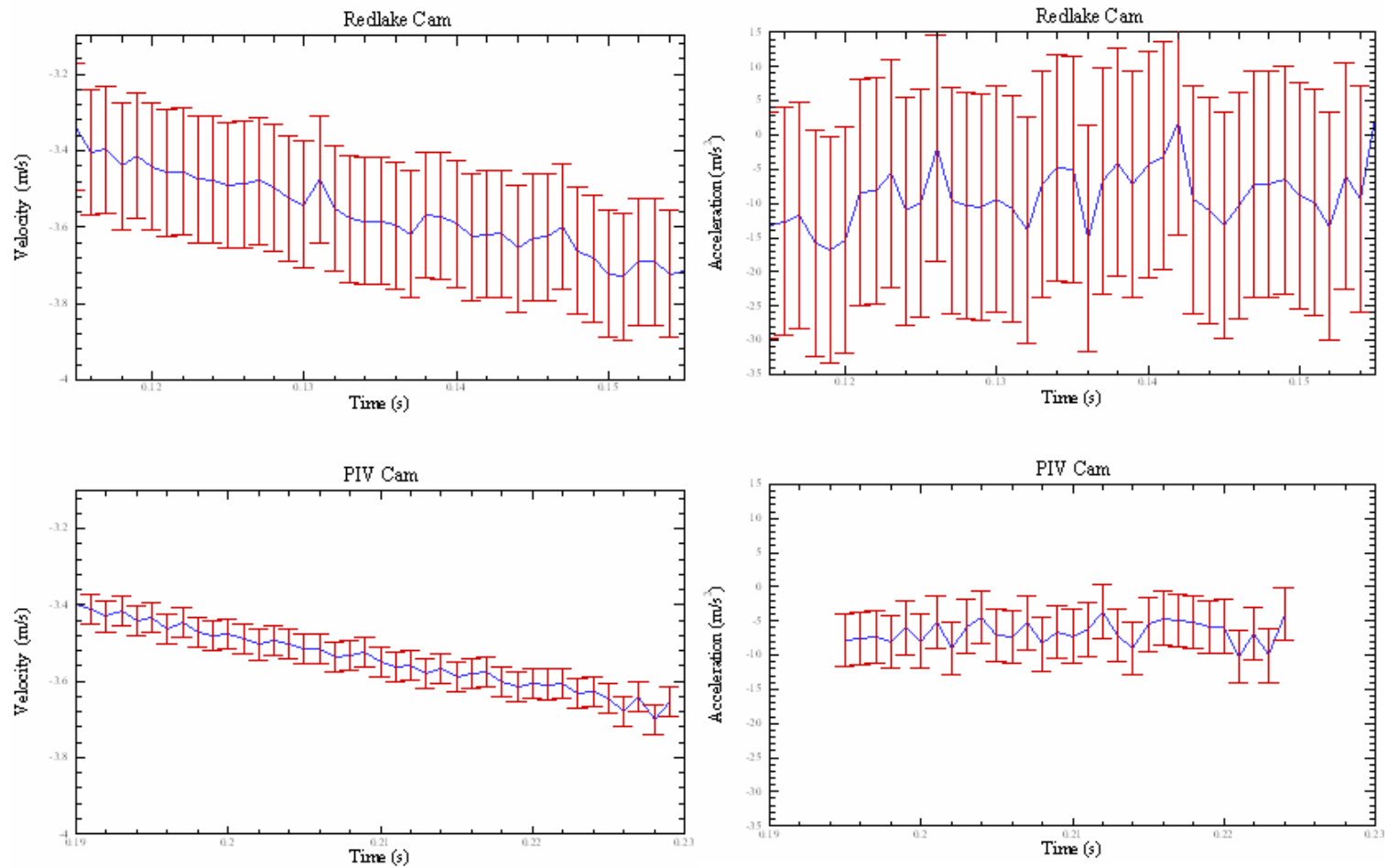

Figure 3.31. Comparison of velocity and acceleration estimates and error of a dropped bead captured with Photron and Redlake cameras simultaneously.

\subsubsection{Effect of Bead Shape}

Spherical beads were compared to the elliptical cross-section cylindrical beads used during testing in the BON1 scale physical model. In many of the tests, the round beads produced much better results than the oblong beads. The velocity and acceleration estimates of the round beads dropped in air were closer to gravity with less jitter in the calculations than the oblong beads. As shown in Figure 3.32, the velocity and acceleration measurements from both the skip-5 method and the simple-averaging method are very accurate, and even the unsmoothed curves depict fairly well the velocity and acceleration of free-falling beads. A possible explanation of the improvement is that the potential rotation of the model beads (oblong) could create an additional maximum error of 0.5 (length-diameter ratio) while the rotation of the spherical beads doesn't create this problem. 

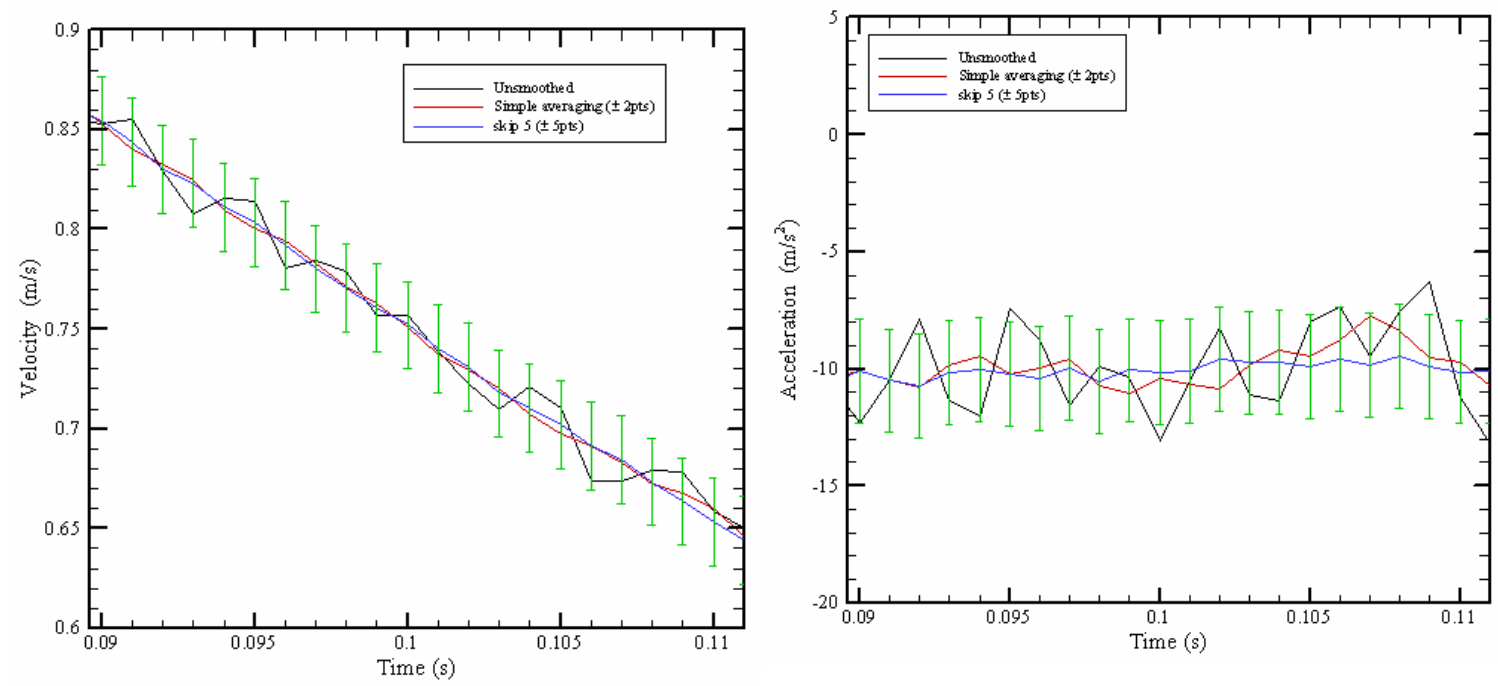

Figure 3.32. Velocity and acceleration estimates of a dropped spherical bead with images captured by the Photron camera.

\subsubsection{In-Water Bead Measurement}

Bead velocity and acceleration rates were calculated for image data collected with the Photron camera when elliptical cross-section cylindrical beads used in model testing were released into a jet of water in a tank. Results showed that velocity and acceleration calculations are not sensitive to the smoothing methods, and the velocity and acceleration plots for the non-smoothed and smoothed data were almost identical (Figure 3.33). Results of this test show that the Photron camera measurements in this test are very accurate and would substantially improve the resolution of the data collected in the turbine model and reduce the amount of smoothing necessary to provide better estimates of bead displacement, velocity, and acceleration.

\subsection{Error Analysis of Bead-Tracking in 1:25 Scale Turbine Physical Model}

The resolution of bead data that can be obtained depends on a number of factors that are relatively easy to control including camera resolution, frame rate, and placement of the cameras. As a starting point the error in velocity and acceleration estimates was calculated relative to the viewing area of the camera, a function of the camera's placement, and frame rate, which directly correlates with pixel resolution, for both the Redlake and Photron cameras. Estimates of error in velocity and acceleration relative to the individual pixel resolution $(\Delta y)$ for two frame rates and two viewing areas are provided in Table 3.11. 

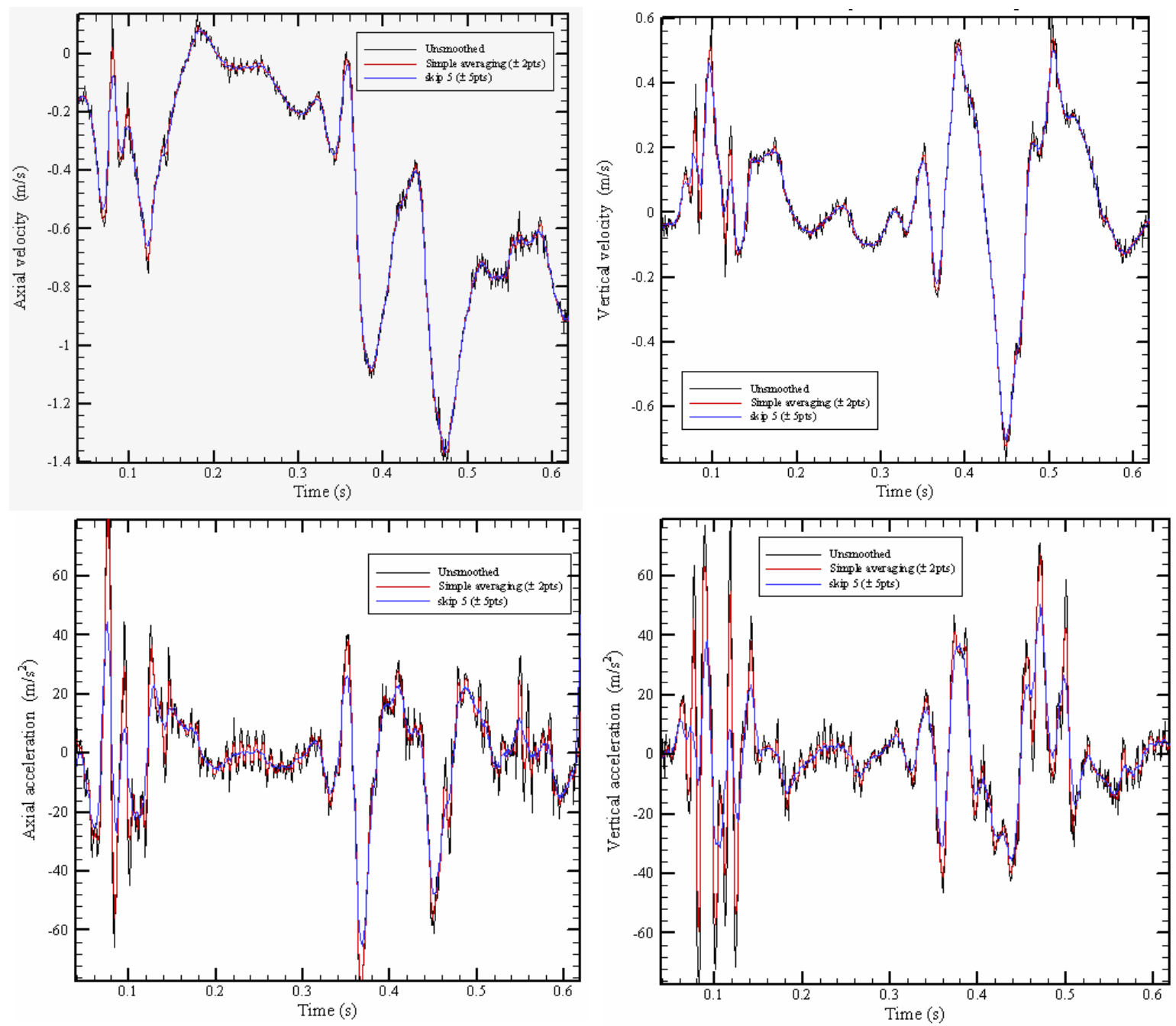

Figure 3.33. Calculated velocity and acceleration of a bead released into a water jet water tank captured with the Photron camera showing unsmoothed data and data smoothed using two different methods.

For all four test cases, reliable velocity measurements can be obtained using the Redlake camera and an appropriate smoothing method but the error in estimates of acceleration was improved substantially by smoothing, as shown above, using a higher resolution camera (Photron), and keeping the viewing area of the cameras small. At issue with this tight viewing window is the size of the target (bead) relative to pixel size. In our analysis, the brightest pixel was used to calculate the bead position. A small viewing window and the brightest pixel not always being at the same position on the bead could result in additional error in bead position. Using the centroid of the bead may provide better position estimates when the target of interest is much larger than an individual pixel and the brightest pixel is not in the same location on the target of interest. 
Table 3.11. Error in estimates of velocity and acceleration relative to viewing area $(12 \times 10.5$ inches and $20 \times 17.5$ inches) for Redlake and Photron cameras at 500 and 1000 frames/s.

\begin{tabular}{|c|c|c|c|c|c|c|}
\hline \multicolumn{7}{|c|}{ Random errors for $12 \times 10.5$ inch viewing area, 500 frames $/ \mathrm{s}$} \\
\hline & \multicolumn{3}{|c|}{ Redlake Camera } & \multicolumn{3}{|c|}{ Photron Camera } \\
\hline & $\Delta y(\mathrm{~m})$ & $\Delta \mathrm{v}(\mathrm{m} / \mathrm{s})$ & $\Delta \mathrm{a}\left(\mathrm{m} / \mathrm{s}^{2}\right)$ & $\Delta y(\mathrm{~m})$ & $\Delta \mathrm{v}(\mathrm{m} / \mathrm{s})$ & $\Delta \mathrm{a}\left(\mathrm{m} / \mathrm{s}^{2}\right)$ \\
\hline Un-smoothed & 0.00095 & 0.476 & 238 & 0.00024 & 0.119 & 59.5 \\
\hline Simple averaging & 0.00095 & 0.212 & 47.6 & 0.00024 & 0.053 & 11.9 \\
\hline Skip-2 & 0.00095 & 0.095 & 9.53 & 0.00024 & 0.024 & 2.38 \\
\hline Skip-5 & 0.00095 & 0.048 & 2.38 & 0.00024 & 0.012 & 0.60 \\
\hline \multicolumn{7}{|c|}{ Random errors for $12 \times 10.5$ inch viewing area, 1000 frames/s } \\
\hline Un-smoothed & 0.00127 & 1.266 & 1266 & 0.00024 & 0.238 & 238 \\
\hline Simple averaging & 0.00127 & 0.566 & 253 & 0.00024 & 0.106 & 47.6 \\
\hline Skip-2 & 0.00127 & 0.253 & 50.6 & 0.00024 & 0.048 & 9.52 \\
\hline Skip-5 & 0.00127 & 0.127 & 12.7 & 0.00024 & 0.024 & 2.38 \\
\hline \multicolumn{7}{|c|}{ Random errors for $20 \times 17.5$ inch viewing area, 500 frames $/ \mathrm{s}$} \\
\hline Un-smoothed & 0.00159 & 0.794 & 397 & 0.00040 & 0.198 & 98.9 \\
\hline Simple averaging & 0.00159 & 0.355 & 79.4 & 0.00040 & 0.089 & 19.8 \\
\hline Skip-2 & 0.00159 & 0.159 & 15.9 & 0.00040 & 0.040 & 3.96 \\
\hline Skip-5 & 0.00159 & 0.080 & 3.97 & 0.00040 & 0.020 & 0.99 \\
\hline \multicolumn{7}{|c|}{ Random errors for $20 \times 17.5$ inch viewing area, 1000 frames $/ \mathrm{s}$} \\
\hline Un-smoothed & 0.00212 & 2.116 & 2116 & 0.00040 & 0.398 & 398 \\
\hline Simple averaging & 0.00212 & 0.946 & 423 & 0.00040 & 0.178 & 79.6 \\
\hline Skip-2 & 0.00212 & 0.423 & 84.6 & 0.00040 & 0.079 & 15.9 \\
\hline Skip-5 & 0.00212 & 0.212 & 21.1 & 0.00040 & 0.040 & 3.98 \\
\hline
\end{tabular}


Characterization of Bead Trajectories through the Draft Tube of a Turbine Physical Model 


\subsection{Discussion}

The primary objective of this project was to assess the feasibility of tracking nearly neutrally buoyant beads from below the runner through the draft tube region of a 1:25 scale Kaplan turbine physical model and characterizing large-scale turbulence. The feasibility of tracking beads through each section imaged below the turbine runner and through the draft tube region of the turbine and our ability to characterize the response of beads to flow through each section of the draft tube is discussed. Ways to improve video image resolution and quality of trajectory and related kinematics are also discussed. Data were only collected for beads released at mid-depth in the gatewell slots for two operation conditions. Bead trajectories and turbulence response may differ with depth of release and would definitely vary with operating condition.

\subsection{Bead Passage and Distribution below the Runner Region}

Use of a single camera looking up toward the underside of the turbine runner provided good estimates of bead distribution as beads first became visible exiting the turbine runner. Without a second camera, it was not possible to calculate velocity and acceleration of beads as they passed beneath the turbine runner. A second camera was not used to track beads through this model section because of the lack of definable points on the model to use for reference and our inability to place a calibration jig in this region of the model. Calculation of tortuosity (linearity) for these 2-D trajectories using only one camera may be somewhat in error due to the lack of depth (third axis) in the calculation. This may be the reason that beads released into intake $\mathrm{C}$ had the lowest overall tortuosity value for 2-D trajectories but had the highest calculated tortuosity value for 3-D trajectories. Simply viewing the images of bead trajectories below the hub, the beads released into the $\mathrm{C}$ intake displayed more circling below the runner than do beads released into the A intake.

Results also show that fewer beads pass near the runner tip at maximum operation than at the lower $1 \%$ efficiency. The further a fish is from the runner tip, the lower the incidence of injury. Laboratory tests by Turnpenny et al. (1992) found that fish passing near the hub region are less likely to be injured or killed than fish passing near the blade tip. This has also been found true in field tests (TSP 2004). Bead collision with the leading edge of the blades could not be determined by the cameras due to model design. Bead path linearity was generally better under the maximum rated operation condition for all three intake slots tested. More irregular bead paths were evident at the lower $1 \%$ operation level, which increased travel times in this region. The more tortuous paths may also increase the likelihood of beads coming in close contact with the draft tube walls and splitter region. Fish following these paths may experience increased likelihood of disorientation due to vestibular disruption or physical injury from shear.

The radial distribution of beads from the hub showed that the majority of beads released in the A slot were more likely to be detected near the mid blade and tip as compared to beads released in the B and C slots for both operation conditions. From all three release location, more beads passed through the runner closer to the blade tip at the lower $1 \%$ operation efficiency than at the maximum rated output. 


\subsubsection{Bead Passage through the Elbow Region}

Good tracks of beads in 3-D were possible through the elbow region of the model using paired cameras. The tracks were continuous and few points were dropped due to beads being lost in a "hot spot" or behind a structure. This region of the model was optimal for camera placement and lighting since most of this region was unobstructed and few glue seams were visible to hinder tracking. The calibration jig was relatively easy to place in this section of the model although the area that was covered by the calibration jig was a $6 \times 4 \times 3$-inch region immediately upstream of the splitter. Actual position of the beads tracked, according to bias testing, deviated with increased distance from the splitter. This slight deviation should not affect velocity and acceleration estimates due to the high frame rate at which the data were collected.

A majority of the beads passed through the draft tube exhibiting nearly linear trajectories; however, a few exhibited nonlinear trajectories with slight deviations from linearity to fast turns or looping. These erratic movements were most common when the model was operating at the lower $1 \%$ efficiency and to a lesser extent directly in front of the splitters at both operation levels. High rates of acceleration were also found in the elbow region and the splitter region of the draft tube at the lower $1 \%$ operation level but mainly within the splitter region at the maximum rated output. These are possible areas where fish may become injured or disoriented from rapid change in direction.

\subsubsection{Bead Passage through the Splitter Region}

Tracking of beads through the splitter region was difficult, mainly because of lighting problems due to the large number of bubbles in the glued seams of the model. These bubbles caused bright spots where beads could not be tracked resulting in incomplete trajectories. The brightness of light reflected from bubbles also resulted in problems with the contrast, making it difficult to detect beads. The accuracy of the bead trajectories in this region was also reduced because the image quality of the calibration jig was poor compared to the image quality obtained in the elbow region of the model, making it difficult to identify the center of the nodes and to resolve individual beads due to loss of contrast. Another problem was finding a position for the calibration jig in the splitter region where a large enough number of the individual jig nodes were visible with both cameras and the vertical section of the splitter was also in view as a point of reference for calibration. It was only possible to look at one of the four divided splitter regions at a time because of the bubbles in the model seams and optical distortion for locations where the optical path to a bead was through a curved section of the splitter structures.

Total bead distribution through the splitter region of the draft tube was skewed to the left side (looking downstream) at both operating conditions tested, which would be expected since flow distribution through the turbine draft tube barrels is not uniform because the left-hand barrel (looking downstream) carries more flow than the right. This flow distribution was more apparent at the lower $1 \%$ operation efficiency than at maximum operation level, which is consistent with velocity measurements made at the exit of the draft tubes for this and other turbine physical models (TSP 2004). At maximum operation condition the beads were concentrated in the bottom half of the draft tube at the splitter. This was especially noticeable for beads released into the A intake. The splitter region was the area with the least linear trajectories, especially the lower section of the splitter. 


\subsection{Tracking Resolution}

\subsubsection{Smoothing}

Smoothing of the data by skipping points reduced jitter and resulted in realistic velocity and acceleration estimates that are within the range of estimates from CFD models and data collected with the Sensor Fish. Tests using a camera with greater resolution (due to a larger dimensioned CCD array) than were used for our testing were found to reduce the amount of smoothing necessary. More accurate displacement data makes it more feasible to estimate the force of a bead strike or collision and to provide more accurate and precise estimates of velocity and acceleration.

The distance of the camera relative to the size of the object being tracked also needs to be considered for bead tracking in physical turbine models. When the camera is too near the object of interest, the object may fill multiple pixels and, depending on the method used to calculate bead position, may result in increased error in bead displacement and other estimates of motion.

\subsubsection{Detection Method}

Peak-pixel intensity was used to track the bead data with the Sensors Applications Inc. software. This method can result in jitter in position estimate, especially if the object of interest occupies more than one pixel. Because the light is not consistently reflected from the same place on the bead the brightest pixel may not always be in the same location on the bead. This results in "jitter" in the bead position estimate. The centroid method may be better used to represent the object where the central pixel within the target of interest is used to calculate location. Use of spherical beads will also improve consistency in tracking for both the brightest pixel and centroid techniques.

\subsubsection{Camera Resolution}

The best way to improve the accuracy of bead position estimates and velocity and acceleration is to improve camera resolution by selecting cameras with large-dimensioned CCD arrays and high frame rates. Estimates of error in acceleration were reduced by about five-fold for images collected with the high-resolution Photron camera compared with the Redlake cameras we used during model testing. However, higher precision cameras are more expensive and acquired data sets are larger.

\subsubsection{Error and Bias in Tracking}

There are several sources of error that can affect the accuracy of bead tracking and velocity and acceleration estimates. Error due to quantization of the image data is due to collection of the data in digital format where the data image is divided into individual non-overlapping subregions (pixels), compared to an analog image that is more or less a continuous image. A second source of error is radial distortion of images; this is most noticeable near the corners of the camera and can be diminished with proper calibration of the camera. Other sources of error include bias from uncertainties in the location of nodes in a calibration jig. Uncertainties on the order of the dimensions of the particle being tracked are sufficient to cause significant errors in particle position estimates. The calibration jig we built and used was slightly damaged when it was placed in the physical model and a couple of the vertical posts were slightly bent. The jig was repaired as best as possible given the situation, but may have remained slightly bent. This damage may explain some of the bias in position estimates we encountered when we tested the bias in position estimates attributed to the calibration jig. 
A major cause of error in estimates of velocity and acceleration, as stated above, is camera resolution. The pixel density of the camera, along with the distance of the camera from the object will result in jitter in the velocity and acceleration estimates. This is due in part to the difficulty in continuously tracking the exact same position on the bead, but also the estimated position of the bead is only as good as the resolution of the camera. In a three-dimensional space, camera resolution is a continuously changing variable with the distance of a particle being tracked from the camera lens. The choice of bead shape is also significant. Spherical beads are easier to track accurately than cylindrically shaped beads.

The error and bias we encountered in our testing can be improved by using higher resolution video cameras, a more accurate calibration jig, and spherical beads. Improvements in calibration could also be achieved by placing visible marks at known locations on model structures within the desired field of view. This would expedite the calibration process and could provide a larger number of reference marks throughout the model.

\section{$4.3 \quad 3-D$ Trajectories and Metrics}

Accurate 3-D position estimates of beads passing through the physical model permit characterization of aspects of the hydraulic environment. In this study we calculated bead velocity and acceleration and described the linearity of the bead trajectories using tortuosity. Since it was necessary to smooth the data to reduce error, especially to obtain reasonable estimates of acceleration, it was not feasible to calculate other metrics such as impulse, force, or jerk. The error in unsmoothed acceleration estimates was mainly due to the quantization errors discussed previously. The data were determined to be of insufficient quality to calculate jerk, the rate of change in acceleration or the third derivative of displacement. Changes to calibration and data acquisition methods as well as selection of beads and cameras that would enable more detailed description of bead response to flow field conditions were identified.

The beads used in the model were similar in scale to $110-\mathrm{mm}$ salmon smolts. However, more data and analysis are needed before it is possible to extrapolate with confidence exposures observed for beads in a physical model to those likely experienced by live smolts passing through a full-scale turbine. We know from field studies that live fish are not, in general, passively carried by flow during turbine transit. Live test fish released into the turbine intake at McNary Dam with gastrically implanted acoustic tags and tracked in 3-D through the intake to the scroll case did not follow the same paths as near neutrally buoyant drogues. The trajectories of fish and drogues differed in the vertical component and in transit time (Carlson et al. 2002), which clearly demonstrated that fish are active during turbine transit through a turbine intake. Because water velocities are much higher through the turbine runner and in portions of the draft tube than in the turbine intake it is possible that fish may be more likely to be carried more or less passively with flow through these regions. The evolution of tools to study fish behavior in environments such as turbines will likely permit comparisons of bead trajectories in physical models with those observed for live fish passing through full-scale turbines. Such comparisons should permit more informed use of physical models to understand the exposures fish experience during turbine passage. Physical models are currently the lowest cost alternative for the study of exposure conditions in turbines.

Numerous studies on the trajectories of organisms in 3-D have been conducted although few have quantified their analysis of trajectories (Crenshaw et al. 2000). One group has developed equations to 
describe in 3-D the torsion, curvature, and velocity of an object with 6 degrees of freedom relative to the organism's frame of reference (Crenshaw 1993, Crenshaw and Edelstein-Keshet 1993, Crenshaw 1993, Crenshaw 2000). Although assumptions about scaling of the prototype and passive particles versus behavior of fish need to be cautiously made, comparison of bead motion using this 6 degree of freedom method of analysis with the 6 degree of freedom data collected with the Sensor Fish (Deng et al. 2004) could aid in our understanding of the draft tube conditions and help in the decision making process to improve turbine passage survival of fish. 
Characterization of Bead Trajectories through the Draft Tube of a Turbine Physical Model 


\subsection{Conclusions}

Observations of bead dynamics in the 1:25 scale model were consistent with other measures of flow conditions made using the physical models and also comported with observations made at full-scale turbines. Bead trajectory and passage estimates from image data in the model suggest that operating the turbine at or near the maximum rated operation level can reduce injury and disorientation to fish relative to operating at the lower $1 \%$ efficiency. As beads passed through the turbine runner, fewer beads passed near the runner tip at maximum operation than at the lower $1 \%$ efficiency for all three release locations. Field studies have shown that fish passing through a runner nearer the tips of the runner blades have a higher incidence of injury and mortality. Flow below the turbine runner and through the draft tube was less turbulent at the maximum rated operation level than at operation $1 \%$ down from peak efficiency. Bead trajectories were more irregular (higher tortuosity) at lower discharges. Travel times for beads through the study regions also increase, as expected, at lower discharge. These more tortuous paths may increase the likelihood of beads coming in close contact with the draft tube walls and splitter region. Fish following these paths may also experience an increased likelihood of disorientation due to vestibular disruption or physical injury from shear. High rates of acceleration were also found in the elbow region and the splitter region of the draft tube at the lower $1 \%$ operation level and to a lesser extent within the splitter region at the maximum rated output. The splitter region is a possible area where fish may become injured or disoriented from rapid changes in direction at both operation conditions.

For the original higher speed video cameras used in the study, point-to-point velocity estimates based on bead position estimate data were unrealistic in some cases and quite variable because of the relatively coarse image pixel density resulting from optical path constraints and the reduction in pixel density required to operate the camera at high frame rates. Smoothing of the data (low pass filtering) reduced jitter and resulted in velocity estimates within the range of estimates for similar operating conditions obtained using CFD models and data collected with the Sensor Fish for full-scale turbines operating at discharges similar to those tested in the physical model. Exploratory tests conducted using a camera with higher pixel density (due to a larger dimensioned CCD array and the ability to acquire data at high frame rates at higher pixel densities) produced the expected result of higher precision bead tracking data. The higher resolution of the larger dimensioned CCD array permitted increased accuracy in point-to-point estimates of bead velocity, which, in turn provided data sets that permit much better estimation of the force of a bead strike or collision.

Another source of jitter investigated was the bead tracking technique used to process acquired video images. Peak-pixel intensity was used by the software package procured to perform image analysis to track bead movement and provide three-dimensional position estimates for bead locations in individual video frames. This method resulted in unacceptably large variations in bead position estimates from video frame to frame because tracked bead images occupied more than one image pixel and because light reflected off the beads inconsistently so the brightest pixel on the bead was not necessarily in the same location on the bead from frame to frame. While higher pixel density in the camera array did reduce this effect, other strategies such as the use of spherical beads and centroid particle tracking methods would most likely produce even better results. 
There were other sources of error that affected the accuracy and precision of the bead tracking and thereby the velocity and acceleration estimates. Always a problem with images typical of those we acquired is radial distortion in the periphery of the images due to the effects of camera lenses and refraction of light in the water running through the model. One source of error that affects bead position estimates is uncertainty in the location of nodes in a calibration jig in a model. The accuracy of bead location estimates can be no better than the estimates of calibration jig node positions. Measurement error increases in magnitude as the distance increases from the jig to where position estimates are sought. Position bias doesn't significantly affect velocity and acceleration estimates. The distance of the camera relative to the size of the object being tracked and the volume of interest also need careful consideration for bead tracking in physical turbine models. For example, when the camera is too near the object of interest, the object may fill multiple pixels and, depending on the method used to calculate bead position, may result in increased error in bead displacement and other estimates of motion.

The error and bias identified in our testing can be significantly reduced by using higher resolution video cameras with large-dimensioned CCD arrays, a more accurate calibration jig, and spherical beads, and by processing images using centroid tracking techniques. Improvements in calibration could also be achieved by placing visible marks at known locations on model structures within the desired field of view. Fiducial marks provide the most accurate means for identifying exact positions within a model and their use would expedite aspects of the calibration and quality assurance processes by removing the need to shut down the model for calibration checks and by providing the means to accurately calibrate a larger region in the model where bead tracking would be feasible.

Use of physical models is a cost-effective method for evaluating the turbine environment. Tracking near neutrally buoyant beads through the model with 3-D imaging technology increases our understanding of what fish may experience during turbine passage. It also aids identification of areas where fish may be vulnerable to injury and assists in determining turbine operations that provide safer passage. 


\subsection{References}

Cada, G.F. 2001. "The development of advanced hydroelectric turbines to improve fish passage survival." Fisheries 26(9): 14-23.

Carlson, T.J., M.A. Weiland, V.K. Sutton, A.R. Wirtz, M. Macaulay, J.R. Skalski. 2002. Ultrasonic 3-D tracking of fish and drogues passing through a Kaplan turbine intake at McNary Dam, 1999 \& 2000. PNNL-SA-36991, Prepared for the USACE Walla Walla District, by Pacific Northwest National Laboratory, Richland, Washington.

Crenshaw, H.C. 1993. "Orientation by helical motion-I. Kinematics of the helical motion of organisms with up to six degrees of freedom." Bulletin of Mathematical Biology 55:197-212.

Crenshaw, H.C and L. Edelstein-Keshet. 1993. "Orientation by helical motion-II. Changing the direction of the axis of motion." Bulletin of Mathematical Biology 55:213-230.

Crenshaw, H.C. 1993. "Orientation by helical motion-III. Microorganisms can orient to stimuli by changing the direction of their rotational velocity." Bulletin of Mathematical Biology 55:231255 .

Crenshaw, H.C., C.N. Ciampaglio, and M. McHenry. 2000. "Analysis of the three-dimensional trajectories of organisms: estimates of velocity, curvature and torsion from positional information." Journal of Experimental Biology 203:961-982.

Dahmen, H.J. and J.Zeil. 1984. "Recording and reconstructing three-dimensional trajectories: a versatile method for the field biologist." Proceedings of the Royal Society of London: Biological Sciences 222:107-113.

Deng, Z, M.C. Richmond, C.S. Simons, T.J. Carlson. 2004. Six-degrees-of-freedom sensor fish design: governing equations and motion modeling. PNNL-14779, Pacific Northwest National Laboratory, Richland, Washington.

Krenshaw, H.C., C.N. Ciampaglio, and M. McHenry. 2000. "Analysis of the three-dimensional trajectories of organisms: estimates of velocity, curvature and torsion from positional information.” Journal of Experimental Biology 203:961-982.

Nietzel, D.A., M.C. Richmond, D.D. Dauble, R.P. Mueller, R.A. Moursund, C.S. Abernethy, G.R. Guensch. 2000. Laboratory Studies on the Effects of Shear on Fish. DOE/ID-10822, U.S. Department of Energy Idaho Operations Office, Idaho Falls, Idaho.

Pan, X.H, R. Luo, X.Y. Yang, and H.J. Yang. 2002. “Three-dimensional particle image tracking for dilute particle-liquid flows in a pipe." Measurement Science and Technology 13:1206-1216.

Rayner, J.M.V. and H.D.J.N. Aldridge. 1985. "Three-dimensional reconstruction of animal flight paths and the turning flight of microchiropteran bats." Journal of Experimental Biology 118:247-265.

Tucker, V.A. 1991. "Stereoscopic views of three-dimensional, rectangular flight paths in descending African white-backed vultures (Gyps africanus)." Auk 108:1-7. 
Turbine Survival Program (TSP) Phase I Report 1997-2003. 2004. Prepared by USACE Portland District, Walla Walla District, Hydroelectric Design Center, Engineering Research and Development Center-Waterways Experiment Station, Vicksburg, Mississippi.

Turnpenny, A.W.H., M.H. Davis, J.M. Fleming, and J.K. Davies. 1992. Experimental studies relating to the passage of fish and shrimps through tidal power turbines. Marine and Freshwater Biology Unit, National Power, Fawley, Southhampton, Hampshire, England.

Weiland, M.A. and T.J. Carlson. 2003. Technologies for evaluating fish passage through turbines. PNNL-14437, Prepared by Pacific Northwest National Laboratory, Richland, Washington.

Wilga, C.D. and G.V. Lauder. 1999. "Locomotion in sturgeon: function of the pectoral fins." Journal of Experimental Biology 202: 2413-2432. 